University of Rhode Island

DigitalCommons@URI

Open Access Master's Theses

1997

\title{
PUBLIC PLAYGROUNDS: An Examination of Current Issues Associated with Public Play Facilities
}

Albert V. Ranaldi Jr.

University of Rhode Island

Follow this and additional works at: https://digitalcommons.uri.edu/theses

\section{Recommended Citation}

Ranaldi, Albert V. Jr., "PUBLIC PLAYGROUNDS: An Examination of Current Issues Associated with Public Play Facilities" (1997). Open Access Master's Theses. Paper 567.

https://digitalcommons.uri.edu/theses/567

This Thesis is brought to you for free and open access by DigitalCommons@URI. It has been accepted for inclusion in Open Access Master's Theses by an authorized administrator of DigitalCommons@URI. For more information, please contact digitalcommons-group@uri.edu. 


\section{PUBLIC PLAYGROUNDS \\ An Examination of Current Issues Associated with Public Play Facilities \\ by}

ALBERT V. RANALDI, JR.

A RESEARCH PROJECT SUBMITTED IN

PARTIAL FULFILLMENT OF THE REQUIREMENTS

FOR THE DEGREE OF

MASTER OF COMMUNITY

PLANNING

UNIVERSITY OF RHODE ISLAND 


\section{MASTER OF COMMUNITY PLANNING RESEARCH PROJECT \\ OF}

ALBERT V. RANALDI, JR

Approved:

Major Professor

Acknowledge:

Program Director

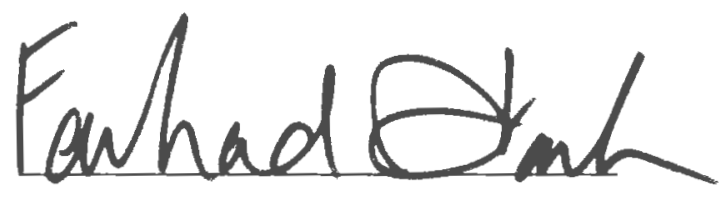

Dr. Farhad Atash

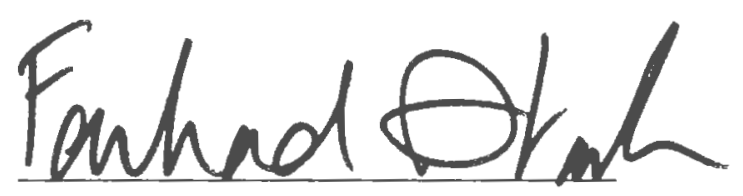

Dr. Farhad Atash 


\begin{abstract}
The issues surrounding playgrounds are in need of attention. This research paper attempts to address the safety and developmental concerns regarding playground equipment and design. Since the most immediate concern is safety, the discussion will focus on issues concerning playground safety. A brief history of playground development, developmental theories of play, and safety issues will be presented. Discussion of these issues will lead to recommendations for a mandatory public playground safety policy and program. The standards for the safety policy and program will be adopted from the 1991 U.S. Consumer Product Safety Commission's Handbook For Public Playground Safety, the 1993 American Society for Testing and Materials' standards for manufactured play equipment, and the guidelines of National Recreation and Park Association.
\end{abstract}




\section{ACKNOWLEDGEMENTS}

I would like to take this opportunity to thank the following people who helped me see this research project to its completion; Dr. Farhad Atash and Marjorie Jensen for their time, commitment, and guidance on this project; my mother for her never-ending support and encouragement; my sister Christina who typed my long hand; and to my best friend Mia who without her support, guidance, and patience, I would have never completed this project. 


\section{TABLE OF CONTENTS}

\section{CHAPTER 1 - INTRODUCTION}

Statement of the Problem 1

Main Questions to be Addressed 1

Methods of Analysis 2

Significance of the Research 3

Organization of the Study 7

\section{CHAPTER 2 - HISTORY OF PLAYGROUNDS}

The First Playgrounds 8

Municipal and School Playgrounds 11

The Traditional Playground 12

Adventure Playgrounds 13

The Playscape Concept 14

Recreational Planning $\quad 16$

Local parks 17

Neighborhood parks 18

Community parks 18

Metropolitan parks 19

Special use parks 19

\section{CHAPTER 3 - THE DEVELOPMENTAL IMPACTS OF} PLAYGROUNDS

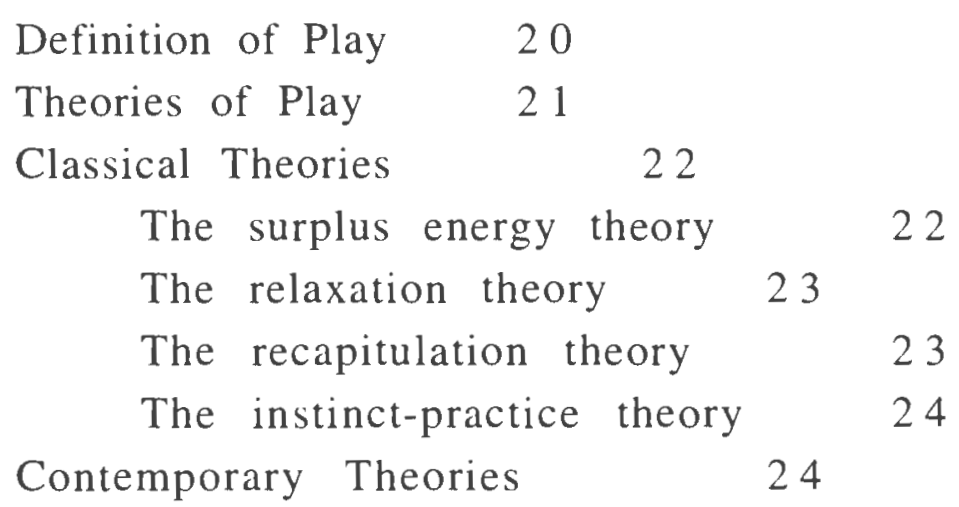


The psychoanalytical theory 24

Cognitive-developmental theory 26

Arousal modulation theory 28

The Importance of Play in Overall Development 29

Physical development 29

Emotional development 31

Intellectual development 31

Social development $\quad 34$

CHAPTER 4 - ISSUES RELATING TO PUBLIC PLAYGROUNDS

Safety Issues 36

Surface Area Under or Surrounding Play Equipment 36

Surface area hazards 36

Tripping hazards 39

Playground Facilities and Equipment

39

Protrusion and entanglement hazards 40

Entrapment openings 41

Lack of maintenance 42

Pinch, crush, shearing, and sharp edge hazards 42

Platforms with no guardrails 43

Equipment NOT recommended for public playgrounds 43

Playground Design Hazards 44

Inadequate fall zones 44

Lack of supervision 45

Age-inappropriate activities 45

Developmental Issues 47

Traditional playground design deficiencies 48

\section{CHAPTER 5 - PUBLIC PLAYGROUND RECOMMENDATIONS}

The Standard of Care for Public Playgrounds

U.S. Consumer Product Safety Commission 51

The American Society for Testing and Materials 54

Developing a Comprehensive Public Playground Safety Program

Develop a mission statement $\quad 56$ 
Conduct safety inspections and/or safety audits 56 Implement proactive programs 57

Document all activities 58

Developing a Public Playground Safety Policy 60

The National Playground Safety Institute Certification Program

\section{CHAPTER 6 - PUBLIC PLAYGROUND SAFETY AUDIT AND} INSPECTION

Public Playground Safety Audit 62

General environment

63

General environment hazards

63

Age/size appropriateness design

64

Accessibility design

64

Playground protective surface

64

Fall zone/use zone

65

Site specific play equipment

65

Audit summary 65

Public Playground Safety Inspection

Establishing a Safety Inspection Schedule 68

Use characteristics

68

Equipment design elements

69

CHAPTER 7 - CONCLUSION 72

\section{APPENDICES}

APPENDIX A - CPSC's Handbook For Public Playground Safety 75

APPENDIX B - NRPA's Playground Safety Audit Form 108

APPENDIX C - NRPA's Playground Safety Inspection

Form $\quad 130$

TABLES Table 3.1: An Overview of the Theories of Play 


\section{CHAPTER 1 \\ INTRODUCTION}

\section{Statement of the Problem}

Recreation plays a large role in the development of children.

Alone or combined with educational experiences, recreation can assist in the proper physical, emotional, intellectual, and social development of children. Although playground design and the theory of learning and development through play have received decades of attention from city officials, landscape architects, and educators, the majority of America's playgrounds contain equipment, surface areas, and design plans which can be hazardous to children at play and which fail to provide a stimulating play environment optimal to the development of children. This research project will establish the need for federal, state, and local design and safety regulations and standards by which all new and existing playground facilities can be designed and assessed. Once this need is demonstrated, design and safety regulations will be outlined and recommended. When applied to the design of new play environments or the revamping of existing facilities, these regulations and standards will create playgrounds which will stimulate the growth and development of the child's physical, emotional, social, and intellectual abilities within a safe surrounding.

\section{Main Questions to be Addressed}

This research project will address four questions. 
1) How are the developmental needs of a child met through the actions of play?

2) What types of playground design options are available to cities and towns? How well does each design option address the developmental needs of children and the recognized safety guidelines for playgrounds?

3) How can playground designers, developers and city and town officials address the main issues related to playground design, such as safety, maintenance, and child development, and

4) What methods and procedures might be used to evaluate existing playground facilities?

Answering these questions will effectively address the problems associated with many existing and proposed playground facilities, delineate the available design options and equipment, and provide much needed insight into the issues of safety and maintenance and child development. The discussion will establish standards and guidelines for playground design. The application of these standards and guidelines will result in playground designs which will enhance the physical, emotional, intellectual, and social development of all children.

\section{Methods of Analysis}

Below are the methods of analysis which will be employed to answer the main questions of the research project.

1) Research current literature on playground safety and design including books, journal articles, pamphlets, and the U.S. Consumer 
Product Safety Commission's Handbook For Public Playground Safety. This research will provide the history of play areas, define the developmental importance of play for children, outline safety and maintenance concerns, and ascertain appropriate guidelines for addressing safety concerns.

2) Construct an evaluation audit and inspection survey by which new and existing playgrounds can be assessed for safety and the developmental needs of children. The evaluation audit and inspection survey will incorporate the guidelines put forth by the U.S. Consumer Product Safety Commission, Handbook For Public Playground Safety. The evaluation audit and inspection survey's purpose are to serve as general guidelines by which city and town officials can assess the safety of their new and existing play areas.

\section{Significance of the Research}

With more mother's working and a growing concern for how children spend their time out of school, there is increasing public demand for new and better designed playgrounds which are stimulating and safe for all children. Such play environments can provide the shelter and protection of a separate play space available to all children as well as varied play areas designed to stimulate the growth and development of a child's physical, emotional, social and intellectual abilities (Woodbridge,1990).

Within the past thirty years, playground design has received serious attention from landscape architects, city officials, educators and concerned parents. Critical examination of the deficiencies 
associated with the traditional playground has called attention to the enormous developmental potential of play areas. Although studies indicate that playgrounds could contribute to a child's physical, emotional, intellectual, and social growth, many cities and towns remain unmotivated to redesign the traditional playground.

Consequently, many playgrounds maintain the traditional design and thereby fall short of their potential for the development of the "whole child" (Eriksen, 1985).

The traditional playgrounds which exist in many cities and towns are often hard surfaced areas containing standardized playground equipment which is surrounded by cyclone fencing. The primary intent for these playgrounds was to provide physical exercise for children and easy maintenance for town officials. According to Aase Eriksen, "the desire for simple maintenance has led to both dangerous playground equipment and hard surfaces under the equipment; each year large numbers of serious injuries occur in such playgrounds". The quest for easy maintenance has also led to the elimination of the natural landscaping, such as trees and shrubs, within the play area. This disregard for the natural landscaping creates play environments which lack visual interest and do little to stimulate a child's development other than physically. Furthermore, access to most traditional playgrounds is limited largely to children without disabilities (Eriksen, 1984).

A town's desire for simple maintenance and standardized exercise equipment has many serious drawbacks. In 1988, the Center for Disease Control reported that playground-related injuries in preschool aged children in the United States accounted for almost 
200,000 injuries treated in emergency rooms, annually. The hard surfacing of traditional playgrounds contributes to the majority of these injuries. The National Electronic Injury Surveillance System (NEISS) reported that falling is the most common cause of injury in playgrounds; falling accounts for 58 percent of all injuries. A fall from as little as three to five inches onto the traditional surface of concrete or asphalt can result in a life threatening injury. Poorly designed and maintained playground equipment is another danger. The U.S. Consumer Product Safety Commission (CPSC) ranked playground equipment as the fifth most hazardous consumer product (Allen, Johnson, 1995).

In the past, many playground injuries were considered unavoidable accidents. However, this is no longer the case. Media attention on these safety issues has resulted in a more informed American public which is demanding that cities and towns attend to their responsibilities for providing safe play areas. A greater understanding of and willingness to use our legal system has increased public awareness of the sizable financial awards associated with negligence cases. The issue of liability and accountability rests largely on the cities and towns which maintain playground facilities. Consequently, cities and towns are at risk of having to pay substantially for damages incurred in play areas (Teague, 1996).

Fortunately, many playground injuries can be prevented by the proper design and maintenance of the facilities. In 1981, the U.S. Consumer Product Safety Commission (CPSC) recognized the potential hazards associated with public playgrounds and published the HANDBOOK FOR PUBLIC PLAYGROUND SAFETY which contains 
playground equipment safety information and guidelines. The handbook is presented in the form of voluntary guidelines. Due to the many factors which may affect playground safety such as site location, size, budget, and community needs, the CPSC believes guidelines, rather than mandatory rules, are appropriate when designing playground facilities. Over the past decade, the CPSC has issued an updated handbook on playground safety which prompted some public agencies to seriously examine their existing playground facilities (Wallach, 1996). Similarly, the American Society for Materials and Testing Standards (ASMT) has published a handbook of voluntary equipment standards containing more specific safety requirements for manufacturers of public playground equipment (Allen, Johnson, 1995).

Although there have been several attempts to mandate federal standards or regulations governing public playground facilities, only a few states and local communities have enacted standards or regulations. The need for improved playground safety has been established by countless playground injuries which are the direct result of poorly designed and maintained playground facilities and the rising risk of city and town liability (Allen, Johnson, 1995).

Many of the hazards associated with playgrounds could be minimized if reasonable safety standards and regulations were mandated and enforced. Once these regulations are incorporated into a city's or town's laws, the city or town can then focus on its future plans to construct new playgrounds and/or renovate existing playgrounds which will be safe and developmentally stimulating to all children. 


\section{Organization of the Study}

This study is divided into seven chapters. After this introduction; Chapter 2 presents an overview of the history of public playgrounds. Chapter 3 discusses the developmental impacts of playgrounds on children. Chapter 4 addresses the current issues relating to public playgrounds. Recommendations for a comprehensive public playground safety policy and program is presented in Chapter 5. Within Chapter 6, a playground safety audit and safety inspection are discussed. Chapter 7 summarizes the major findings of this study and offers suggestions for further research. 


\section{CHAPTER 2 \\ HISTORY OF PLAYGROUNDS}

\section{The First Playgrounds}

The history of playgrounds can be directly correlated with the history of urban open space. The ancient Greeks included open space areas in the planning of their cities. These open space areas were of two types: the agora, which means "to gather", and the plateia, which means "plateaued space". The agora was located at the center of the city and provided a place for men to meet and trade. The plateia was a large open space which was used for community festivals and dances, weekly parades, marriage celebrations and children's play. The village greens of Feudal Europe and the marketplaces of medieval towns also provided open spaces where the community could meet and interact (Eriksen, 1985).

Although specific areas of land like the plateia and the marketplace had been planned and designated as communal open space, the concept of a playground did not develop until the end of the nineteenth century. Before this time, there was no separate space designated specifically for children. Adults as well as children had a part in providing for the family by working in the home or on a farm. During the nineteenth century, children were separated from the adult world as a result of social change, the enactment of child labor laws, the growth of public education, and the prosperity of the middle and lower classes. Children did not have to work for wages anymore; instead, they worked at getting an education. Ultimately. children were given more and more leisure time for unconstructed 
play. Thus, the need for a specialized place for children to play developed (Eriksen, 1985).

The Boston Common was one of the first public open spaces in the United States to be dedicated to children's needs and originated the concept that children need specialized spaces in which to play. The Common was founded in 1885 in the city of Boston, Massachusetts and is considered the first playground (Eriksen, 1985).

However, the first organized playgrounds in the United States were not established until the 1880 s and 1890s. These early playgrounds consisted of a large sandbox made of wood and was located in the Parmenter Street Chapel and West End Nursery in Boston. The playground was called a "sand garden" and was funded and constructed by the Massachusetts Emergency and Hygiene Association. Within two years, ten sand gardens were built in Boston. By 1899, the association had sponsored a total of twenty-one sand gardens in the city (Eriksen, 1985).

The main purpose of these early playgrounds was to get urban children off the streets where horse and trolley traffic presented both health and bodily dangers (Eriksen, 1985). In the article "Urban Playgrounds, An Institution of Learning for Children"; L. Pettis Patton, explains that,

Through a single movement the entire nation focused its attention on its most precious resource "its children." This was perhaps the most dynamic child saving reform effort of the century. The intended purpose of this reform was to rescue city children from social and economic hazards which included economic exploitation, moral chaos, alienation and threats to law and order fostered by unsupervised adolescent street culture (Patton, 1996). 
These early playgrounds were developed for the use of young children who lived in the densely populated inner cities and were open and maintained only during the summer vacation period.

Recognizing the success of the early sand gardens to get children off the streets and away from bodily harm, officials began to design playground with the goal of combatting juvenile delinquency. Playground design began to incorporate specific apparatus, activities and supervision which would best attract and guide children. Not unlike the traditional playground of today, the early playgrounds combined ball playing areas with areas of fixed, commercially manufactured equipment designed for physical exercise. Playgrounds were built on hard surfaces such as asphalt or cement. As noted by Aase Eriksen in the book, Playground Design: Outdoor Environments for Learning and Development, "These playgrounds were somewhat experimental in nature but were based on the recognition that play has educational as well as recreational value..." (Eriksen, 1995).

The first designed playground was built in 1894 at the Jane Addam's Hull House in Chicago. Other designed playgrounds were built in Philadelphia, Providence, New York, and Boston. Expanding on the concept of a designed playground, the Massachusetts Emergency and Hygiene Association proposed the first large recreational park in 1886. Designed by Frederick Law Olmstead, the Charlesbank Playground in Boston was built from 1889-1891 and provided specialized recreation areas for adults as well as children. The Charlesbank Playground offered an open-air gymnasium with a running track for men at one end of the park and another 
gymnasium for women and a playground for children at the other end. Conveniently located within the playground were buildings equipped with locker rooms, a variety of gymnastic apparatus and paid instructors. This type of playground became popular in the United States. Similar recreation parks were built in Louisville, Philadelphia, New York, and Chicago (Eriksen, 1995).

\section{Municipal and School Playgrounds}

The second stage in the playground movement in America began when municipal and educational agencies recognized the educational merits of recreation and began to fund new public playground projects. Early municipal playground systems were modeled after the Charlesbank Playground in Boston. The municipal playground contained indoor as well as outdoor facilities for public use. These parks were open day and evenings year-round. They offered athletic and ball fields, indoor and outdoor gymnasiums, swimming pools, field houses and auditoriums, as well as playgrounds for small children (Eriksen, 1995).

About the same time municipal playgrounds were being developed and gaining popularity with the public, recreational activities and physical exercise were being incorporated into the public school curriculum. The first publicly funded school playground was built in Philadelphia in 1896. Other cities quickly followed suit. The inclusion of physical education classes in the school curriculum spread across the country and the number of new school playgrounds increased dramatically over the next decade. Even more significant growth in the popularity of municipal and 
school playgrounds came when President Theodore Roosevelt declared his interest in physical fitness and exercise and the need to provide adequate playgrounds to all people. Eventually, school playgrounds were developed to include both the recreational goals for the municipality and the goals of the school curriculum on one site. This combination was developed to avoid redundant spending of public money on both municipal and school facilities (Eriksen, 1995).

\section{The Traditional Playground}

Originally, playgrounds were funded and developed to get city children off the streets and away from bodily harm. The focus then changed to municipal and school funded recreational facilities and programs designed for people of all ages and all levels of society. These community based playgrounds offered free form areas for play as well as structured areas with fixed equipment (Eriksen, $1995)$.

With the advancement of World War I, the country focused its attention on the physical fitness of its youth. Physical exercise and competitive sports became the emphasis in school recreational curriculum. Areas set aside for free-form, fantasy, and quiet play were redeveloped and replaced with fixed equipment designed to promote physical fitness. Standardized equipment such as swings, horizontal bars, see-saws, and slides quickly became popular because they effectively and inexpensively achieved the goal of providing physical fitness. Concerns shifted from well thought-out recreational sites and programs to inexpensive, easily maintained equipment 
designed for physical fitness only and facilities which could be used by a large number of children without much need for adult supervision (Eriksen, 1995).

While the playground movement was well underway and the traditional playground was becoming the norm in design, a handful of professionals recognized the inherent deficiencies in these playgrounds and published recommendations for revision or improvement. Unfortunately, these recommendations went unheard and the trend towards standardized equipment, hard and flat surfaces, and easy, inexpensive maintenance continued (Eriksen, $1995)$.

\section{Adventure Playgrounds}

As the traditional playground took hold, very few new playground design concepts became established within recreational planning. The one most noteworthy challenge to the traditional playground concept was developed in 1943, in Copenhagen, Denmark. The concept became known as the adventure playground (Eriksen, 1995).

The adventure playground was not based on standardized, exercise-oriented equipment set in a planned environment. Rather, it provided loose materials such as lumber, old tires, logs, pipes and bricks for children to freely manipulate at their will and imaginations. Play leaders instructed children on how to use tools and conducted other activities in the playground. The basic design concept of the adventure playground was to provide urban children 
the opportunities for free and creative play with unrestricted natural materials not usually found in the city setting (Eriksen, 1995).

The concept of the adventure playground spread throughout Europe. In 1950, the adventure playground was introduced in the United States. Although successful in its infancy stage in some U.S. cities, the adventure playground never gained strong support in the United States. American parents and city officials were reluctant to accept the adventure playgrounds for three reason. First, a successful adventure playground requires a trained play leader. Unfortunately, due to the limited funding for public playgrounds, establishing this position was not possible. Second, parents believed that adventure playgrounds were not as safe as traditional playgrounds. Parents and officials saw rusty nails, splintered lumber, and collapsing structures as great hazards. Third, Americans felt that the unconstructed free nature of the adventure playground was unsightly. Parents saw the concept as a slumlike playground unlike the easily maintained traditional playgrounds (Eriksen, 1995).

\section{The Playscape Concept}

The adventure playground was introduced in the United States as an alternative to the traditional playground. Its main purpose was to provide children with a supervised creative play environment while avoiding the hazards associated with the traditional playground. The adventure playground was not widely accepted (Eriksen, 1984).

One solution to America's playground design dilemma is called the Playscape Concept. This playground design retains the best 
features of the adventure playgrounds such as promoting stimulating and creative play activities while at the same time providing easily supervised playgrounds similar to the traditional playgrounds. (Eriksen 1984)

The Playscape Concept is a carefully designed and landscaped outdoor environment for play that supports activities which are an essential part to the proper physical, emotional, intellectual, and social development of children. The design recognizes children's play as a series of linked activities while affording spatial and textural diversity within the natural landscape. The playscape's physical designs takes into accounts a child's need for a place of their own which is secure against adult intrusion, yet respects an adult's concern for easy supervision. (Eriksen 1984)

The Playscape Concept is based on three important principles. First, a playscape design seeks to provide a play environment for children of any age and in various stages of development within the same site location. The playscape environment encourages children of different ages to mingle and play together by the proximity of their separate zones and in the spared zones of nature play, ball play and structured play. Second, the playscape design is adoptable to any size location whether the site be a neighborhood park or a vacant lot. It can be designed to blend in with the character of the surrounding neighborhood and accommodate the existing natural topography of the site. Finally. the playscape concept is very amenable to the participatory design process in which a series of design meetings are conducted and children as well as adults take 
part in the actual planning and design of their own playscape playground (Eriksen 1984).

The playscape concept can be a great outdoor learning environment for children as well as an amenity to the whole community. The design flexibility of this concept allows the playground to become an attractive, green space which blends with the atmosphere of its surroundings. The playscape concept offers children an environment which supports activities that are an essential part of the child's physical, emotional, social, and intellectual development (Eriksen 1985).

\section{Recreational Planning}

While the need for well designed and maintained public playgrounds is established, public playgrounds are just one element of a community's recreational system. In many communities, a smaller public playground is incorporated into a larger neighborhood park serving a broad range of residents. The components which make up a successful community recreational system are very similar to the components which make up a successful local playground (Butler 1950).

The chief objective sought in local recreational planning is the enrichment of individual and community life through a municipality's ability of providing recreational opportunities which promote the proper physical, emotional, intellectual and social development of the community at large. Due to different local conditions and resources as well as varied recreational interests, habits and culture of people, recreational planning today must 
comprise of many various types of sites developed for a variety of local uses. Several types of recreational opportunities are essential to a well-balanced recreation program (Butler, 1950).

Standards promoted by the National Recreation and Park Association (NRPA) have been widely adopted in many municipalities. These standards describe the function size and approximate locations of the recommended recreational facilities.

The recreational standards held by a municipality should be generalized and actual neighborhood circumstances should be incorporated when applying the standards to new projects. The standards classify existing parks by acreage and the area which a particular park would efficiently service. "A park system with too few acres dedicated to local parks, for example, will result in over crowded and, perhaps, dangerously crowded play areas" (Butler, 1950). The following are the recreational standards set forth by the National Recreation and Park Association (NRPA).

\section{Local Parks}

A local park is classified as having $1 / 4$ to 1 acre and serving an area between $1 / 4$ to $1 / 2$ miles in radius. A local park can be designed as a passive park with formal or informal green spaces. This type of local park is geared towards adults who wish to relax in a natural setting. A local park can also be geared towards younger children. This park is intended for young children under the supervision of an adult. It would contain play equipment such as, slides, swings, climbing devices and benches for the adults. 
The recommended acreage for a local park is 0.5 acres per 1000 people of the area. For example, if a neighborhood has 5000 residents, there should be 2.5 combined acres dedicated to local parks.

\section{Neighborhood Parks}

A neighborhood park is classified as having 4 to 7 acres and serving an area of $1 / 2$ to 1 mile in radius. This type of park can be designed to have both active and passive recreational uses. A neighborhood park design may have: play equipment for older children; a play area for younger children; open fields for informal play activities such as baseball, softball, and football; court game such as basketball, hockey, and tennis; and landscaped sitting areas for passive activities. The recommended acreage for a neighborhood park is 1.5 acres per 1000 people.

\section{Community Parks}

A community park is classified as having 8 to 20 acres and serve and area of 1 to 2 miles in radius. This type of park usually is intended to serve several neighborhoods. The community park contains large areas devoted to athletic fields and smaller sub-areas intended for passive use. Common athletic facilities are baseball and softball diamonds, football fields, soccer fields, jogging tracks, spectator seating and parking areas. The recommended acreage for a community park is 5 acres per 1000 people. 


\section{Metropolitan Parks}

A metropolitan park is classified as having 100 or more acres and serving an entire community or region. Within this park are a variety of recreational activities ranging from athletic fields to small play areas. This park may also include water areas, zoo, picnic areas, and conservation areas. The recommended acreage for a metropolitan park is 10 acres per 1000 people.

\section{Special Use Parks}

A special use park is classified according to the use which it is intended to provide. Special use parks may include uses such as pools, golf courses, gymnasiums, bike trails, and handicap facilities. The recommended acreage varies with the population it is intended to serve.

Effective integration and development of existing and future recreational sites into the overall land use of the community must be based upon accepted objectives, principles, and standards designed to promote the health safety and welfare of the community. It is important that town recreational planning concerns itself not only with the physical development of recreational sites but also with the enrichment of life through recreational activities for children as well as adults residing within the community (Butler, 1950). 


\section{CHAPTER 3}

\section{THE DEVELOPMENTAL IMPACTS OF PLAYGROUNDS}

\section{Definition of Play}

Developmental psychologists generally agree that play has an important role in the development of the "whole child" (Schell, Hall, 1983). Unfortunately, when asked to define play, psychologists offer contrasting definitions and disagree about the biological and psychological motivation of play (Frost, Klein, 1979). One reason for the disagreement is that the same behavior can be considered play in one instance and work in another (Schell, Hall, 1983). For example, ten-year olds engrossed in a neighborhood game of touch football are at play while members of a professional football team are not playing when they are out on the field on Sunday afternoon. While psychologists can not agree on one definition for play, they have identified five basic elements which are typical of play (Hughes, $1991)$.

The five essential characteristics of play are that it be intrinsically motivated, freely chosen, pleasurable, nonliteral, and actively engaged in by the player. First, play is intrinsically motivated when the activity is an end in itself and done only for the sheer satisfaction of doing it. Second, play must be freely chosen by the child; if not, the child may consider the activity as a work assignment and not play. Third, the play experience must be pleasurable to the child. If the child does not enjoy the experience, the experience can not be considered play. Fourth, the notion of play must be nonliteral. For play to be nonliteral, the activity must have 
a certain element of make-believe or a distortion of reality to accommodate the interest of the child. Finally, a play activity must be actively engaged in by the player. The child must be involved both physically and psychologically in what is going on during the activity (Hughes, 1991).

\section{Theories of Play}

The question of why humans play is complex and longstanding. Since classical times, theorists have recognized play as being universal and not simply as an activity experienced by human beings. Theorists saw that all higher animals, from humans to fish, exhibit some degree of play activity, that is, mental or physical action which is not directly related to its survival (Roberts, 1995). Over the centuries, developmental psychologists have offered several theories of play, but no one theory has completely explained the significance of play in a child's development. The theories of play has evolved from the classical theories of the late nineteenth century which emphasized the biogenetic significance of play as an instinctive mechanism to promote optimal physical development, to the contemporary theories of the twentieth century which emphasize the psychological value of play and its significance to a child's intellectual, social, and emotional development. Examining the evolution of the theories of play will provide a helpful framework within which child development and the aspects of play can be better understood (Hughes, 1991). Table 2.1 offers an overview of the evolution of the theories of play. 
TABLE 3.1 - An Overview of the Theories of Play.

$\begin{array}{lll}\text { Theories } & \text { Reasons for Play } & \text { Greatest Benefits } \\ \text { Surplus Energy } & \begin{array}{l}\text { To discharge excess } \\ \text { energy of the body }\end{array} & \text { Physical } \\ \text { Relaxation } & \begin{array}{l}\text { To avoid boredom while } \\ \text { the body restores its } \\ \text { energy supply }\end{array} & \text { Physical } \\ \text { Recapitulation } & \begin{array}{l}\text { To relive periods in the } \\ \text { evolutionary history of } \\ \text { the human species }\end{array} & \text { Physical } \\ \text { Instinct-Practice } & \begin{array}{l}\text { To develop skills and } \\ \text { knowledge necessary for } \\ \text { functioning as an adult }\end{array} & \\ \text { Psychoanalytic } & \begin{array}{l}\text { To reduce anxiety by giving } \\ \text { a child a sense of control } \\ \text { over their world and to } \\ \text { express forbidden impulses }\end{array} & \\ \text { Cognitive - } & \begin{array}{l}\text { To facilitate general } \\ \text { Developmental } \\ \text { cognitive development } \\ \text { and growth }\end{array} & \\ \text { Arousal Modulation } & \begin{array}{l}\text { To keep the body at an } \\ \text { optimal state of arousal } \\ \text { To relieve boredom } \\ \text { To reduce uncertainty }\end{array} & \\ & \end{array}$

\section{Classical Theories}

\section{The Surplus Energy Theory}

In 1875, Herbert Spencer introduced the surplus energy theory (Frost, Klein, 1979). Spencer described play as a goalless activity necessary to allow children to discharge pent-up energy. He argued that each human being is equipped with a certain amount of energy to be used in the process of survival. If excess energy remains after the necessary activities of survival have been satisfied, it must be 
discharged. Spencer theorized that children discharge their excess energy in activities of play. An example of this theory can be seen in the relaxed nature of children after recess period. However, parents and teachers often noticed that children would play to the point of sheer exhaustion but appear to be even more energized than before they engaged in the activity (Hughes, 1991).

\section{The Relaxation Theory}

In 1916, G.T.W. Patrick argued a theory of play which opposed Spencer's surplus energy theory. According to Patrick, the purpose of play was the renewal of energy, not the release of excess energy. Patrick believed that when children are relaxed and tired, play keeps them occupied and helps them to avoid boredom while their natural energy supply is restored. This theory can easily explain the basis of sedentary play; however, it can not explain the high energy, rough and tumble play that also makes up a child's play activities (Hughes, 1979).

\section{The Recapitulation Theory}

The origins of the Recapitulation Theory can be traced back to Darwin's theory of the evolution of humans. Luther Gulick and G. Stanley Hall formalized the Recapitulation Theory which describes play as a result of human biological inheritance: through play the evolutionary history of the human species is recapitulated or repeated (Frost, Klein; 1979). For example, an infant crawling about at play would represent the period in evolutionary history when humans walked on all fours. The game of "cops and robbers" would 
represent a period when our prehistoric ancestors would hunt and gather food (Hughes, 1991). Although this theory was popular at the turn of the century, it does not take into account the social interactive aspects of play or play with toys and games (Frost, Klein, 1979).

\section{The Instinct-Practice Theory}

Karl Groos presented the Instinct-Practice Theory of play which suggested that play is the body's natural way of preparing itself for adult life (Hughes, 1991). He explained that although human beings inherit instinctive behaviors, practice is needed to perfect specific behaviors and movements needed during adult life (Frost, Klein; 1979). For example, the child who plays "house" would be preparing for its adult role of running a household. In fact, many activities of children's play resemble adult activities (Hughes, 1991).

\section{Contemporary Theories}

Contemporary theories of play offer the most useful and practical analysis of play. These theories view the action of play not as a single function such as the release of surplus energy or a mode to relaxation, but as a multiplicity of functions directly influencing a child's physical, emotional, social, and intellectual growth and development.

\section{The Psychoanalytical Theory}

According to psychoanalyst Sigmund Freud, play's value is primarily emotional in that play allows children to reduce anxiety. 
Freud observed two types of anxiety experienced by children. The first is object anxiety which is the fear of the external world. Infants and young children soon realize that they are helpless and must rely on a caretaker for their most basic needs. Fear of abandonment is particularly strong during this developmental period. According to Freud, play reduces object anxiety by giving a child a sense of power and control over his or her environment. For example, when a baby plays with a rattle, the rattle becomes an extension of the baby's body and provides the child with the illusion of power. When older children play with dolls or toys resembling adult objects, play reduces the large and overwhelming adult world to a size that the child can control and command (Hughes, 1991).

The second form of anxiety is instinctual anxiety. According to Freud, a child's feelings of anger, unreasonable fear, and the wish to be messy or destructive are discouraged by adults causing the children to repress rather than express their feelings. This repression creates a sense of anxiety. During play, children can explore these feelings within the limits of the play activity. For instance, a child is free to aggressively squeeze and pound ceramic clay or destroy a sandcastle within the activity of play (Hughes, $1991)$.

The psychoanalytic perspective on play is also reflected in the writings of Erik Eriksen. He suggested that play serves as an egobuilding function since it promotes the development of physical and social skills that enhance a child's self-esteem (Hughes, 1991). Eriksen viewed play as a developmental progression in which a child adds new and more complex understandings about the world. 
Eriksen outlined three stages. The first stage is called autocosmic play. It begins at birth and centers around an infant's exploration of its own body. The next stage is called microsphere play in which a child creates a small world of manageable toys and objects. The third stage of play occurs when a child reaches nursery school age. This stage is called macrosphere play in which a child shares play with other children. Macrosphere play contains elements of the earlier two stages (Frost, Klein; 1979).

\section{Cognitive - Developmental Theory}

The cognitive - developmental theory typically regards play as a mechanism for facilitating the intellectual growth of human beings. Swiss biologist and philosopher Jean Piaget is perhaps the most noteworthy cognitive theorist who has explored the concept of play as it relates to the intellectual development of children (Hughes, 1991). Piaget's theory is based primarily on the concept that the development of intelligence is an adaptation between an individual's maturation and his or her social and physical environment (Salkind, 1990). Such adaptation is necessary for an individual's survival. He suggests that a living organism can adapt in two ways. Physical adaptation is when an organism adjusts its body to the surrounding environment. For example, when a human is overheated, the body perspires to cool itself down. Psychological adaptation is when a human adjusts his or her ways of thinking to incorporate new information. Psychological adaptation is necessary for the continued growth of the intellectual structures of the mind (Hughes, 1991).

The process of physical and psychological adaptation occurs 
through the process of assimilation and accommodation (Frost, Klein, 1979). Cognitive assimilation is the process of incorporating new material from the outside world into one's already existing intellectual and physical structures (Salkind, 1990). For example, humans are presented new information every day which is then incorporated into their minds. In a physical sense, the body assimilates food by digesting it so that it eventually becomes part of the body itself (Hughes, 1991).

Accommodation is the adjusting of the intellectual or physical structures in reaction to the newly incorporated material (Salkind, 1990). The human body adjusts to the newly digested food by growing and changing while the mind adjusts its perspective on life after incorporating the new intellectual material. Therefore, physical or intellectual growth will not occur unless both assimilation and accommodation take place. According to Piaget's theory of cognitive development as it relates to play, the action of play is viewed as the assimilation of environmental stimuli with little regard to the limitation imposed by accommodations. (Hughes, 1991). In their book, Developmental Psychology Today, Robert E. Schell and Elizabeth Hall state,

"Jean Piaget (1951), ... Believed that all the conditions of play were included in his own simple definition that play is primarily assimilation. The pleasure involved is simply the emotional expression of that assimilation, in which the child responds to the "whims of the ego" instead of accommodating to the demands of the world" (Schell, Hall; $1983)$. 


\section{Arousal Modulation Theory}

The arousal modulation theory of children's play is based on the premise that there is some optimal level of central nervous system arousal that a human being tries to maintain. Within the ideal environment, there is neither too much nor too little stimulation. A human being will strive for just enough stimuli to keep him or her optimally aroused. Each person has his or her own level of optimal arousal which ranges somewhere between uncertainty and boredom (Hughes, 1991).

According to this theory, when new stimuli enters a persons environment, the person becomes confused and uncertain causing his or her level of arousal to become elevated. In order to reduce this elevated level down to its optimal level, a person must explore the new stimuli to alleviate the object's uncertainty. In contrast, when there is a lack of stimulation in the person's environment, the optimal arousal level falls. This causes a person to seek stimulation to maintain the desired arousal level. At this point, the concept of play is used to generate new environmental stimulation. The newly created stimulation in turn raises the person's arousal level back to its desired state. According to H. Ellis and G. Fein, children at play produce exciting new stimuli which at first may make them apprehensive by the uncertainty of the new situation but later as the new situation is explored and the uncertainty is reduced, the action of play becomes positive within the children (Hughes, 1991). 


\section{The Importance of Play in Overall Development}

Theories of play have evolved from focusing on the physical development of a child to incorporating the psychological value of play and its significance in promoting intellectual, emotional, and social development. Play is the initial stage in the lifelong process of growth and development which every individual experiences. Children's play activities are the major medium of learning for children. Play and learning are synonymous terms and represent an integrated, continuous process in the lives of children. A well designed and maintained playground which offers a variety of play activities can assist in the proper physical, emotional, intellectual, and social development of children (Miller, 1972).

\section{Physical Development}

Physical development is the most recognized benefit of play. The action of play contributes to the physical growth, motor development, physiological functioning, and general physical fitness of children. Through play children instinctively practice on a regular basis the basic motor skills of jumping running, hopping, walking, throwing, and leaping in varied forms and combinations. Coordination, agility, balance, strength, and endurance are all acquired through actions of play such as swinging, climbing, and other activities (Miller, 1972).

While in play, children use gross motor and fine manipulative movements to preform sensory motor activities. Sensory motor activities develop skills in the child's perception of body positions and movement in space. Children also become aware of their 
environment and of their being distinct from their surroundings (Miller, 1972).

Early acquisition of these basic motor skills, proper physical growth, fitness, and physiological functioning have significant implications for a child's present as well as future success. These movement patterns are the basis for the child's future recreational pursuits and future mental activity. A considerable amount of research has indicated a positive correlation between motor development and future mental abilities and performance. Miller explains,

"Human development is characterized by an orderly progression of changes in physical development and body structure from infancy through adolescence. A broad base of fundamental motor skills (a variety of motor experiences) is necessary for the sequential and systematic mental growth and development of the individual according to Piaget" (Miller, 1972).

Research also shows that the more physical activities children are allowed to experience, the healthier, livelier, and happier they will be. The research also indicates that their overall development will become accelerated thus enabling the child to reach their optimal potentials. Children have a great need for proper physical development. Therefore, any new or proposed playgrounds should contain a variety of play activities and sufficient space and equipment to accommodate this need (Eriksen, 1985). 


\section{Emotional Development}

Experiences that develop children's abilities to understand and control their emotions are as important as those activities which affect a child's physical, intellectual, and social development (Eriksen, 1985). Through play activities children grow and develop in their understanding and knowledge of themselves as individuals. This helps to establish a concept of self and a sense of body image and self-esteem. As a child plays, he/she learns self-expression and selfdiscipline. Play can offer an outlet for a child to express his/her inner feelings and sometimes anger and frustration. Through play children learn self-confidence, self-reliance, and independence. They learn their abilities and limitations by taking calculated risks while playing. The child must take risks in order to learn and grow (Miller, 1972).

Through play children build their own individual value system and gain emotional fitness (Miller, 1972). The emotional stimulation that a child experiences through play is essential to improving the child's ability to deal with difficult or stressful situations. Children must actually experience emotions in order to develop these emotions within themselves (Eriksen, 1985).

\section{Intellectual Development}

Originating from Jean Piaget's contemporary theory and research on play, five stages of intellectual (cognitive) development have been established (Biehler. Snowman, 1993). Each stage has its own characteristic form of play as it relates to a particular age group (Eriksen 1985). 
The sensorimotor stage is the period from birth to eighteen to twenty-four months of age. During this stage, the child develops from the passive responses of infancy to active responses such as searching for objects or expressing anger. Play can be characterized as functional or practice play in the form of repetitious actions. Children gain great pleasure from being able to control themselves and their surrounding environment to some extent (Biehler, Snowman, 1993).

The preconceptual stage is the period from age eighteen to twenty-four months to four years old. During this stage, children develop the ability to create symbols, imitate the actions of others, and learn to speak (Eriksen, 1985). Children in this age group replace repetitive and random movements with purposeful movement, language imitation, and dramatics. Children use various play materials. The goalless play of the sensorimotor stage gives way to purposeful play with the end product being a creation in the eyes of the child (Frost, Klein, 1979). Until about the age of four, children primarily play within their own world while giving little attention to the activities of other children and only occasionally will interact with others (Eriksen, 1985).

The intuitive stage of development is from four years to eight years old. The characteristic of this stage is a child's increasing ability to conceptualize and organize their experiences into increasingly logical concepts. Children develop and use their intuition and will continually attempt to make their intuitions correspond to reality (Eriksen, 1985). 
During this developmental stage, children become aware of other children they meet during school. Children gradually expand on the elements of the preconceptual stage of play and begin to participate in games with rules. While participating in the games, the individual child learns to control and adjust his or her behavior to the rules of the game. By the age of seven, the predominant form of play is games with rules which ultimately continues into adulthood (Eriksen, 1985).

The concrete operations stage of development occurs from eight years old and continues to the age of twelve. Within this stage, thought becomes more detached from perception or action (Biehler, Snowman, 1993). Children are better at organizing their experiences into categories such as class, relation and number. Children in this age group form complex social relations and have great interest in playing games with rules. They often work as a team in order to achieve a common goal. Children in this developmental stage strive to experience everything on a first-hand basis (Eriksen, 1985).

The final stage of childhood development is the formal operations stage which begins at age twelve and continues to age sixteen. During this stage, children begin to develop adult thought processes. They can formulate theories and hypotheses that can be tested against reality. Children remain preoccupied with the rules of the games. love to create complex situations, and strive to anticipate all the possible outcomes of a game or activity (Eriksen. 1985). 


\section{Social Development}

Children also learn to socialize through play. They grow away from the egoism which characterize the infant and young child and become more social with others (Miller, 1972). Proper social development requires that children learn to relate to and interact with other children. Children learn to adapt their egocentric views of the world to include other children and adults (Eriksen, 1985).

Through play children learn about other people. They learn about cooperation and the rights of self in relation to the rights of others. Children learn to compromise, share, and work as teams. The social skills developed as children are often the basis for young adult social relations (Miller, 1972).

Recent research has suggested that mixing children of different ages is an important factor in positive social growth. While children of different ages have different physical, emotional, intellectual, and social needs, it is important that a play environment provide areas where younger and older children can interact. Research has shown that younger children find it extremely stimulating to be with older children. Often the older children are viewed as role models. The social development of older children is enhanced by learning to care for and understand the younger children (Eriksen, 1985).

The function of play in childhood development has been essentially misunderstood in the past. Surprising numbers of people still maintain that the primary function of play is to "let off steam" so that children can return to the more important business of study and learning. Developmental psychologists have done countless studies of how intelligence develops in children; these studies have shown 
that precisely the reverse is true. Play is the way in which children develop and learn. An understanding of the physical and psychological value of play is essential if recreational officials wish to design play environments that will encourage the proper development of the "whole child". 


\section{CHAPTER 4 \\ ISSUES RELATING TO PUBLIC PLAYGROUNDS}

\section{Safety Issues}

Over the past 20 years, the U.S. Consumer Product Safety Commission (CPSC), the National Playground Safety Institute (NPSI), and the American Society for Testing and Materials (ASTM) have been the national leaders in the growing movement to improve the safety of public playgrounds. Studies conducted by these organizations have identified 12 leading causes of injuries on public playgrounds ( American City \& Country 1995). These injuries can be grouped into three categories. The three categories are surface area under or surrounding play equipment located within playgrounds, existing or proposed play equipment, and existing or proposed playground design plans (Frost, Klein 1979).

\section{Surface Area Under or Surrounding Play Equipment Surface Area Hazards}

Each year hospital emergency rooms treat an estimated 200,000 children who have been injured in playground accidents (ERIC clearinghouse, 1996). According to the National Electronic Injury Surveillance System (NEISS), the most frequent hazards associated with playgrounds are falls onto hard-packed surface areas under or around play equipment (Frost, Klein 1979). Falling from playground structures onto a hard surface such as asphalt, cement or packed earth can cause serious injury and even death for children (Hennger, 1993). NEISS reported that falling is the most common 
cause of injury in playgrounds; falling accounts for 58 percent of all injuries. Of this 58 percent, falling from climbing equipment was implicated in 23 percent of the cases while swings accounted for 16 percent, slides 13 percent and other equipment at 6 percent of the cases. A fall from as little as three to five inches onto the traditional surface of concrete or asphalt can result in a life threatening injury (Allen, Johnson, 1995). According to the NRPA and the NPSI, more than 70 percent of all accidents on playgrounds result from children falling onto hard surfaces. The statistics pointing to falls onto hardpacked surfaces are staggering. According to the NRPA, the NPSI, and the US CPSC, hard surfaces, such as concrete asphalt, and packed earth or grass are not acceptable under play equipment (American City \& County 1995).

Unfortunately, until 1981, changing the surfacing of playgrounds was met with great resistance. The surfacing preferred by recreational and school officials was either concrete, asphalt or grass. In 1981, the U.S. Consumer Product Safety Commission published its first issue of the Handbook for Public Playground Safety. The handbook recognized and documented the safety hazards associated with hard-packed surface areas and made recommendations for softer alternatives. Some municipalities incorporated these recommendations, but many of today's playgrounds still have hard surfaces (Wallach 1996).

Hard-packed surfaces are preferred over softer surfaces because there is nothing loose to trek into buildings or parking lots, and they do not need raking or care. When asphalt or cement was not chosen, grass was often selected but quickly turned to hard dirt 
under the equipment when the grass wore away from lack of maintenance (Wallach 1996). Other alternatives to asphalt, concrete and grass were available but did not offer easy maintenance. Rubber mats were available and installed in some playgrounds but were considered too costly for most municipalities. Sand and pea gravel were fairly inexpensive but required constant maintenance (Hennger 1993). Regrettably, the cost and maintenance of available surfacing alternatives outweigh the concerns for child safety. The traditional playground with its hard surfaces still exists in many cities and towns in America (American City \& County 1995). Concerned parents and municipal officials must work together to replace these surfaces with more appropriate materials in order to reduce this unnecessary hazard (Hennger 1993).

Today, there are many playground surfaces that offer substantially more protection from falls than the traditional surfaces of asphalt, concrete and grass. According to the NPSI, acceptable natural play surfaces are hardwood fiber/mulch, sand, and pea gravel. These surfaces must be maintained at a depth of twelve inches and be free of standing water and debris. The surfaces must be maintained periodically so that the material does not become compacted. Playground manufacturers also offer synthetic or rubber tiles and mats that are designed to provide protection from falls. The CPSC and the ASTM offer information and guidelines on available play surface materials (National Playground Safety Institute, 1996). 


\section{Tripping Hazards}

In addition to the hazards associated with falling onto hardpacked surfaces, a poorly maintained playground surface could create tripping hazards. As the playground equipment is used, the surfacing under and around the play equipment erodes. Over time, concrete footings may become exposed, surface elevations may change abruptly, and tree roots and rocks may appear. These tripping hazards contribute further to the overall hazards associated with playground surface areas and can easily be eliminated by periodic maintenance of the playground surface (National Playground Safety Institute, 1996). The CPSC recommends that once a tripping hazard has been identified, it should be immediately corrected (U.S. Consumer Product Safety Commission, 1991).

\section{Playground Facilities and Equipment}

The age of a playground can be determined by the style and condition of its equipment. In the 1940's and 1950's, playground equipment was relatively inexpensive; it consisted of single-use pieces such as a see-saw, monkey bars, and swings which were installed on concrete, asphalt or grass. In the 1960's and 1970's, federal funds provided for wooden play equipment. Then in 1980, federal funding began to dry up and recreational officials turned to local and community fundraising to support the construction or refurbishing of new or existing playgrounds (Patton 1996).

Unfortunately, local funding was lacking, so the traditional playground equipment of the 1940's and 1950's and the large 
wooden play structures of the 1960's and 1970's still exist in many of America's recreational systems. This obsolete equipment accounts for the next largest percentage of injuries to children on public playgrounds. According to the 1988 NEISS report, climbing equipment was implicated in nearly one-quarter of emergency room visits. The U.S. Consumer Product Safety Commission recently ranked playground equipment as the fifth most hazardous consumer product (Allen, Johnson 1995).

The National Recreation and Parks Association and the National Playground Safety Institute have identified six equipment associated hazards. The six identified equipment hazards are: Protrusion and Entanglement Hazards, Entrapment Openings, Lack of Maintenance, Pinch, Crush, Shearing and Sharp Edge Hazards, Platforms with No Guardrails, and Equipment Not Recommended for Public Playgrounds. Many of the equipment hazards can be identified by a simple site visit (American City \& County 1995).

\section{Protrusion and Entanglement Hazards}

Protrusion and Entanglement hazards involve the extension of a component or piece of hardware that can catch hold of a string or item of clothing which might be worn around a child's neck. The result is the possible strangulation of the child. Other examples of protrusion and entanglement hazards include bolt ends that extend more than two threads beyond the face of the nut, hardware configurations which form a hook or leave a gap or space between components and open "S" type hooks (American City \& County 1995). The NPSI pointed out that rungs or handholds for equipment that 
protrude outward from a support structure may be capable of penetrating a child's eye socket. They also noted that special attention should be given to the area at the top of slides and sliding devices. Ropes should be anchored securely at both ends and not be capable of forming a loop or a noose (National Playground Safety Institute, 1996).

Protrusion and entanglement hazards can easily be identified during periodic safety inspections or during a safety audit. The CPSC recommends that once a protrusion and entanglement hazard has been identified, it should be immediately documented and the specific hazard should be corrected (U.S. Consumer Product Safety Commission, 1991).

\section{Entrapment Openings}

Entrapment in openings of playground equipment is another hazard. Enclosed openings on playground equipment must be checked for head entrapment hazards. Children may enter these openings feet first and attempt to slide through the opening. If the opening is not large enough it may allow the child's body through the opening but entrap the child's head. According to the NRPA, there should be no opening on playground equipment that measures between three and one half inches and nine inches (American City \& County 1995). Entrapment areas of concern on playground equipment are the openings at the top of a slide, openings between platforms and openings on climbers where the distance between rungs may be less than nine inches (National Playground Safety Institute, 1996). 
Entrapment hazards can easily be identified during a comprehensive safety audit of the playground. During an audit, the safety auditor inspects each piece of play equipment with respect to the 1991 CPSC's Handbook for Public Playground Safety and the guideline set forth in the handbook (National Playground Safety Institute, 1996). The CPSC recommends that once an entrapment hazard has been identified it should be immediately documented and the specific hazard should be corrected (U.S. Consumer Product Safety Commission, 1991).

\section{Lack of Maintenance}

According to NPSI, a playground which receives little to no maintenance is or soon will be considered a hazardous playground. As children use the play equipment, components may become broken, missing or worn out. Wood, metal, or plastic materials may show signs of fatigue or deterioration thus creating hazardous equipment. The surfacing material under the play structure may wear away and cause a hard-packed area which is unable to cushion a fall (Consumer Product Safety Commission - Fact Sheet \# 327).

\section{Pinch, Crush, Shearing and Sharp Edge Hazards}

Inadequately designed, installed, or maintained playground equipment may also contain pinch, crush, shearing and sharp edge hazards. Components in any public playground should be inspected to make sure that there are no sharp edges or points that could cut skin. Special attention should be given to moving components such as suspension bridges and some swings to make sure there are no 
exposed moving parts or mechanisms that may crush or pinch a child's finger or arm (American City \& County 1995).

\section{Platforms with No Guardrails}

The NPSI also identified platforms with no guardrails as a playground hazard. Elevated surfaces, such as platforms, ramps, and bridgeways should have guardrails to prevent accidental falls. Equipment intended for pre-school age children should have guardrails on elevated surfaces higher than 30 inches (American City \& County 1995). The CPSC's handbook offers recommendations for guardrails on play equipment. The recommendations are designed for specific equipment and age groups (U.S. Consumer Product Safety Commission, 1991).

\section{Equipment NOT Recommended For Public Playgrounds}

While the NPSI has identified six potential hazards to playgrounds, the Consumer Product Safety Commission has recognized that the following types of equipment are NOT recommended for use on public playgrounds. According to CPSC, heavy swings such as animal figure swings and multiple occupancy / glide type swings, free swinging ropes that may fray or form a loop, swinging exercise rings, and trapeze bars have produced the greatest safety hazards to children and should be immediately removed from any existing playground (National Playground Safety Institute, 1996). 


\section{Playground Design Hazards}

Playground design has improved remarkably over the past 15 years since the U.S. Consumer Product Safety Commission's Handbook on Public Playgrounds Safety was first published. Landscape Architects, playground designers and recreation officials are no longer forced to rely solely on their design intuition and experience when trying to design a safe play environment. The CPSC handbook has established guidelines that these professionals can refer to when designing a playground. Unfortunately, playgrounds designed and built in the 1940's through the 1970's still exist today and have not benefited from the CPSC guidelines (King 1996).

The National Recreation and Park Association, the National Playground Safety Institute and the U.S. Consumer Product Safety Commission have identified four design associated hazards. The four hazards to be aware of are, inadequate fall zones, insufficient equipment spacing, lack of supervision, and age-inappropriate activities (American City \& County 1995).

\section{Inadequate Fall Zones}

A fall zone or use zone is the area under and around the playground equipment where a child might fall onto another child, land onto a hard surface or fall onto another piece of play equipment. If a playground has inadequate fall zones than more than likely it also has insufficient equipment spacing. Improper spacing between play equipment can cause over-crowding of a play area which may create other hazards. Children need room to circulate and a properly designed playground may prevent the possibility of a child falling off 
of one structure and striking another structure (National Playground Safety Institute, 1996).

According to the NPSI, the fall zones for play equipment that is higher than twenty-four inches above the ground should not overlap. NPSI recommends that there be a minimum of twelve feet between two play structures (National Playground Safety Institute, 1996). The CPSC's handbook offers fall zone recommendations for specific play equipment but notes that regardless of the type of equipment, the fall zone should be free of obstacles that children can run into or fall on top of and cause injury (U.S. Consumer Product Safety Commission, 1991).

\section{Lack of Supervision}

According to the NRPA, it is estimated that more than 40 percent of all playground injuries are directly related to lack of supervision. A playground should be designed so that a parent or caregiver can easily observe children at play. The NPSI explains, "The supervision of a playground environment directly relates to the overall safety of the environment" (National Playground Safety Institute, 1996). Young children at play are constantly challenging their own abilities and may not be able to recognize potential hazards (American City \& County 1995).

\section{Age-Inappropriate Activities}

When designing a new playground or inspecting an existing facility, it is important to make sure the equipment in the playground is appropriate for the age of the intended user. 
Children's developmental needs vary greatly from age two to age twelve. In an effort to provide a challenging playground for all ages, designers often select different play structures for specific age groups. If the age specific play equipment is not separated, the activities of school age children may interfere with the activities of pre-school age children which may cause potential hazards to all that are involved (National Playground Safety Institute, 1996).

The CPSC recommends that a playground should be organized into different areas to prevent injuries caused by conflicting activities and collisions between children running from one activity to another. CPSC recommend that one area be dedicated for active and physical activities. This area should be separate from an area dedicated for more passive and quite activities. Popular play structures which receive heavy use should be dispersed within the playground so to avoid crowding in any one area. Moving equipment such as swings should be located towards the outer edges of the play area (U.S. Consumer Product Safety Commission, 1991).

Although safety hazards have been identified for nearly 20 years, statistics indicate that a growing number of children continue to be treated in hospital emergency rooms for injuries incurred on public playgrounds (Hennger 1993). Since the first publication of the U.S. Consumer Product Safety Commissions Handbook for Public Playground Safety, efforts have been made by local municipalities to make their playgrounds safer for the children using them. However, the process of upgrading public playgrounds to meet the CPSC's guidelines set forth in its handbook have taken a great deal of time. 
Most of the resistance to any change in existing playground environments is based on financial considerations. Municipalities recognize the hazards, but soon discover that it is too expensive for their local community's strapped budget to replace the old obsolete play equipment or to remodel the hazardous playground (Wallach 1996).

Some communities address their playground safety issues by simply removing the hazardous equipment without replacing it. While this solution protects the children against the hazard, it deprives them of play opportunities (LaFarge 1988). Other communities choose to ignore the problem and take on the attitude that "if it was good enough for me, it's good enough for my children". The validity of these attitudes on public playground safety are challenged by CPSC accident statistics and the rising number of civil lawsuits that sited the CPSC Handbook as the standard of care for public playgrounds (Wallach 1996).

\section{Developmental Issues}

Researchers and developmental psychologist have known for a long time how vital it is to provide playgrounds for children. As early as 400 B.C., Socrates was noted as saying children need to have the opportunity to play in order to become effective adults (Burton, 1997). Play is the initial stage in the lifelong process of growth and development which every individual experiences. Children's play activities are the major medium of learning for children and represent an integrated, continuous process in the lives of children. A well designed and maintained playground which offers a variety 
of play activities can assist in the proper physical, emotional, intellectual, and social development of children (Miller, 1972). However, the majority of American playgrounds fail to provide a stimulating play environment optimal to the development of children.

\section{Traditional Playground Design Deficiencies}

The traditional playgrounds which exist in many cities and towns in America contain standardized obsolete playground equipment placed on hard surface material. The primary intent for these playgrounds is to provide physical exercise for children and easy maintenance for town officials. The quest for easy maintenance has also led to the elimination of the natural landscaping, such as trees and shrubs, within the play area. This disregard for stimulating play equipment and the natural landscaping creates play environments which lack visual interest and do little to stimulate a child's development other than physically (Eriksen, 1984). Although studies indicate that playgrounds could contribute to a child's physical, emotional, intellectual, and social growth, many cities and towns remain unmotivated to redesign the traditional playground (Eriksen, 1985).

While the Consumer Product Safety Commission, the National Playground Safety Institute (NPSI), and the American Society for Testing and Materials (ASTM) have been the national leaders in the growing movement to improve the safety of public playgrounds, the agencies offer little recommendations regarding design concepts. The only design recommendations that the agencies make are for 
appropriate fall zones, equipment spacing and age appropriate equipment grouping.

Fortunately, within the past thirty years, playground design has received serious attention from landscape architects, recreational officials, town planners and concerned parents. Critical examination of the deficiencies associated with the traditional playground has called attention to the enormous developmental potential of play areas.

As presented in Chapter 2, one popular option to America's playground design dilemma is called the Playscape Concept. This playground design promotes stimulating and creative play activities and provides easily supervised playgrounds similar to the traditional playgrounds. The Playscape Concept is a carefully designed and landscaped outdoor play environment. Each design promotes and supports activities which are an essential part of the proper physical, emotional, intellectual, and social development of children. The design recognizes children's play as a series of linked activities while affording spatial and textural diversity within the natural landscape (Eriksen 1984).

The Playscape Concept is based on three important principles. First, a Playscape design seeks to provide a play environment for children of any age and in various stages of development within the same site location. The Playscape environment encourages children of different ages to mingle and play together by the proximity of their separate zones and in the spared zones of nature play, ball play and structured play. Second, the Playscape design is adoptable to any size location whether the site be a neighborhood park or a 
vacant lot. It can be designed to blend in with the character of the surrounding neighborhood and to accommodate the existing natural topography of the site. Finally, the Playscape Concept is very amenable to the participatory design process in which a series of design meetings are conducted and children as well as adults take part in the actual planning and design of their own Playscape playground (Eriksen 1984).

The Playscape Concept can be a great outdoor learning environment for children as well as an amenity to the whole community. The design flexibility of this concept allows the playground to become an attractive green space which blends with the atmosphere of its surroundings. The Playscape Concept offers children an environment which supports activities that are an essential part of the child's physical, emotional, social, and intellectual development (Eriksen 1985). 


\section{CHAPTER 5 \\ PUBLIC PLAYGROUND RECOMMENDATIONS}

A child's playground should be an environment dedicated to learning and development. Each child develops at his or her own pace, and because of this diversity, it is important that a play environment provides a variety of activities that can meet the developmental needs of children. While diversity in a play environment will create challenges for some children, it may also create hazards for others. Unfortunately, hundreds of thousands of children will be injured on public playgrounds annually (Kutska, Hoffman 1992).

\section{The Standard of Care for Public Playgrounds}

\section{U.S. Consumer Product Safety Commission}

In the United States, the playground safety issue goes back as far as the 1930's when National Recreation and Park Association recommended that a specific play apparatus be removed because it was determined to be unsafe for public playgrounds. However, it was not until the late 1970's that the U.S. Consumer Product Safety Commission became involved in public playground safety and developed the Handbook For Public Playground Safety. The handbook was first published in 1981 and made available to the general public (Christiansen. ed. 1995).

This handbook is intended for use by recreational officials, school officials, landscape architects, city planners, equipment purchasers and installers, and any other member of the general 
public concerned with public playground safety. Due to the many factors which may affect playground safety, the handbook presents playground equipment and design safety information in the form of guidelines, rather than mandatory rules. The CPSC states in its handbook that,

"These guidelines are not a CPSC standard and are not mandatory requirements. Therefore, the Commission is not endorsing them as the sole method to minimize injuries associated with playground equipment. The Commission believes, however, that the safety features in many of the recommendations in this handbook will contribute to greater equipment safety. Publication of the handbook is expected to promote greater safety awareness among those who purchase, install, and maintain public playground equipment." (U.S. Consumer Product Safety Commission, 1991)

The CPSC's Handbook for Public Playground Safety addresses and provides recommendations for such issues as layout and design, installation and maintenance, playground equipment materials and constructions, general hazards, access and platforms, surfacing, and use zones for equipment. The handbook also has a section on specific popular play equipment such as slides, swings and climbing equipment. In addition, the handbook offers recommendations on, suggested general maintenance checklists, entrapment requirements and test methods, characteristics of surfacing materials, and a description of loose-fill surfacing materials (U.S. Consumer Product Safety Commission, 1991).

Since the 1981 publication of the CPSC's Handbook and its recent revision in 1991, the courts have seen a major increase in the 
number of lawsuits instituted against local park departments and school districts over playground injuries. The contents of the 1991 CPSC Handbook for Public Playground Safety served as the criteria against which playground facilities could be measured. Soon this publication became the state-of-the-art resource for accident claims resulting from improper design or poor maintenance. Initially, the handbook received little attention from recreation officials since it only provided recommendations or guidelines, not mandated regulations. However, as the handbook gained credibility in the court systems, it became obvious that adherence to the handbook's recommendations was critical. Those municipalities who choose to simply ignore the handbook's recommendations are vulnerable to negligence charges for failing to use federal guidelines to make safer play environments for their children (Wallach, 1996b).

Negligence is the legal theory which most often appears in the litigation. Negligence is defined as,

"the ommission to do something which a reasonable [person], guided by those ordinary considerations which ordinarily regulate human affairs, would do, or the doing of something which a reasonable and prudent [person] would to do." (Black's Law Dictionary).

The elements of negligence are a legal duty of care, breach of the legal duty, the breach of the legal duty as the primary cause of the injury, and substantial harm (Clement, 1989).

The legal duty implies a minimal standard of care that all playground officials and personnel must adhere to. Unfortunately, a clear cut statement of what that standard of care should be for a 
town's public playgrounds is seldom stated in literature on physical activity or specifically stated within a town's by-laws pertaining to their recreational system. If a town has a published and enacted standard of care for the recreational systems, the court will merely implement the standard. When it is not stated, the court will use the U.S. CPSC handbooks, literature in general, previous case law, and expert testimony to develop a standard of care for a particular situation (Clement, 1989).

When a legal duty exists and children are injured, the court must prove that the breach of the duty was the real cause of the injury. For negligence to be proven the injured party must have sustained substantial damage (Clement, 1989). At the present time, the CPSC Handbook for Public Playground Safety is considered to be the standard of care by those considered experts in the public playground safety field (Christiansen. ed, 1995). It is recommended that every municipality, through its recreational and planning departments, obtain at least one copy of the CPSC Handbook for Public Playground Safety (see Appendix A). The recreational officials and town planners should become very familiar with the handbook's contents and apply this standard of care into a comprehensive public playground safety program.

\section{The American Society for Testing and Materials}

As the CPSC Handbook took legal foothold in the public playground safety movement, the manufacturers of playground equipment became more concerned with legal liability and petitioned the American Society of Testing and Materials (ASTM) to develop a 
safety standard for public use playground equipment. This standard would serve as the national benchmark for judging play equipment safety (Wallach, 1996). In 1988, The American Society for Testing and Materials accepted the petition and began to develop the first voluntary industry standard for public playground equipment manufacturers. It is recommended that every municipality purchase playground equipment from reputable manufacturers and require, in writing, that the equipment complies with the most current ASTM standards (Christiansen. ed, 1995).

\section{Developing a Comprehensive Public Playground Safety Program}

Most municipalities and recreational officials may be facing a real dilemma in their attempt to meet current playground safety guidelines, avoid potential legal liabilities arising from noncompliance with CPSC's guidelines, balance budgets, and still provide a reasonably safe and enjoyable playground environment for the children in their community (Kutska, Hoffman, 1992). Even though there is not one generic public playground safety program available, the task of developing a safety program that will bring a municipality's public playgrounds into compliance is not as difficult as it appears. A comprehensive playground safety program contains four vital elements. The elements are a program mission statement, safety inspections and/or safety audits, proactive programs promoting safety, and proper documentation. 


\section{Develop a Mission Statement}

The first step in creating a playground safety program is to develop a mission statement regarding the objectives for the municipality and its staff. This statement should include information relating to specific program goals and safety issues that exist in each particular playground. The mission statement is designed to give the program purpose and direction, while also reminding playground personnel of the importance of maintaining a safe environment (Teague, 1996).

The mission statement should also identify problem areas and dangerous equipment, determine priorities, and set a reasonable plan of action. If the municipality can develop an effective mission statement and can demonstrate that it has taken a reasonable approach to developing and implementing its safety programs, then the program can also provide an affirmative defense against alleged legal wrong-doing on the part of the municipality (Kutska, Hoffman, 1992).

\section{Conduct Safety Inspections and/or Safety Audits}

A playground safety inspection is a written record of the condition of a playground at a particular point in time. The purpose of an inspection is to identify hazards and routine maintenance tasks such as litter, surfacing maintenance, vandalism and improper equipment functions. Safety inspections can be done daily, every other day, weekly, monthly or seasonally (Kutska. Hoffman, 1992). 
However, a safety inspection is only as good as the inspector who is performing it. Inspectors with high levels of knowledge and training are able to identify hazards and potential problems, take appropriate action to eliminate correctable hazards, and follow up with the next inspection in a timely manner. Inspectors with low to moderate levels of knowledge or training are able to identify basic maintenance tasks such as vandalism, litter and surfacing problems (Kutska, Hoffman, 1992).

A playground safety audit is a comprehensive document that identifies a wide range of known playground hazards based on the 1991 CPSC Handbook for Public Playground Safety. A safety audit

will determine where the most serious and potentially life threatening hazards exist on specific types of playground equipment as well as the playground environment as a whole. A safety audit is usually performed once on an existing playground or until area standards have changed. The auditor must be highly trained and experienced with the CPSC guidelines and the ASTM standards (Kutska, Hoffman, 1992).

\section{Implement Proactive Programs}

A public playground is only as good as the people who care for it. Municipalities should provide these workers with on-going training and test their knowledge and skill relating to playground issues. It should be noted that failure to train and failure to provide adequate training may be causes for legal action (Kutska, Hoffman, 1992). 
A municipality should conduct playground inspections on a consistent basis. Each town should establish its own basis for the frequency of the inspections. The inspectors should be equipped with the necessary tools and supplies to make immediate repairs (Kutska, Hoffman, 1992).

All public playground equipment should be purchased from reputable manufacturers who can verify, in writing, that the equipment complies with the most current CPSC safety guidelines or ASTM standards (Kutska, Hoffman, 1992). Recreational officials or personnel should never alter the design or installation of equipment without the written approval of the manufactures. Alterations can invalidate the warranty and place liability for injuries on the municipality (Teague, 1996).

A proactive program involves the continual evaluation of decisions regarding the playground's environment and equipment. Recreational officials have the responsibility to remain current on all safety and design issues and changing industry standards when they are made available (Teague, 1996).

\section{Document All Activities}

It is imperative that recreational officials and personnel fully document all their actions regarding public playground safety. Each inspection or maintenance service must be followed up with a written report. The report should contain the name of the inspector or maintenance personnel, when the inspection or service was done, what unsafe conditions were found, and what actions were taken to 
rectify the problems. This type of information can be vital in the event of litigation (Christiansen, ed. 1995).

Proper and thorough documentation serves several purposes. Documentation communicates the safety program to all personnel within the department and to the public. It creates a paper trail of the recreation department's plan of action for reducing playground hazards. Documentation also helps to ensure consistent implementation of the safety plan and demonstrates that the municipality is acting to meet its legal duty to provide a safe playground environment for the public (Christiansen, ed. 1995).

Failure to document the actions regarding public playground safety has great consequences to a recreation department and the municipality. Proper and thorough documentation may become a recreation department's primary defense against a claim or lawsuit alleging negligence. Without proper documentation the department will have no factual information on which to base motions of dismissal or summary judgement on behalf of the department (Christiansen, ed. 1995).

It is the responsibility of the recreation department and the municipality to provide a play environment where children can safely participate in stimulating developmentally appropriate activities. By establishing and implementing a well designed comprehensive public playground safety program, the municipality will reduce the number of injuries to children as well as reduce the chances of litigation. Since litigation is a very real concern for recreation officials and municipalities as a whole, it is strongly recommended that a comprehensive public playground safety 
program be developed and implemented within the municipality. A well designed safety program could reduce the frequency and severity of injuries on a public playground as well as reduce the likelihood of undue litigation (Teague, 1996).

\section{Developing a Public Playground Safety Policy}

As in any organization, a successful safety program can only be achieved if it is supported by the governing officials of the department and municipality. A recognized and enacted playground safety policy is an effective tool for communicating to the public and departmental personnel the purposes of the playground safety program. A playground safety policy approved and supported by the governing officials is vitally important to the long term success of the safety program since this top management will be responsible for providing the necessary resources to implement and sustain the program (Kutska, Hoffman, 1992).

It is recommended that each municipality develop and enact a public playground safety policy in conjunction with and support of their playground safety program. A well designed playground safety policy should be simply and clearly written and include the philosophies and objectives of the playground safety program. The policy should be enacted into the municipality's by-laws and supported by top officials through the appropriation of the necessary resources needed to accomplish the goals of the program. The policy should establish continuity regarding all safety issues between all playground sites and departments within the municipality. The 
complete playground safety policy should be made available to all departments (Kutska, Hoffman, 1992).

\section{The National Playground Safety Institute Certification Program}

A public playground safety program is only as effective at reducing injuries as the personnel responsible for implementing the program. It is recommended that each municipality offer and encourage personnel to attend the National Playground Safety Institute's Safety Inspector Certification Course. The NPSI Certification Course is a training program specifically designed to meet the needs of recreation personnel working in public parks and recreation agencies, day care facilities, school districts, playground manufactures, and installers (King, 1996).

Currently presented in a two-day seminar, this training program includes classroom lectures, discussions, and hands-on examples of playground safety and maintenance problems. The course enables trainees to identify playground hazards, establish repair priorities, repair techniques, and set long-term plans to upgrade existing playgrounds (King, 1996).

NPSI certified inspectors can be an integral part in conducting reliable playground inspections and safety audits (King, 1996). Those who pass the certification exam have demonstrated the necessary knowledge and skill to utilize the CPSC Handbook and the ASTM Standards in playground inspections and audits. Each certified inspector has also proven his/her ability to use judgement in effectively identifying potential playground hazards (Wallach, 1996). 


\section{CHAPTER 6 \\ PUBLIC PLAYGROUND SAFETY AUDIT AND INSPECTION}

\section{Public Playground Safety Audit}

Developing and implementing a comprehensive public playground safety policy and program which promotes the guidelines set out by the CPSC's Handbook for Public Playground Safety and the ASTM Standards is the first step in any municipal wide campaign to upgrade playgrounds. The next step begins with a safety audit of all existing play environments including newly constructed playgrounds. A safety audit is essential to any public playground safety program since it identifies and documents the existing play equipment and surfacing in the playground and the condition of these elements in respect to the CPSC guidelines and the ASTM Standards, and the safety of their placement and installation within the play area (Wallach, 1996).

Developing a safety audit could be a long and complicated process. A poorly designed safety audit could have far reaching consequences for the success of the safety program. Fortunately, the National Recreation and Park Association (NRPA) offers an excellent example of a comprehensive safety audit which can be modified to the needs of a municipality (see Appendix B). The NRPA's safety audit is a compilation of the suggested guidelines of the CPSC's Handbook for Public Playground Safety, the American Society for Testing and Materials' Standards, and expert opinions from consultants in the field of playground safety (Kutska, Hoffman, 1992). 
The safety audit is implemented by assigning hazard index points to specific types of playground hazards. The hazard index points are based on the hazard's potential to cause serious injury or loss of life. Hazard index points which range from 1 to 4 indicate minor, non-disabling injury resulting from the potential hazard. Hazard index points ranging from 5 to 9 indicate serious injury or illness resulting in temporary disability. Hazard index points from 10 or more indicate permanent disability or loss of life or limb resulting from the potential hazard (Kutska, Hoffman, 1992). NRPA's safety audit is divided into eight elements which address specific safety aspects of playgrounds. The elements are general environment, general environment hazards, age/size appropriateness design, accessibility design, playground protective surface, fall zone/use zone, site specific play equipment and audit summary.

\section{General Environment}

This section establishes the type of playground being audited, the type and amount of play equipment that exists at the play site, and any potential hazards directly abutting the playground.

\section{General Environment Hazards}

This section addresses the overall safety of the play site. The safety auditor looks at the accessibility to and within the playground and checks the condition of the existing pathways for potential hazards such as standing water. uneven pavement. or low hanging branches. It also directs the auditor to inspect perimeter fencing, area seating, signage. and trash receptacles for potential hazards. 


\section{Age/Size Appropriateness Design}

This section identifies whether or not the existing play equipment is appropriate for the age of the intended user. It examines the site for separate play areas designed for specific age and developmental levels and whether or not the play area has proper signage which informs users and parents of the intended user age group.

\section{Accessibility Design}

This section examines the play environment for safe accessibility within the playground. An auditor focuses on issues such as the accessibility of the playground to disabled people, accessibility to the public restroom facilities, and available seating.

\section{Playground Protective Surfaces}

This section can be considered the most critical section of the safety audit. As presented in Chapter 4, falling from playground structures onto a hard surface such as asphalt, cement or packed earth can cause serious injury and even death for children (Hennger, 1993). According to this section, an auditor examines the playground surfaces for potential hazards associated with surface type such as asphalt, cement or hard-packed dirt. The auditor examines surface maintenance; for example, the auditor assesses whether or not the surfaces are cleaned and raked daily, weekly, monthly, or seasonally. The surface material under and around equipment is then examined for its depth as set forth by the CPSC guidelines. 


\section{Fall Zone/Use Zone}

This section of the audit focuses on the CPSC's guidelines for safe equipment spacing within use zones. This section examines the spacing between pieces of play equipment, the spacing between equipment and fixed objects such as trees and buildings, and the spacing between areas for active play such as ball games and play equipment and areas for quiet activities such as a sandbox or outdoor seating.

\section{Site Specific Play Equipment}

This section of NRPA's safety audit offers safety questions and criteria for many of the popular play equipment used in existing playgrounds. Recreation officials can modify NRPA's safety audit to

address the site specific equipment needs of their playground. If a unique play structure exists in a particular playground and safety criteria is not offered within NRPA's safety audit, the municipality should contact the manufacturer of the equipment for safety and maintenance recommendations.

\section{Audit Summary}

The audit summary section presents and compares the subtotals of each section and combines them to form an overall site hazard score. The summary can be used to reduce playground hazards and develop long term planning strategies. For example, the safety audit results can identify specific potential hazards by displaying a high hazard score for that particular section. If a high score exists, the recreation officials should research ways to correct 
the problem. The audit can help to identify playground equipment design flaws which may be correctable by contacting the equipment manufacturer to see if parts are available to eliminate the potential hazard. The summary of the safety audit can assist a recreation department and/or municipality developing and prioritizing their playground equipment replacement schedules. The audit identifies safety concerns on specific types of equipment and on the overall play site based on the hazard scores. The agency can then compare the scores between all of their existing playgrounds within the municipality and make better decisions on where to direct available funds to eliminate the most serious playground hazards first (Kutska, Hoffman, 1992).

Ultimately, a well designed and implemented playground safety audit will reveal hazards not found during routine inspections. The ideal auditor should have over 5 years of public playground auditing experience, be a NPSI's Certified Playground Safety Inspector, be a participating ASTM member, and make an excellent expert witness in court (Burton, 1997).

\section{Public Playground Safety Inspections}

It is estimated that 28 percent of all accidents on public playgrounds could have been avoided if a safety inspection program was in place. Most people would agree that when it comes to the safety of children and the frequency of safety inspections, more is better. Unfortunately, the resources available for ensuring public playground safety are not unlimited. A municipality must examine its available resources and develop a frequency of playground 
inspections that would make efficient use of these limited resources (Kutska, Hoffman, 1992).

Two types of safety inspections are available. The first type of safety inspection is called the high frequency inspection. This inspection is preformed daily or on a routine basis. During a high frequency inspection, the playground should be inspected for any obvious hazards such as vandalism, glass, trash, and the need for raking surface material back under the fall zones of the play equipment. Next, the inspector should examine each piece of play equipment for any safety hazards such as vandalism, cracked swing seats, exposed concrete footings, or broken or rotted wood. When major hazards are identified and can not be corrected on site, the inspector should notify his or her supervisor immediately so that corrective actions can be taken quickly to eliminate the hazard (Kutska, Hoffman, 1992).

A low frequency inspection is more comprehensive than a high frequency inspection and takes more time to preform. It is recommended that more experienced park personnel who are able to evaluate the structural integrity of equipment and the wear concerns of each individual piece of playground equipment preform low frequency inspections. Once a hazard has been identified, the inspector should take appropriate action to eliminate correctable hazards, and to perform a follow up inspection in a timely manner. Low frequency safety inspections should be conducted on a scheduled basis ranging from weekly to monthly or on a seasonal basis, depending on existing conditions of the particular playground (Kutska, Hoffman, 1992). 
Developing a comprehensive safety inspection form could be a long and complicated process. A poorly designed safety inspection form can waste valuable resources as well as jeopardize the safety of the children using the playgrounds and the overall success of the safety program. Fortunately, the National Recreation and Park Association (NRPA) offers an excellent example of a comprehensive high frequency inspection form as well as a low frequency inspection form (see Appendix C).

\section{Establishing a Safety Inspection Schedule}

Choosing between high frequency or low frequency safety inspections should be based on factors such as overall use characteristics of each playground within the municipality and the equipment design elements which are unique to each specific play area. Recreation officials should evaluate these factors and establish a playground inspection frequency appropriate for each specific playground located within the municipality. Recreation officials should continually monitor all playgrounds and the factors affecting each and every site and should take the necessary action required in each individual situation (Kutska, Hoffman, 1992).

\section{Use Characteristics}

There are three types of use characteristics which may affect how often a specific playground should be inspected. The use characteristics are vandalism, user demand at a specific playground, and the age range of the users being served. Vandalism is the most unpredictable factor. Inspections can only ensure the immediate, on- 
site safety of a playground at a specific time. Vandals can create an unsafe condition minutes after an inspection is completed. If a specific playground site has experienced recurring vandalism over a long period of time, a more frequent inspection schedule should be instituted for this particular playground. If over the period of a year there has been little or no vandalism, then low frequency inspections would be sufficient for the play site (Kutska, Hoffman, 1992).

The number of children who use a specific playground over the course of a season has a cumulative effect on the frequency of inspections and repairs. Consequently, a playground located next to an elementary school will require more frequent inspections and repairs than a playground located within a small neighborhood. Evening activities in the area also affect the number of users served by that playground in a given day. Park personnel may not be aware of the evening use, but an increased need for garbage and litter pick up is a direct indicator of the site use (Kutska, Hoffman, 1992).

Playgrounds designed and used by pre-school age children tend to have lower equipment with fewer moving parts that can wear. This type of playground requires less frequent inspections. A playground designed and used by older children typically have higher equipment with more moving parts which require more frequent inspections (Kutska, Hoffman, 1992).

\section{Equipment Design Elements}

There are four equipment design elements which can effect the frequency in which a playground should be inspected. The 
equipment design elements are resilient surfacing, equipment materials, type of equipment and equipment age (Kutska, Hoffman, 1992).

Resilient surfacing such as loose surfacing materials require frequent inspections because this material can be moved from areas under or around play equipment where it is needed the most to eliminate injuries from falls. Synthetic matting materials are easier to maintain because they tend to remain in place. This type of surfacing would require less frequent inspections (Kutska, Hoffman, 1992).

The materials which the play equipment is constructed of can effect the frequency of inspection. For example, wood play structures tend to weather, split, splinter and rot faster than other materials and require more frequent safety inspections. Materials such as plastic and steel have greater durability and would require less routine maintenance and inspections (Kutska, Hoffman, 1992).

The type of play equipment is another factor to consider when evaluating a playground for a safety inspection schedule. Equipment which moves is more likely to fail functionally and cause an accident than stationary equipment. Moving equipment requires more preventative maintenance and repairs to the moving parts. Playgrounds containing a larger number of equipment with moving parts should receive frequent safety inspections. Playgrounds with mostly stationary play equipment typically require less frequent inspections (Kutska, Hoffman, 1992).

The age of the play equipment is another factor to consider. Playground equipment and its components will eventually wear out 
causing the equipment to need more maintenance and repairs, or even replacement. New equipment purchased from a reputable manufacturer should require little or no major repairs during the first four years after installation. Consequently, playgrounds containing equipment five to ten years old will require more frequent safety inspections. Many things can begin to affect the structural integrity of older play equipment. Plastic can become brittle; metals begin to rust, and wood can splinter all creating safety hazards (Kutska, Hoffman, 1992).

The overall responsibility for the maintenance, repair, and replacement of equipment within a playground facility can become a much more complicated issue without an established comprehensive public playground safety audit and inspection program. The realities of a limited recreation budget force officials to seriously examine each and every aspect of a community's playground safety program. The grand opening of a new public playground is generally the last time officials can feel somewhat confident that the entire area is safe and hazard free. The first day of a new playground marks the beginning of the playground's routine and preventative maintenance history which should include timely safety inspections and repairs and continued compliance to the current industry safety guidelines and standards (Kutska, Hoffman, 1992). 


\section{CHAPTER 7}

CONCLUSION

The safety of American playgrounds is a constant concern among local governments, school districts, and park and recreation departments. Increased legal litigation has made it necessary for municipalities to ensure reasonably safe play environments. Those municipalities which choose to simply ignore the issue of public playground safety are vulnerable to negligence charges and large legal settlements if injury occurs.

The key to minimizing playground accidents and legal prosecution is for the municipality to develop and implement a comprehensive public playground safety policy and program. This safety policy and program should encompass the current 1991 guidelines set by the CPSC and the 1993 standards from the ASTM.

A carefully designed and implemented public playground safety program should evaluate and document the conditions of the existing playgrounds, establish a priority list of the playgrounds in need of immediate attention, and document a plan of action to bring all playgrounds into compliance with industry standards.

Establishing a safety program will set minimal standards of care to which playground officials and personnel have a legal duty to adhere.

The issue of public playground safety is the most immediate concern for municipalities. However, a playground which fails to provide a stimulating play environment optimal to the development of children can have far reaching consequences for the community's 
quality of life. Consequently, when a community is faced with refurbishing an existing playground or developing a new play site, the Playscape Concept should be encouraged. The Playscape Concept is a carefully designed and landscaped outdoor environment dedicated to play. A Playscape Concept design supports play activities which are an essential part to the proper physical, emotional, intellectual, and social development of children. One important principle of this design concept is that it is very amenable to the participatory design process which encourages community involvement in the creation of the play site. Having community involvement at the infancy stages of site development will create a long lasting bond to the project and the overall success of the playground safety program.

In addition to safety and developmental concerns, further research is needed in developing cost effective design solutions which will accommodate the needs of children with disabilities and enable them to experience the growth and development promoted through the actions of play. On January 26,1997, the Americans With Disabilities Act (ADA) took effect. This legislation protects the rights of people with disabilities. With passage of the ADA, access to recreation and play environments is now a guaranteed civil right for all Americans. Play equipment manufacturers were quick to design and offer specialized equipment for children with disabilities. Unfortunately, this specialized equipment is very expensive and only serves a limited portion of the community. Municipalities faced with limited resources must make difficult choices about fund allocation 
when it comes to retrofitting existing playgrounds to meet the needs of the ADA. 


\section{APPENDIX A}

CPSC's Handbook For Public Playground Safety 


\title{
CPSC Handbook \\ For Public Playground Safety
}

a 1991 prblication of the U.9. Consumer Product Strety Commisston

\section{INDEXED NPSI EDITION}

\author{
Dafted and Indexed by Monty L. Chriatiangen
}

\section{Preface to the NPSI Edition}

In 1991 the United States Consumer Product Safety Commisaion (CPSC) published this Handbook for Public Playground Safety. It contains many guldelines and recommendations "... which address the potential for falls from and tropact with equipment, the acale of equipment and other deatgon features related to user age. layout of equipment on a playzround, installation and maintenance procedures and general hazards presented by protruatons, sharp edges, and pinch points." (quoted from the Handbook for Public Plouground Safety. pp. (-2)

This publication is a very comprehenstve document organized into twelve topical sectlons and has four supplemental appendices. The complexdty of the subject - public playground safety - necessitated some manner of topical organization. Unfortunately, any organization of this broad subject must, by logic, limit the emphasts of each section to a dominant topic le.g. 84 . Layout and Design; 85. Installation and Maintenance, 86.

Methods of Manufacture and Construction. etc.). with detalls and references to spectic types of playground equipment discussed throughout all the sections. Thus, the material is quite thorough but, in its ordoinal form, very thene-consuming to use if an individual wishes to find all the information about one type of equipment. such as arch climbers, or about one opectilc user group, such as preschool-age chilldren.

This edition, prepared for the National Playground Safety Institute (NPSI) as part of Points About Playgrounds - A Compllaton of Signfficant Safey Information (O1993 Nattonal Recreation a Park Asecclation), has attempted to make the document a more useful resource to playground safety inspectors, playground deatgners, and others interested in public playeround safety.

The 1991 Handbook for Public Ployground Safety is in the public domain. The text, tables, and lliustrations were scanned in their entirety. The organization and chronological order of the original document were left unchanged. Pagination and page composttion were changed to conform to the position of this material. used as one portion of Potrts About Ploygrounds, which has a different page layout, font style and letter size. In addition, the following changes and additions were made to the original document: 
An alphabetized index has been prepared, to asadst users seeking page references for information about specific Items, components, user groups, and detalls. The index pagination is specific to this NPSI Edition.

Major general safety recommendations and those safety recommendations spectilc to preschool-age chuldren where they differ from those for school-age children have been set apart from those paragraphs which contain the recommendations and are enclosed in a box to expedite notice by the users of this edition.

- Rows and sections of tables have been delineated by shading to facllitate identification of recommendations for each item and for ready compartson between items.

- References to figures have been revised to correspond to new placement of the figures within the document.

- Lists provided in the appendices have bullet symbols to emphastze each Item listed distinct from any discussion or explanatory text.
Figure B-1 and Figure B-2 have been redrawn, replacing the original sttck figures with three dtmensional figures to clartfy the examples of bounded openings in playground settings.

Spelling has been standardized where differences were noted ( for example "Pre-School Age Chlldren" and "Preschool-Age Children" were changed untformly to the latter spelling ).

Computer scanning is not $100 \%$ precise and occasional typographical errors occurred in the process - as when the word "burn" became "bum" when the optical character recognition software converted the scanned mage into word procesaing text. The editor assumes all responsiblilty for any such incorrect topographical translations which appears uncorrected in this edition.

\author{
Monty L. Christiansen \\ State College. Pennsylvania \\ August 1993
}




\section{INTRODUCTION}

This handbook presents playground equipment safety information in the form of guidelines. Because many factors may affect playground safety. the U.S. Consumer Product Safety Commission (CPSC) believes that guidelines, rather than a mandatory rule, are appropriate. The safety guidelines for equipment are based on recommendations provided to the CPSC by COMSIS Corporation in a March 1990 report [1]".

The handbook is intended for use by parks and recreation personnel, school officials. equipment purchasers and installers, and any other members of the general public concerned with public playground safety such as parents and school groups. A voluntary standard, to be published by ASTM. will contain more extensive requirements for manufacturers of public playground equipment.

"Public" playground equipment refers to equipment intended for use in the play areas of parks, schools, child care facilities, institutions, multiple family dwellings, restaurants, resorts and recreational developments, and other areas of public use.

The guidelines are not intended to apply to amusement park equipment. equipment normally intended for sports use. or to home playground equipment. Equipment components intended solely for use by the disabled and necessarty modified to accommodate such users safely are also not covered by these guidelines.

The safety of each individual piece of playground equipment as well as the layout of the entire play area should be considered when evaluating a

- Numbers in brackets indicate references that are listed at the end of this document. playground for safety. The installation of protective surfacing under and around all equipment is crucial.

Because all playgrounds present some challenge and because children can be expected to use equipment in unintended and unanticipated ways. adult supervision is recommended. However, it is recognized that this may not be possible for some playgrounds. Equipment design, layout, and maintenance, as discussed in this handbook, are essential for increasing public playground safety.

A playground should allow children to develop progresstvely and test their skills by providing a series of graduated challenges. The challenges presented should be appropriate for age-related abilities and should be ones that children can percelve and choose to undertake.

Preschool and school-age children differ dramatically not only to phystcal stze and ability, but also in their cognitive and soctal skdlls. Therefore. ageappropriate playground destgns should accommodate these differences with regard to the type. scale, and the layout of equipment. Recommendations throughout this handbook address the different needs of preschool and schoolage chtldren: "preschool" refers to chilldren 2 to 5 years old, and "schoolage" refers to chilldren 5 to 12 years old.

These guidelines are not a CPSC standard and are not mandatory requirements. Therefore, the Commission is not endorsing them as the sole method to minimize injuries assoclated with playground equipment. The Commission believes, however, that the safety features in many of the recommendations in this handbook will contribute to greater equipment safety. Publication of the handbook is expected to promote greater safety awareness among those who purchase, install. and maintain public playground equipment. 


\section{PLATGROUND INJURIES}

The Consumer Product Safety Commission has long recognized the potential hazards that exdst with the use of public playground equipment. A Commission study [2] of playground equipment-related injuries treated in U.S. hospital emergency rooms indicated that the majority resulted from falls from equipment. These were primartly falls to the ground surface below the equipment rather than falls from one part of the equipment to another part.

Other hazard patterns involved impact by swings and other moving equipment. colliding with stationary equipment. and contact with such hazards as protrusions. pinch points. sharp edges, hot surfaces, and playground debris. Fatal injuries reported to the Commission involved falls. entanglement of clothing or other items on equipment such as alldes. entanglement in ropes tied to or caught on equipment, head entrapment in openings, impact from equipment tjpover or structural fallure. and tmpact by moving swings.

The recommendations in this handbook have been developed to address the hazards that resulted in these playground-related injuries and deaths. The recommendations include those which address the potential for falls from and impact with equipment, the need for protective surfacing under and around equipment. openings with the potentlal for head entrapment. the scale of equipment and other design features related to user age. layout of equipment on a playground, installation and maintenance procedures, and general hazards presented by protrusions, sharp edges, and pinch points.

\section{DEFINITIONS}

Compostte Structure - Two or more play structures, attached or directly adjacent, to create one integral unit that provides more than one play actuvity le.g. combination climber, slide. and horzontal ladder).

Entrapment - Any condition that impedes withdrawal of a body or body part that has penetrated an opening.

Fall zone - The surface under and around a piece of equipment onto which a chlld falling from or exiting from the equipment would be expected to land.

Footing - A means for anchoring playground equipment to the ground.

Gundrall - An enclosing device around an elevated platform that is intended to prevent inadvertent falls from the platform.

Inoul - Material(s) used in a protective barner to prevent a user from passing through the banter.

Non-Rigld Component - A component of playground equipment that significantly deforms or deflects during the normal use of the equipment.

Preschool-Afe Chlldren - Children from 2 years of age to not more than $\mathbf{S}$ years of age.

Protective Barder - An enclosing device around an elevated platform that is intended to prevent both inadvertent and deliberate attempts to pass through the barrier.

Protective 8urincing - Surfacing materlal in the fall zone that conforms to the recommendations in Section 10.2 of this handbook.

Roller 8lide - A slide that has a bed consisting of a series of individual rollers over which the user travels. 
Bchool-Age Children - Children over 5 years of age but not over 12 years of age.

Tube slide - A slide in which the sliding section consists of a totally enclosed tube or tunnel.

Upper Body Equipment - A device designed to support a child by the hands only (e.g., horkzontal ladder. overhead swinging rings).

\section{Layout And Design of Playgrounds}

\subsection{Chooding a Site}

When planning a new playground, it is important to consider hazards or obstacles to children traveling to or from the playground. A barrier surrounding the playground is recommended to prevent children from inadvertently running into a street. Such a barrier should not preclude supervision.

\subsection{Fincing Equipment}

The playground should be organized into different areas to prevent injuries caused by conflicting activities and children running between activities. Active, physical activities should be separate from more passjve or quiet activities: areas for play equipment. open fields. and sand boxes should be located in different sections of the playground.

In addition, popular, heavy-use pieces of equipment or activitles should be dispersed to avold crowding in any one area. The layout of equipment and activity areas should be without visual barrlers so that there are clear sight lines everywhere on the playground to faclittate supervision.

Moving equipment. such as swings and merry-go-rounds should be located toward a comer or edge of the play area. Slide exits should also be located in an uncongested area of the playground.

Composite equipment has become increasingly popular on public playgrounds. Care should be taken to ensure that the play and trafic patterns of chlldren using adjacent components of composite equipment are complementary.

\subsection{Age Separation of Equipment}

It is recommended that playgrounds have separate areas for younger chlldren with appropriately stzed equipment and materials to serve their less advanced developmental levels. It is also important to recognize that preschoolers require more attentive supervision on playgrounds.

Throughout this handbook. consideration is given to spectic recommendations for equipment destgned for preschool-age chlldren (2 to 5 years).

The design and scale of equipment should make the intended user group obvlous. Some playgrounds, often referred to as "tot lots", are designed only for younger children, so separation is not an issue.

In playgrounds intended to serve children of all ages the layout of pathways and the landscaping of the playground should show the two distinct areas for the two age groups. The areas should be separated at least by a buffer zone of ample physical space. Signs posted in the playground area can be used to give some guidance to adults as to the age appropriateness of the equipment. 


\section{INSTALLATION AND MATNTENANCE OF EQUTPMENT}

\subsection{Anembly and Installation}

Proper assembly and installation of playground equipment are crucjal for structural integrity, stability, and overall safety. The people who assemble and install playground equipment should not devlate from the manufacturer's instructions. After assembly. equipment should be thoroughly inspected before its first use.

As a precaution, the manufacturer's assembly and installation instructions. and all other matertals collected concerning the equipment should be kept in a permanent flle.

\section{B.1.1 Btability}

When property installed as directed by the manufacturer's instructions and specifications, equipment should withstand the maxtmum anticjpated forces generated by active use which might cause it to overturn, tp. slide, or move in any way. Secure anchoring is a key factor to stable installation, and because the required footing stzes and depths may vary according to equipment type, the anchoring process should be completed in strict accordance with the manufacturer's spectifications.

\subsection{Mnintennnce}

Inadequate maintenance of equipment can lead to injuries on the playground. Because the safety of playground equipment and its sultablity for use depend on good inspection and malntenance. the manufacturer's maintenance instructions and recommended inspection schedulesshould be strictly followed.

A comprehensive maintenance program should be developed for each playground as a whole. Generally, all equipment should be inspected frequently for any potential hazards. for corrosion or deterioration from rot. insects, or weathering. The playground area should also be checked frequently for broken glass or other dangerous debris.

For each piece of equipment, the frequency of thorough inspections will depend on the type of equipment, the amount of use, and the local cllmate. Based on the manufacturer's recommendations regarding maintenance schedules for each piece of equipment, a maintenance schedule for the entire playground can be created. The detailed inspections should give spectal attention to moving parts and other components which can be expected to wear. Inspections should be carried out in a systematic manner by tratned personnel.

One posstble procedure is the use of checklists. Some manufacturers supply checklists, for general or detalled inspections, with their maintenance instructions. These can be used to ensure that inspections are in compliance with the manufacturer's specifications. Inspections alone do not constutute a comprehenstve matntenance program. All hazards or defects Identified during inspections should be repaired promptly. All repairs and replacements of equipment parts should be completed in accordance with the manufacturer's instructions. A suggested general maintenance checklist that may be used as a guide for frequent routine inspections of public playgrounds is included at Appendtx A.

In addition to this general maintenance inspection, more detalled inspections should be conducted on a regular basis. The procedures and schedules for these detalled inspections will depend on the types and amount of equipment on the playground, the level of use, and the 
local climate, as well as the maintenance instructions provided by equipment manufacturers. Therefore, this checklist is only one of many elements which should be considered in the development of a comprehensive inspection schedule and system of maintenance. Any damage or hazards detected during inspections should be repaired immediately, in accordance with the manufacturer's instructions for repair and replacement of parts.

The suggested general maintenance checklist at Appendix $A$ is intended to address only general maintenance concerns. It does not provide a complete safety evaluation of equipment design and layout. For example. It does not address the risk of falls from equipment, moving impact incidents, or head entrapment. Therefore. It is essential to use this checklist only for general maintenance purposes. The detailed destgn recommendations contained in the Handbook should be used to evaluate the safety of each plece of equipment and the playground as a whole.

Complete documentation of all maintenance inspections and repatrs should be retained. Including the manufacturer's maintenance Instructions and any checklists used. A record of any accidents and Injuries reported to have occurred on the playground should also be collected. This will help Identify potential hazards or dangerous design features which warrant attention.

\section{MATERIAL OF MANUFACTURED CONSTRUCTION}

\subsection{Durablitty and finish}

Purchasers should be sure that the equipment Is manufactured and constructed only of matertals which have a demonstrated record of durability in the playground or simular outdoor setting.

A major concern for playground equipment materials is corrosion or deterioration. Ferrous metals should be painted. galvantzed, or otherwise treated to prevent rust.

All paints and other similar finishes must meet the current CPSC regulation for lead in paint [3] $(0.06 \%$ maximum lead by dry weight). Regardless of the matenal or treatment process. the manufacturer should ensure that the users of playground equipment cannot Ingest, inhale, or absorb potentially hazardous amounts of substances as a result of contact with equipment.

Purchasers and installers of playground equipment should obtain

documentation from the manufacturer that the preservattves or other treatments applied to the equipment would not present a hazard to the consumer.

Wood should either be naturally rot and insect-resistant or treated to avoid such deterioration. The most common wood treatments used in playground equipment are the inorganic arsenicals. Chromated copper arsenate (CCA) is acceptable for use as a treatment of playground equipment wood. If the dislodgeable arsenic on the surface of the wood Is minimized. inorganic arsenicals should be applied by the manufacturer or wood preserver in accordance with the specifications of the American Wood Preservers Association $\mathrm{C} 17$ standard. This standard states that the treated wood should be visibly free of residues which may contain high levels of arsentc (the greenish coloration of CCA treated wood is acceptable). Wood preservers and playground equipment manufacturers should practice technologies and procedures that minimize the level of dislodgeable arsenic (that might be removable from the wood surface by skin contact or wiping with testing materials). CPSC staff has found that 
technology exdsts to treat playground equipment wood with CCA so that dlslodgeable arsenic Is below detectable levels using a protocol designed to detect dislodgeable arsenic [4].

Installers, bullders, and consumers who perform woodworking operations. such as sanding, sawing, sawdust disposal. on pressure treated wood should read the consumer information sheet often avallable at the point of sale [5]. The sheet contains important health precautions and disposal Information.

Creosote. pentachlorophenol, and tributyl tin oxide are too toxic or irritating and should not be used as preservatives for playground equipment wood. Pesticide-containing fintshes should also not be used.

Other preservatives that have low tordcty and may be suitable for playground equipment wood are copper or anc naphthenates, and borates.

\subsection{Bardware}

When Installed and tightened in accordance with the manufacturer's instructions, all fasteners, connecting. and covering devices should not loosen or be removable without the use of tools. lock washers, self-locking nuts, or other locking means should be provided for all nuts and bolts to protect them from detachment. Hardware in moving Joints should also be secured against unintentional or unauthorized loosening. in addition, all fasteners should be corrosion resistant and be selected to minimize the likellhood of corrosion to the materials they connect. Bearings used in moving joints should be easy to lubricate or be self-lubricating. All hooks, Including Shooks, should be closed as tighthy as posstble (see also Section 9.2.1).

\subsection{Metal Surfaces}

To avold the risk of contact burn injury in geographical regions where intense sunlight can be expected. bare or painted metal surfaces on platforms and slide beds should be avoided unless they can be located out of the direct rays of the sun. As an altemattve to bare or palnted metal, platforms may be fabricated from wood or vinyl coated metal and slide beds may be fabricated from plastic (see also Slides, paragraph 9.1.4).

\section{GENERAL HAZARDS}

There are a variety of general hazards common to many types of playground equipment. The guidelines in this section apply to all elements of the playground.

\subsection{Bhnp Polnto, Corners, and Angles}

There should be no sharp points. corners, or edges on any components of playground equipment which could cut or puncture children's skdn. Frequent Inspections are tmportant in order to prevent injuries caused by the exposure of sharp points, corners, or edges due to wear and tear on the equipment.

Wood parts should be smooth and free from splinters. All corners, metal and wood, should be rounded. All metal edges should be rolled or have rounded capping. Special attention to sharp edges on slides, especially metal edges, is warranted. The exit end and the sides along a slide bed can be particularly dangerous If protective measures are not taken (see also Section 9.1.5).

\subsection{Protruilons and Projections}

Protrusions or projections on playground equipment should not be capable of entangling children's clothing. because such entanglement can cause sertous injurtes or death by 
strangulation. Particular attention should be given to avolding protrusions or projections at the top of slides to mintmize the risk of entanglement with clothing. Jackets with hoods and/or drawstrings have been implicated in such entanglement or strangulation incidents.

When tested In accordance with the procedure in Paragraph 7.2.1, no protrusion should extend beyond the face of any of the three gauges having dimensions shown in Figure 1, below:
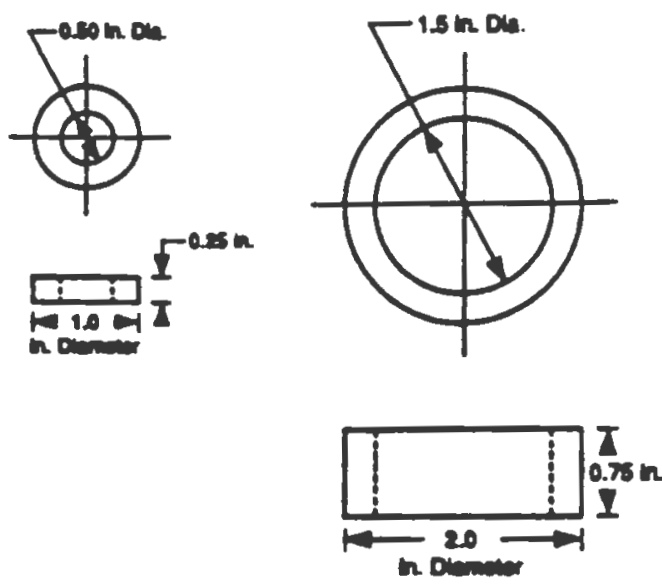
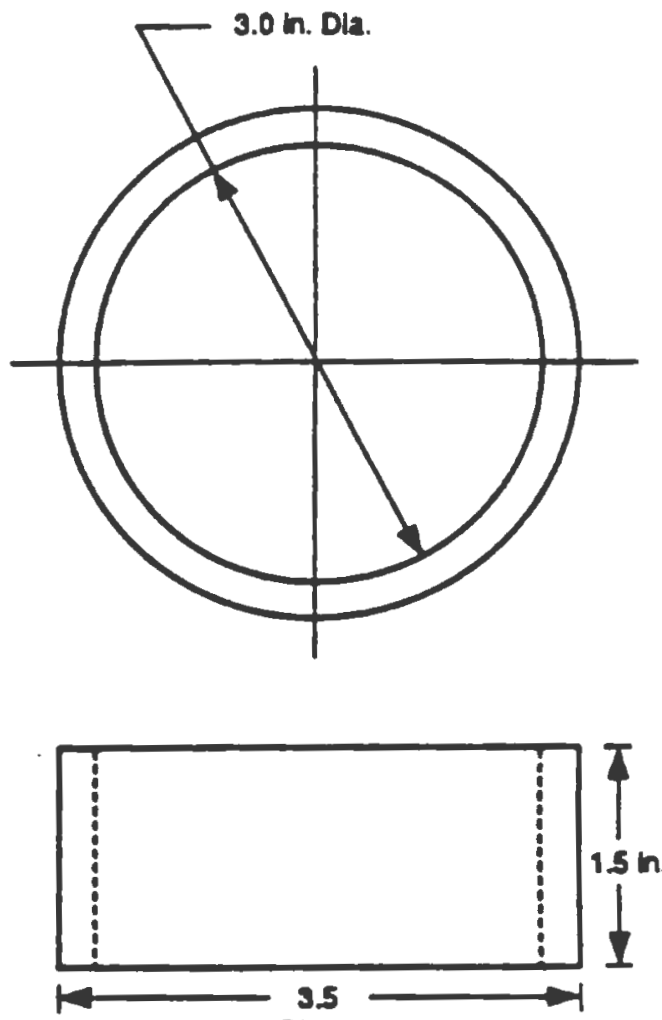

m. Diameter

Figure 1. Protruton Test Gauges

\subsubsection{Protrusion Test Procedure}

Successtvely place each gauge (see Figure 1. above) over any protrusion or projection and determine if it projects beyond the face of the gauge. (see Figure 2, shown on the right)

\subsection{Protrualons on 8uspended Members of 8wing Amemblies}

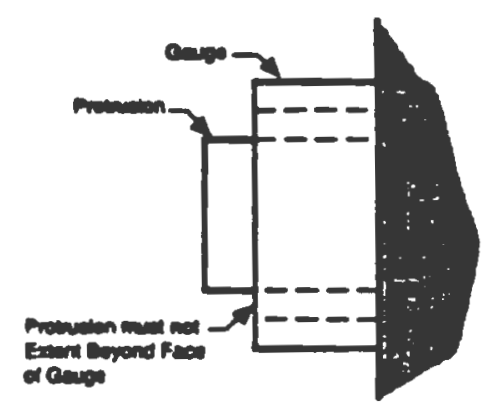

Figure 2. Protrusion Text

These form a special case because they can be extremely hazardous, given the potential for impact incidents: 
therefore, a special test gauge lsee Figure 3 shown on the right ) and procedure are recommended. No surface in the potential impact region on suspended members should protrude when tested In accordance with the following method.

Conduct the test with the suspended member in tts rest position. Place the gauge over any protrusion on the front or rear surface of the suspended member such that the axds of the hole in the gauge is parallel to both the intended path of the suspended member and a hortzontal plane. Visually determine if the protrusion penetrates through the hole and beyond the face of the gauge.

\subsection{Pinch, Crulh, and Bhearing Polnte}

There should be no accessible pinch. crush. or shearting points on playground equipment that could injure children or catch thetr clothing. Such points can be caused by components moving relattve to each other or to a fixed component when the equipment moves through its antictpated use cycle. To determine if there is a possible pinch. crush or shear point, consider the llkellhood of entrapping a body part and the configuration and closing force of the components. Additional information on pinch, crush, and shear points is provided in the recommendations addressing specific pieces of equipment in Section 9.

\subsection{Entrapment}

It is possible for children to entrap their heads in openings or entangle loose clothing in certain angled openings.

\subsubsection{Bead entrapment}

A component or a group of components should not form openings that could trap a child's head. A child's head may become entrapped if the child attempts to enter an opening elther feet first or head first. Head entrapment by headfirst entry generally occurs when

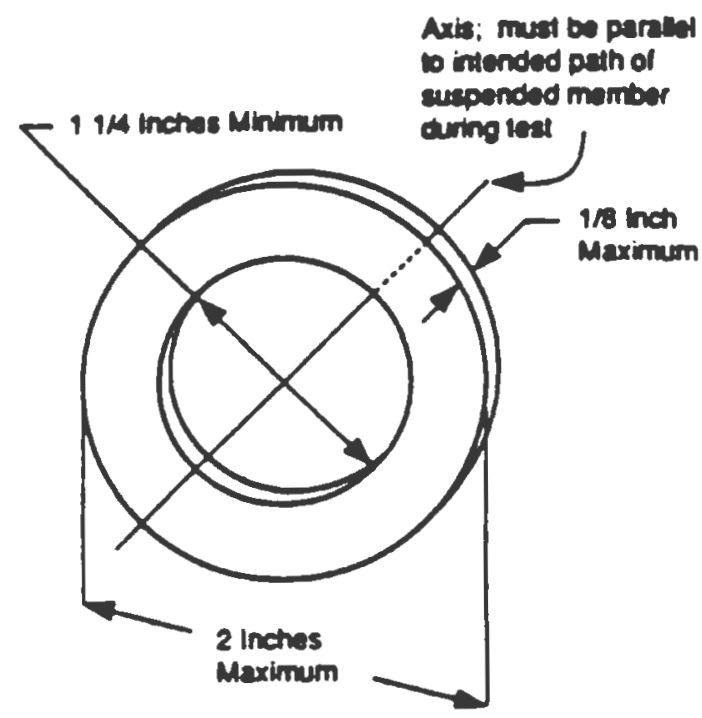

Note: Gauge may be made of any rigid material

Migure 3. Protrudon Test Gauge for Buppended Areemblles

chtldren place thetr heads through an opening in one orientation, then, after turning their heads to a different orientation, they are unable to withdraw from the opening. Head entrapment by feet-first entry involves children who are generally sitting or lying down and sidde thetr feet into an openting that ts lange enough to permit passage of their bodies but is not large enough to permit of their laad which then become entrapped.

In general. an opening may present an entrapment hazard if the distance between any interior opposing surfaces is greater than $\mathbf{3 . 5}$ inches and less than 9 inches.

When one dimension of an opening is within this potentially hazardous range. all dimensions of the opening must be considered together to fully evaluate the possibility of entrapment. This recommendation applies to all completely-bounded openings (see Figure B-1 in Appendix B) except where the ground serves as an opening's lower boundary. Further, it applies to all openings regardless of their height 
above the ground. Even those openings that are low enough to permit children to touch the ground with their feet can present a risk of strangulation for an entrapped chlld. because younger children may not have the necessary cognittve abiltty and motor skills to extricate their heads. especially if scared or panicked.

The most approprate way to determine whether an opening is hazardous is to use test fixtures. Recommended test fixtures, performance requirements, and test methods, are described in Appendix B. These recommendations apply to all playground equipment. both for preschool-age and school-age children. Fixed equipment as well as moving equipment (in its stationary position) should be tested for entrapment hazards. There are two spectal cases for which separate procedures are given: completely bounded openings where depth of penetration is a critical issue, and openings formed by non-rigd climbing components.

\subsubsection{Angtes}

The angle of any vertex formed by adjacent components should not be less than 55 degrees, unless the lower leg is horzontal or projects downwards (see Figure 4, shown on the top right). An exception to this recommendation can be made if a rigid shield is attached to the vertex between adjacent components and the shield is of sufficient stze to prevent a 9 tnch diameter circular template from stmultaneously touching components on either side of the vertex (see figure 5 . shown on the bottom right).

\subsection{Tripping Bazerds}

All anchoring devices for playground equipment, such as concrete footings or hortzontal bars at the bottom of flexdble climbers, should be installed below the playing surface to eliminate the hazard of tripping. This will also prevent children who may fall from sustaining additional injuries due to exposed footings. in addition, attention should be given to environmental obstacles in the play area, including rocks, roots. and other protrusions from the ground that may cause children to trip.
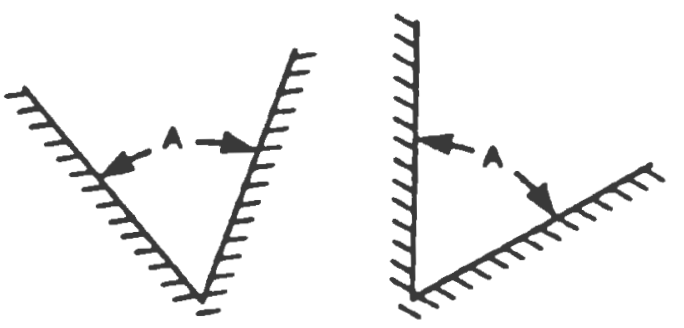

Angle A should exceed $55^{\circ}$

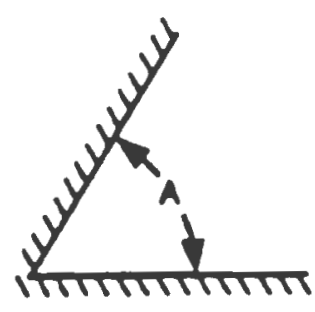

Ancle A its exempl ll ono log of the ves b horizontll or slopes downurard from the apex

Mogure 4. Recommendatlons for Anples

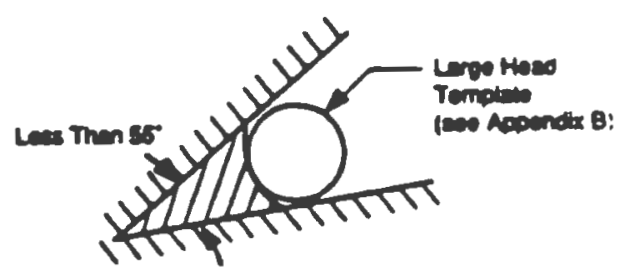

Mgure 5. Bhield for Angle Iew then $65^{\circ}$

Retaining walls are commonly used to help contain loose surfacing materials. In order to minimize the trip hazard. retaining walls should be highly visible and any change of elevation should be obvilous. The use of bright colors can 
contribute to better visibility.

\subsection{Buppended Brands}

Cables, wires, ropes, or stmilar flexible components suspended between play units or from the ground to a play unit within 45 degrees of hortzontal should not be located in areas of high traffic because they may cause injuries to a running child. It is recommended that these suspended members be either brightly colored or contrast with surrounding equipment to add to their visibility. This recommendation does not apply to suspended members that are located 7 feet or more above the playground surface.

\section{ACCESS AND PLATFORMS}

\subsection{Genernl}

Access to playground equipment can take many forms, such as conventional ramps, stairways with steps, and ladders with steps or rungs.

Access may also be by means of climbing components, such as climbing nets, arch climbers, and fire climbers (see Figure 6, shown on the right). Such climbing components are typically destgned to be more challenging than stairways and stepladders, and 80 require better balance and coordination of the children.

Rung ladders are generally considered to present a level of challenge tntermediate between stairways or stepladders and climbing components.

Rung ladders and climbing components such as climbing nets, arch climbers. and fire climbers, should not be used as the sole means of access to equipment intended for preschoolers.
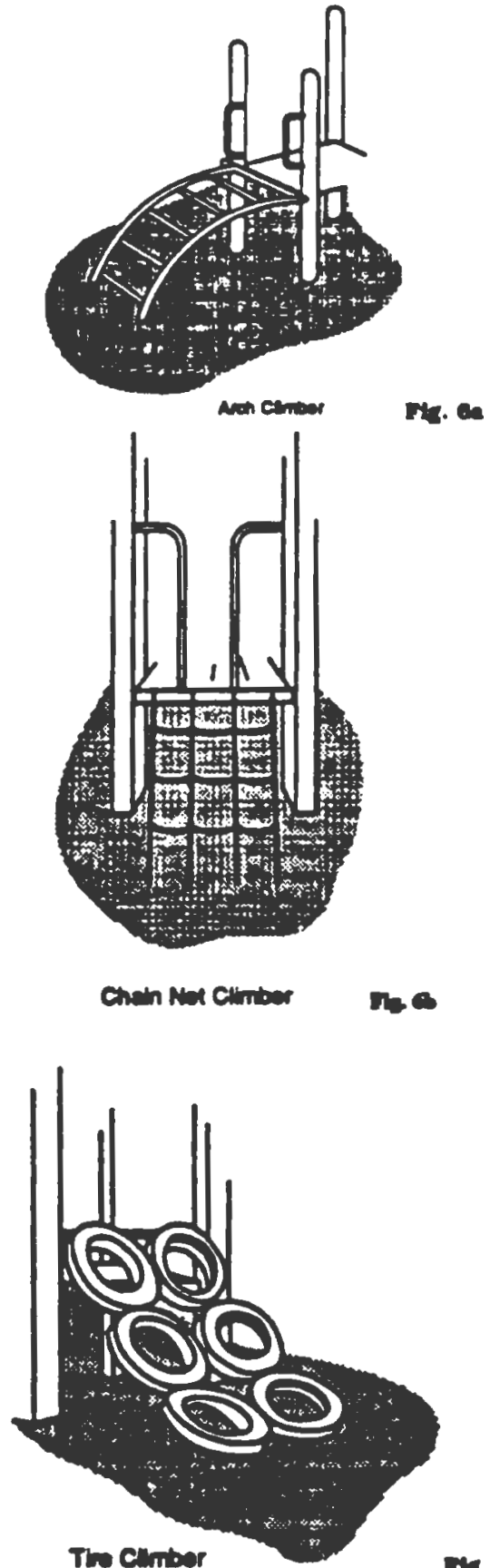

Mrurea 6a - c. Eramples of More Chnllenging Modes of Access

Platforms over 6 feet in helght (with the exception of free-standing slides) should provide an intermediate standing surface where a decision can be made to halt the ascent and to pursue an alternative means of descent. 


\subsection{Btalrwaye and ladders}

Stairways, stepladders, and rung ladders are distinguished by the range of slopes permitted for each of these types of access. However, in all cases the steps or rungs should be evenly spaced. Including the spacing between the top step or rung and the surface of the platform.

Table 1, below, contatns recommended dimensions for access slope, tread or rung width, head depth. rung diameter, and vertical rise for rung ladders, stepladders, and stairways. Table 1 also contatns slope and width recommendations for ramps.

These recommendations are not intended to address ramps designed for access by wheelchairs.

TABLE 1

Recommended Dimentons for Access slope, Tread or Rung Width, Tread Depth, Rung Diameter, and Vertical Rice for Rung Ladders. Btepladders. Btalimays, and Rampe.

\begin{tabular}{|c|c|c|c|}
\hline \multirow[b]{2}{*}{ Type of Access } & & \multicolumn{2}{|c|}{ Age of Intended User: } \\
\hline & & 2-5 Years & 5-12 Years \\
\hline Rung Ladders & $\begin{array}{l}\text { Slope } \\
\text { Rung Width } \\
\text { Vertical rise (tread to tread) } \\
\text { Rung Diameter }\end{array}$ & $\begin{array}{l}75^{\circ}-80^{\circ} \\
\geq 12^{\prime \prime} \\
\geq 12^{\prime \prime} \\
1^{\prime \prime}-1.67^{\prime \prime}\end{array}$ & $\begin{array}{l}75^{\circ}-90^{\circ} \\
\geq 16^{\prime \prime} \\
\geq 12^{\prime \prime} \\
1-1.67^{\prime \prime}\end{array}$ \\
\hline $\begin{array}{l}\text { Etepledders } \\
\square\end{array}$ & 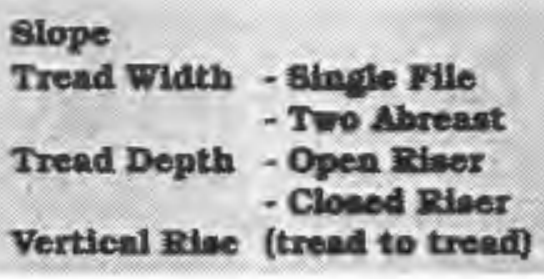 & $\begin{array}{l}50^{\circ}-75^{\circ} \\
12^{\prime \prime}-21^{\prime \prime} \\
2 \\
\geq 7^{\prime \prime} \\
\geq 7^{\prime \prime} \\
\leq 9^{\prime \prime} 0\end{array}$ & $\begin{array}{l}50^{\circ}-75^{\circ} \\
\geq 16^{\prime \prime} \\
\geq 40^{\prime \prime} \\
\geq 8^{\prime \prime} \\
\geq 6^{\prime \prime} \\
\leq 12^{\prime \prime} 0\end{array}$ \\
\hline Stairways & $\begin{array}{l}\text { Slope } \\
\text { Tread Width } \\
\begin{array}{l}\text { - Single File } \\
\text { - Two Abreast }\end{array} \\
\text { Tread Depth - Open Riser } \\
\text { - Closed Riser } \\
\text { Vertical Rise (tread to tread) }\end{array}$ & $\begin{array}{l}\leq 35^{\circ} \\
\geq 12^{\prime \prime} \\
\geq 30^{\prime \prime} \\
\geq \mathbf{7}^{\prime \prime} \\
\geq \mathbf{7}^{\prime \prime} \\
\leq \mathbf{9}^{\prime \prime}\end{array}$ & $\begin{array}{l}\leq 35^{\circ} \\
\geq 16^{\prime \prime} \\
\geq 40^{\prime \prime} \\
\geq 8^{\prime \prime} \\
\geq 8^{\prime \prime} \\
\leq 12^{\prime \prime}\end{array}$ \\
\hline $\begin{array}{l}\text { Rampn } \\
\text { (not fratendod } \\
\text { for access by } \\
\text { the dileabled) }\end{array}$ & 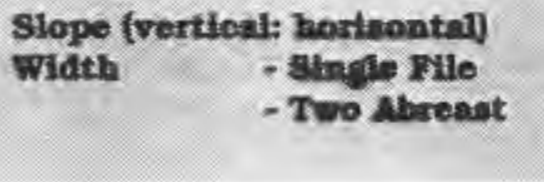 & $\begin{array}{l}\leq 1: 8 \\
\geq 12^{\circ} \\
\geq 30^{\prime \prime}\end{array}$ & $\begin{array}{l}\leq 1: 8 \\
\geq 16^{\prime \prime} \\
240^{\prime \prime}\end{array}$ \\
\hline
\end{tabular}

8 Entrapament provisions apply

Not recommended for preschoolers 
Openings between adjacent steps or rungs and between the top step or rung and underside of a platform should preclude the possiblity of entrapment.

Risers on statrways and stepladders should be closed if the distance between opposing interior surfaces of consecutive steps is between 3.5 and 9 inches (see Section 7.5). Since the design of rung ladders does not permit risers to be closed, the space between consecutive rungs should not be between 3.5 and 9 inches.

When nsers are closed, treads of statrways and ladders should prevent the accumulation of sand, water, or other materials on or between steps.

\subsubsection{Runos and Other Bnndoripping Components}

Whereas the steps of statrways and stepladders are used only for foot support. the rungs of rung ladders are used for both foot support and for hand support by a climbing child atnce rung ladders generally do not have handrails.

Rungs are generally round in cross section and should have a diameter or madmum cross sectional dimension between 1 and 1.67 inches. Other components intended to be grasped by the hands such as the bars of climbers should also have a diameter or maxdmum cross sectional dimension between land 1.67 inches.

Rungs or other handgnipping components that are intended to be grasped in a manner such that users will support their entire body weight by their hands should be generally round in cross section with a diameter between 1.00 and 1.55 inches. To benefit the weakest chtld in each age group, a diameter of 1.25 inches is preferred.

\subsection{Findralls}

Handrails on stairways and stepladders are typically intended to provide hand support and to steady the user. Continuous handralls extending over the full length of the access should be provided on both sides of all stairways and stepladders. regardless of the height of the access. Rung ladders do not require handralls since rungs or supports provide hand support on these more steeply inclined accesses.

\subsubsection{Bindrall Heloght}

Handrails should be avallable for use at the appropriate height. beginning with the first step. The vertical distance between the top front edge of a step (tread nosing) and the top surface of the handrall above it should be no less than 22 and no more than 38 inches.

\subsubsection{Findrall Dinmeter}

The diameter or madmum crosssectional dimension of handratls should be between 1.00 and 1.67 inches.

\subsection{Trandition from Accees to Platform}

On any transition from an access mode to a platform, handralls or handholds should be adequate to provide support until the child has fully achieved the destred posture on the platform. Any opening between a handrall and an adjacent vertical structure (e.g.. vertical support post for a platform or vertical slat of a protective barnier) should not pose an entrapment hazard (see Section 7.5).

On accesses that do not typically have side handralls - such as rung ladders. flexdble climbers, arch climbers, and fire climbers - special attention should be given to providing hand support to facilitate the transition between the top of the access and the platform. Options include vertical handralls and loop handgrips which may extend over the top of the access. 


\subsection{Pintforms}

\subsubsection{Deston Considerations}

Platforms should be within $\pm 2^{\circ}$ of a hortzontal plane and openings should be provided to allow for dralnage.

\subsubsection{Guardralls and Protective Barriere}

Either guardralls or protective barriers may be used to prevent inadvertent or unintentional falls off elevated platforms. Protecttve barriers, however. provide a greater degree of protection in that they should be designed to prevent intentional attempts by children seeking to defeat the barrier efther by climbing over or through the barrier.

Guardralls may have hortzontal ralls with openings that are greater than 9 inches. Such openings would not present an entrapment hazard but would not prevent a child from dellberately attempting to climb over or through the openings.

On the other hand, protective barriers should be designed to preclude passage of a child during both inadvertent and intentional attempts to defeat the barrier. Therefore, any openings between uprights or between the platform surface and lower edge of a protecttve barrier should preclude passage of small torso template (see Appendtx B).

\subsubsection{Mntmum Elevation Requiring Genardilis and Protective Barter}

Guardralls or protective barriers should be provided on platforms, walkways. landings, and transitional surfaces in accordance with the following minimum elevation recommendations.

Preschool-Age Chlldren: Since younger children have poorer coordination and balance and are more vulnerable to injury than school-age children, guardrails or protective barriers are warranted at lower elevations. An elevated surface that is more than 20 inches above the undertying surface should have a guardrail or protective barrier to prevent falls. Guardrails are acceptable for platforms greater than 20 inches and less than or equal to 30 inches high, but a full protective barrier may be preferable for this age group since it affords a greater degree of protection from falls. Protective barriers should always be used for platforms that exceed 30 inches in height.

School-Age Children: An elevated surface that is more than 30 inches above the undertying surface should have a guardrail or protective barrier to prevent falis. For platforms greater than 30 inches and less than or equal to 48 inches high. guardrails are acceptable although a full protective barrier always provides greater protection. Platforms that exceed 48 inches in height should always have a protective barrier.

An elevated surface is exempt from these recommendations if a guardrail or protective barsier would interfere with the intended use of the equipment. This includes most climbing equipment, and platforms that are layered so that fall helght does not exceed 20 inches on equipment intended for preschool-age chilldren or 30 inches on equipment intended for school-age children.

\subsubsection{Mnimum Betogt of Gundrall}

The minimum height should prevent the langest child from inadvertently falling over the guardrall. In addition, the guardrall should extend low enough to prevent the smallest child from inadvertently stepping under It (see Figure 7. shown on the next page).

Infll may be used between the top and intermediate ralls to minimize the likelihood of climbing. When solid panels are used as infill. It is recommended that there be some transparent areas to facilitate supervision and to permit viewing from the platform. To prevent head entrapment, guardrails should conform 
to the entrapment requirements in Section 7.5 .

Preschool-Age Children: The top surface of guardralls should be at least 29 inches high and the lower edge should be no more than 23 inches above the platform.

Echool Age Children: The top surface of guardralls should be at least 38 inches high and the lower edge should be no more than 26 inches above the platform.

\subsubsection{Minimum Beloht of Protectre Barrier}

The minimum height should prevent the largest child from inadvertently falling over the protective barrier. In addition. because the protective barrier should not permit children to climb through or under it. openings in the barrier should prevent passage of the small torso template (see Appendix B).

Freachool-Age Chlldren: The top surface of protective barriers should be at least 29 inches high. Vertical infill for protective barriers may be preferable for younger children because the vertical components can be grasped at whatever height a child chooses as a handhold.

Bchool Age Chlldren: The top surface of protective barriers should be at least 38 inches high.

\subsubsection{Other Dealon Considerations for Gundirills and Protective Barters}

Both guardralls and protective barriers should be designed to prevent tnadvertent or unintentional falls off the platform. prevent the possiblilty of entrapment, and facllitate supervision. Hortzontal cross-pleces should not be used as infll for the space below the top rall because the provide footholds for climbing.

\subsection{Stepped Platforms}

On some composite structures. platforms are layered or tiered. so that falls from a higher platform can be terminated by a lower platform rather than by the ground surface.

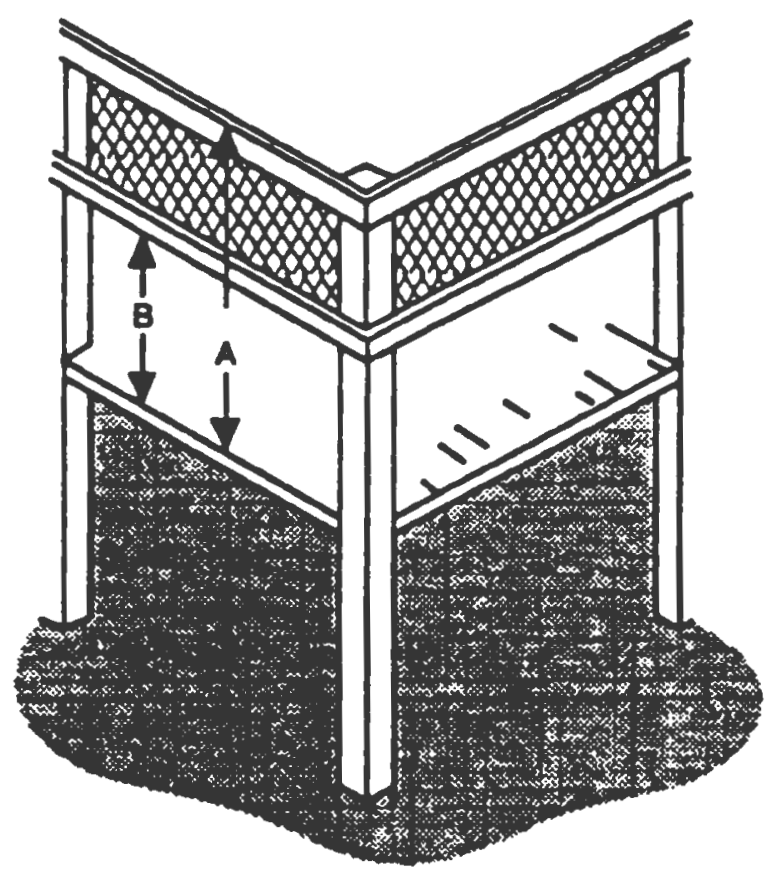

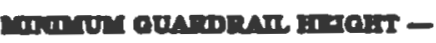

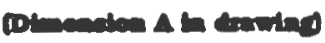

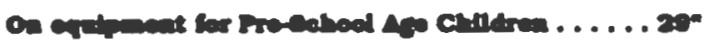

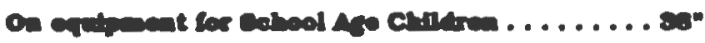

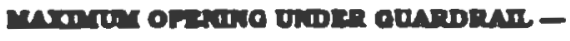

(1)

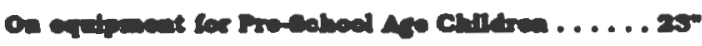

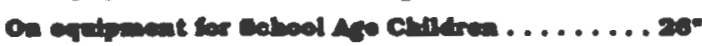

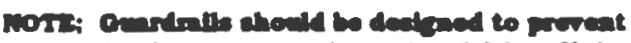
balvertient or wintentional sill of the

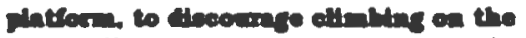

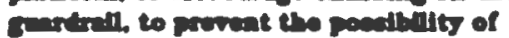

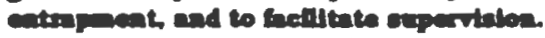
cos coetton 0.8.4 for cetinited

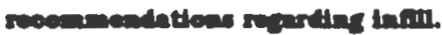

Fugure 7. Guardinils on Elevated Burfinces 
Uniess there is an alternate means of access/egress, the maxtmum difference in height between stepped platforms should be:

Preschool-Age Chuldren:. . . 12 tnches

School Age Children:. . . . . 18 inches

The space between the stepped

platforms should follow the

recommendations for entrapment in enclosed openings in Section 7.5.

If the space between the stepped platforms exceeds 9 inches and the height of the lower platform from the protective surface exceeds 30 inches for pre-school equipment or $\mathbf{4 8}$ inches for school-age equipment, infll should be used to reduce the space to less than 3.5 inches.

\section{MAJOR TIPES OF PLATGROUND EQUUPMIENT}

\section{Q.1 Elides}

\subsubsection{Ceneral}

Although children under 6 years of age may be more likely to play on slides. older children will still use slides depending on their avallability relattve to other types of equipment.

Children can be expected to descend slide chutes in many different positions, rather than atways sitting and facing forward as they sllde. They will sllde down facing backward, on their knees, lying on their backs, and will walk both up and down the chute. Younger children in particular often slide down on their stomachs, either head or feet first.

Slides may provide a straight, wavy, or spiral descent either by means of a tube or an open slide bed. They may be elther free standing (see Figure 8 , below). part of a composite structure, or bullt on the grade of a natural or manmade slope (embankment slide).

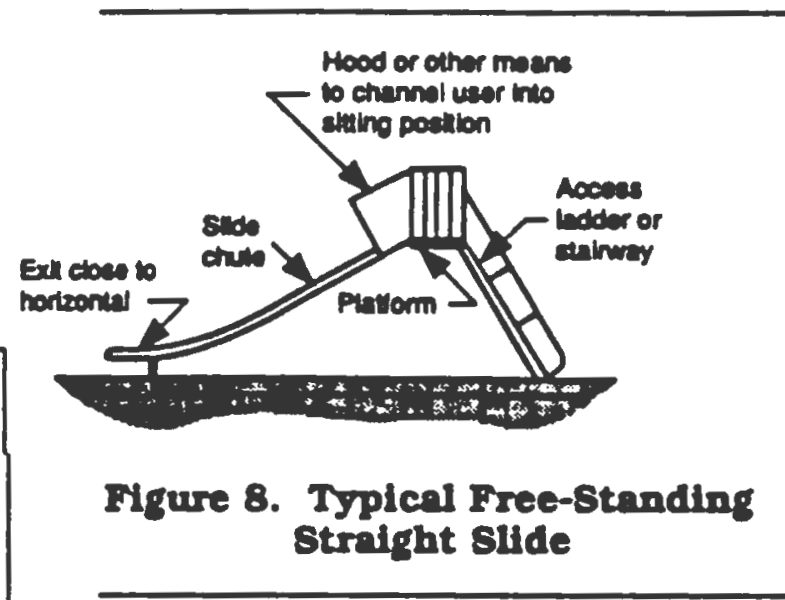

NOTE: The recommendations in this section do not apply to water slides or swimming pool slides.

\subsubsection{Gude Acceas}

With the exception of embankment slides, access to a slide may be by means of a ladder with rungs or steps. a stairway with steps, or the slide may be a component of a composite play structure to which access is provided by other means. Whatever means of access is provided to a slide, it should conform to the guidelines specifled in the general discussion of access to all playground equipment (see Section 8).

\subsubsection{Blide Platform}

All slides should be provided with a platform with sufficient length to facllitate the transition for a chlld from standing to sitting at the top of the inclined sliding surface. The length of the platform will usually not be an issue when the slide is attached to the deck of a composite structure, because decks are typically at least 3 feet square. However, in the case of a freestanding slide, it is recommended that 
the platform have a minimum length of at least 22 inches.

The platform should be horizontal and have a width at least equal to the width of the slide.

Guardralls or protective barriers should surround a slide platform and should conform to the guidelines specified in the general discussion of platforms (see Section 8.5).

Slides should not have any spaces or gaps between the platform and the start of the sliding surface.

With the exception of tube sildes. handholds should be provided at the entrance to all slides to factlitate the transition from standing to sitting and decrease the risk of falls. These should extend high enough to provide hand support for the largest child to a standing position, and low enough to provide hand support for the smallest child in a sitting position.

At the entrance to the chute there should be a means to channel a user into a stting posttion. This may be a guardrall, a hood, or other device. Whatever means is provided, it should be of a design that does not encourage climbing.

\subsubsection{Eltaing Eection of Btraingt 8ude:}

It is recommended that the average incline of the sliding surface should not exceed $30^{\circ}$ and any change in the slope of the slide chute (1.e., on a wave slide) should not allow a child to lose contact with the sliding surface.

Straight slides with flat open chutes should have sides with a 4 inch minimum height extending along both sides of the chute for the entire length of the inclined sliding surface.

The sides should be an integral part of the chute. without any gaps between the sides and the sliding surface.
Slides may have an open chute with a circular cross section providing that the height of the sides, measured from the lowest point on the chute is no less than half the width of the slide.

Metal slides should either be in shaded areas or face north to prevent burns and glare problems caused by direct sun on the slide chute.

\subsubsection{Edt Reglon}

All sludes should have an exit reglon to help children maintain their balance and facllttate a smooth transition from sitting to standing when exiting.

The exit region should be essentially horkzontal and parallel to the ground and have a minimum length of 11 inches.

For slides that are no more than 4 feet In height. the height of the exit region should be no more than 11 inches from the protective surface.

For alides that are over four feet In height the ext regjon should be at least 7 Inches but not more than 15 inches above the protective surface.

Slide exdt edges should be rounded or curved, to prevent lacerations or other injurtes which could result from impact with a sharp or straight edge.

All slide exits should be located In uncongested areas of the playground.

\subsubsection{Dmban'ment 8lldes}

The design of embankment slides basically eliminates the hazard of falls from height. Embankment slides should follow all of the recommendations given for straight slides (where applicable). It is important that some means be provided at the slide chute entrance to minimize the likelihood that they will be used by children riding skateboards or bicycles. 


\subsubsection{Bpiral 8lides}

It Is recommended that spiral slides follow the recommendations for straight slides (where applicablel. with special attention given to design features which may present problems unique to spiral slides, such as lateral discharge of the user.

Preechool-Age Children: Because younger children have less abillty to maintain balance and postural control. only short spiral slides are recommended for this age group.

\subsubsection{Tube Slides}

Tube slides should meet all the applicable requirements for other slides.

Barriers should be provided or surfaces treated to prevent sliding on the top of the tube slide.

The minimum internal diameter of the tube slide should be no less than 23 inches.

It should be noted that children using tube sudes are not vistble to a supervisor. Constderation should be gtven to extra supervision on playgrounds having tube slides.

\subsubsection{Roller Blideo}

These are not recommended for public playgrounds unless frequent maintenance can be guaranteed.

\subsection{Swinge}

\subsubsection{Cenerd}

Children of all ages generally enjoy the sensations created while swinging. Most often. they sit on the swings. and It is common to see children jumping off swings. Younger children tend to also swing on their stomachs, and older children may stand on the seats.

Swings may be divided Into two distinct types, those having a single axis of motion and those with multiple axes of motion.

A single axis swing is intended to swing back-and-forth in a single plane and generally consists of a seat supported by at least two suspending members each of which is connected to a separate ptvot on an overhead structure.

A multple axis swing conststs of a seat (generally a tire) suspended from a single pivot that permits it to swing in any direction.

Hardware used to secure the suspending elements to the swing seat and to the supporting structure should not be removable without the use of tools.

S-hooks are often part of a swing's suspension system, either attaching the suspending elements to the overhead support beam or to the swing seat. Open S-hooks are hazardous because they can catch a child's clothing and result In strangulation. S-hooks should be pinched closed as tightly as possible.

Swings should be suspended from support structures that discourage climbing. A-frame support structures should not have horzontal cross-bars.

\subsubsection{Blogle Adis Brings}

To help prevent young children from inadvertently running into the path of moving swings, swing structures should be located away from other equipment or activities. Additional protection can be provided by means of a low barrier, such as a fence or hedge. Such barrers should not be an obstacle within the use zone of a swing structure or hamper supervision by blocking vistbillty.

To minimize the likelihood of children being struck by a moving swing. It is recommended that no more than two single axds swings be hung in each bay of the supporting structure. 
Attaching single axds swing structures to composite structures is not recommended.

Swing seats should be designed to accommodate no more than one user at any time. To help reduce the severity of impact injuries, wood or metal swing seats are not recommended. Edges of seats should have smoothly finished or rounded edges and should conform to the protrusion recommendations in Section 7.3 .

To minimize collisions between swings or between a swing and the supporting structure. the clearances noted in Figure 9. shown on the right, are recommended. In addition, to reduce side-to-side motion, swing hangers I on the support beam / should be spaced wider than the width of the swing seat.

\subsubsection{Tot 8wing}

Tot swings are single axis swings intended for very young children to use with adult assistance. The seats and suspension systems of these swings. including the related hardware, should follow all of the other criterja for conventional single axis swings.

Tot swing seats should provide support on all sides of a child (see Figure 10, shown on the right). It is important that such supports do not present a strangulation hazard. Openings in tot swing seats should conform to the entrapment criteria in Section 7.5.

It is recommended that tot swings be suspended from structures which are separate from those for other swings, or at least suspended from a separate bay of the same structure.

\subsubsection{Multiple Ads (Tire) 8wings}

Ture swings are typically suspended in a horizontal orlentation using three suspension chalns or cables connected to a single swirl mechanism that permits both rotation and a swinging motion in any axts.

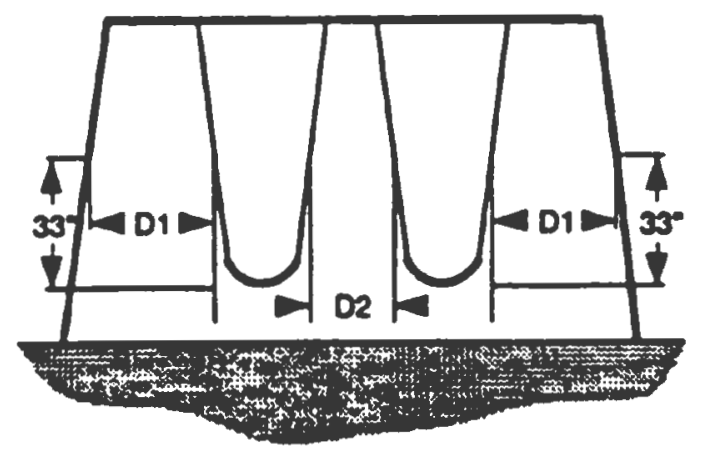

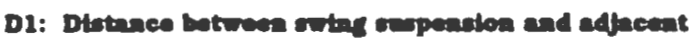
- wport etricters at a potnt 35 abow the ceat

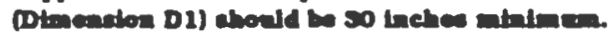

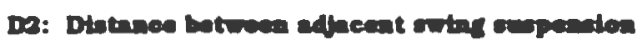

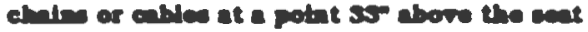

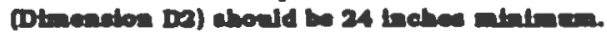

Figure 9. Minimum Clearances for 8wing

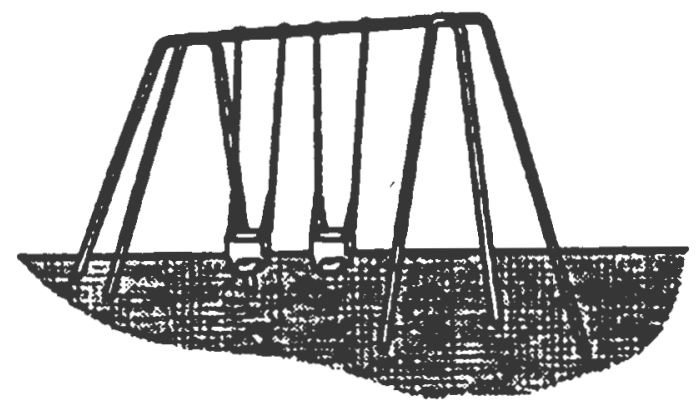

Figure 10. Examples of Tot 8wing

A multuple axis tire swing should not be suspended from a structure having other swings in the same bay.

To minimize the hazard of impact. heavy truck tires should be avolded. Further, if steel-belted radial tires are used, they should be closely examined to ensure that there are no exposed steel belts that could be a potential protrusion or laceration hazard. Plastic 
materials can be used as an alternattve to simulate actual automoblle tires. Drainage holes should be provided in the underside of the tire.

The likelihood of hanger mechanism fallure is increased for tire swings, due to the added stress of rotational movement and multiple occupancy. Special attention to malntenance is warranted. The hanger mechanisms for multiple axis swings should not have any accessible pinch points.

The minimum clearance between the seating surface of a tire swing and the uprights of the supporting structure should be 30 inches when the tire is in position closest to the support structure (see Figure 11, shown on the right).

\subsubsection{8wings Not Recommended for Public Pleyprounds}

The following types of swings are not recommended for use in public playgrounds:

Multiple Occupanes 8nings - With the exceptton of tire swings, swings that are intended for more than one user are not recommended because their greater mass, as compared to single occupancy swings, presents a risk of impact tnjury.

Animal Figure 8wing - These are not recommended because their igid metal framework results in a high mass presenting a risk of impact injury.

Rope Swinge - Free swinging ropes that may fray or otherwise form a loop are not recommended because they present a potential strangulation hazard.

8winging Ererctec Rings and Trapeze Bars - These are generally considered to be items of athletic equipment and are not recommended for public playgrounds.

NOTE: The recommendation against the use of exercise rings does not apply to overhead hanging rings (see figure 12d).

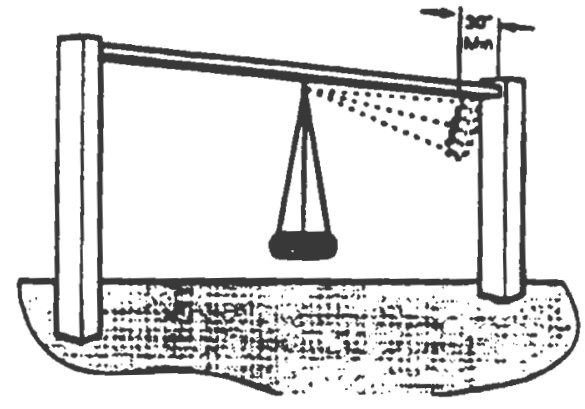

Figure 11. Multiple Ads Tire 8wing Clearance

\subsection{Climbing Equipment}

\subsubsection{General}

Climbers refer to a wide varlety of equipment including arch climbers. sliding poles, chain or net climbers. upper body devices (1.e.. overhead hortzontal ladders and overhead rings). dome climbers, parallel bars. balance beams, cable walks, suspension bridges, and spiral climbers, as well as composite structures with linked platforms (see Figures $12 a-d$ for examples).

Climbing equipment is generally destgned to present a greater degree of physical challenge than other equipment on public playgrounds.

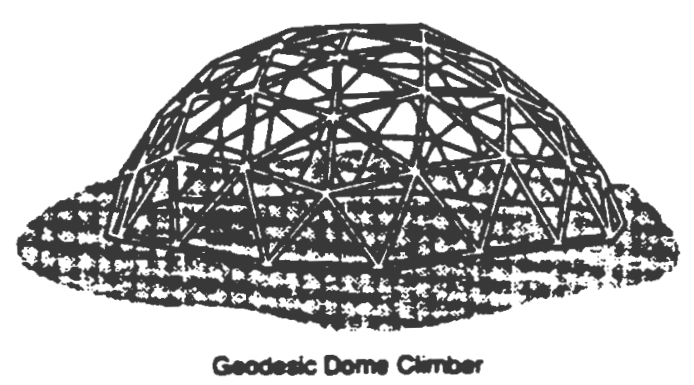

Figure 122. Geodedc Dome Climber 
Older children tend to use climbing equipment more frequently and proficiently than younger ones.

Because very young chlldren have not yet developed some of the physical skills necessary for certain climbing activities (including balance. coordination, and upper body strength) they may have difficulty using more challenging components such as rung ladders, non-rigid climbers, arch climbers, and upper body devices.

\subsubsection{Desion Conniderations}

Since the more challenging modes of access discussed in Section 8 are also intended to be used as climbing devices, the recommendations for the stze of handgripping components and stepped platforms covered in that section are applicable to climbing equipment.

Climbers should not have climbing bars or other structural components in the interjor of the structure onto which a child may fall from a height of greater than 18 inches.

Climbing equipment should allow children to descend as easily as they ascend. One way of implementing this recommendation is to provide an easter. alternate means of descent, such as another mode of access, platform, or piece of equipment. For example. a stairway can be added to provide a less challenging mode of descent than a vertical rung ladder or flexdble climbing device. The levels of challenge that charactertze different types of access are discussed in Section 8.1.

Offering an easy way down is particularty important on climbing devices intended for preschool-age children since their abllity to descend climbing components emerges later than their ablity to climb up the same components.

\subsubsection{Climbers With Non-Rigid Components}

Net and chain clmbers use a flexuble grid of ropes or chains for climbing (see Figure 6b). Tire climbers are also described as flexible climbers. These may have the tires secured tread-totread in the form of a sloping grid (see Figure 6 ) or the tires may be suspended individually by chains or other means to provide access to an elevated platform. Since net, chain, and tire climbers have flexible components that do not provide a steady means of support, and therefore require more advanced balance abllities than conventional ladders, they require special consideration.

which provide access to platforms should be securely anchored at both ends. When one end is connected to the ground, the anchoring devices should be below the level of the playing surface.

Connections between ropes, cables, or chatns within the climbing grid or between tires should be securely fixed. Spacing between the hortzontal and vertical components of a climbing grid should satisfy all entrapment criteria (see Section 7.5).

Flexdble grid climbing devices are not recommended as the sole means of access to equipment intended for preschool-age chlldren.

\subsubsection{Arch Climbers}

Arch climbers consist of metal or wood rungs attached to convex (e.g.. curved outward) side supports. They may be free standing (see Figure 12b, shown on next page) or be provided as a more challenging means of access to other equipment (see Figure 6a). Because of this extra challenge, they should not be used as the sole means of access to other equipment. A less challenging option will ensure that children use the arch climber because they are willing to 
assume the challenge and not because they are forced to use it.

Free-standing arch climbers are not recommended for preschool-age chlldren.

The rung diameter and spacing of rungs on arch climbers should follow the recommendations for rung ladders In Table 1.

\subsubsection{Horteontal Ladders and Overhead Rings}

Four year olds are generally the youngest chlldren capable of using upper body devices such as these. The recommendations below are. therefore. designed to accommodate chlldren 4 through 12 years of age.

The space between adjacent rungs of overhead hortzontal ladders (see Figure 12c, shown on the right) should be greater than 9 inches to satisfy the entrapment requirements (see Section 7.5). The center-to-center spacing of hortzontal ladder rungs should not exceed 15 inches. This does not apply to the spacing of overhead rings (see Figure 12d. shown on the right) because, during use, the gripped ring swings through an arc and reduces the distance to the gripping surface of the next ring.

The first handhold on elther end of upper body equipment should not be placed directly above the platform or climbing rung used for mount or dismount. This mintmizes the risk of children tmpacting rigtd access structures if they fall from the first handhold during mount or dismount.

\subsubsection{Sllding Poles}

Vertical sliding poles are designed to be more challenging than some other types of climbing equipment.

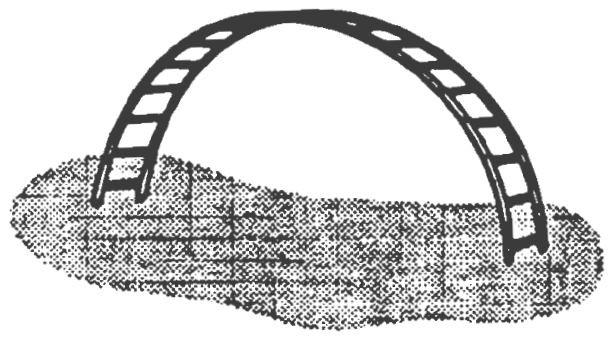

Simple Arch Climber

Figure 12b. Free-standing Arch Climber

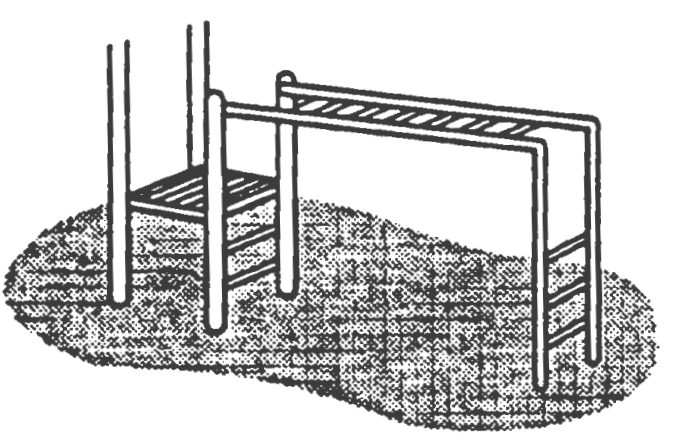

- Ovemead Horizomal Ladder

Fioure 12c. Overhead Borizontal Ladder

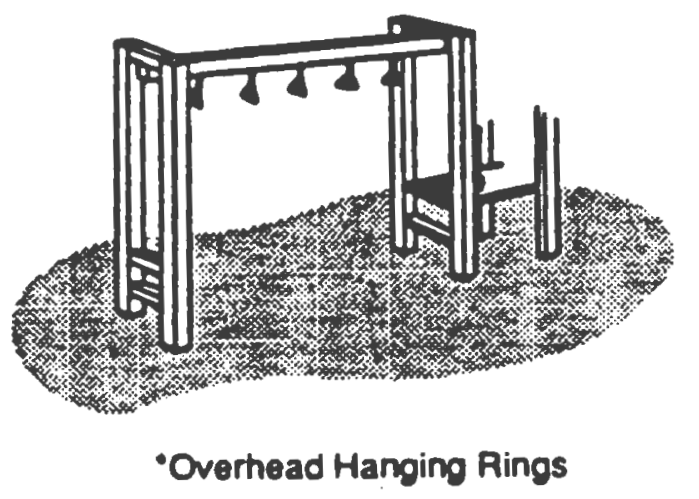

Figure 12d. Overhead Rings

Sliding poles are not recommended for preschool-age children who may lack the requisite upper body strength and coordination to successfully slide down the pole. 
Furthermore, once younger children have grasped the pole. they would be forced to slide down It since there is no alternative option.

Sliding poles should be continuous with no protruding welds or seams along the silding surface and the pole should not change direction along the sliding portion.

The horizontal distance between a sliding pole and the edge of the platform or other structure used for access to the sliding pole should be at least 18 inches. This mintmum distance applies to all points down the sliding pole.

All points on the sliding pole at or above the level of the access structure. where a child is likely to reach for the pole. should not be more than 20 inches away from the edge of the access structure.

The pole should extend at least 38 inches above the level of the platform or other structure used for access to the sliding pole.

The diameter of sliding poles should be no greater than 1.9 Inches.

The design of the access structure should minimize the possibility of interference from surrounding traffic that may be out of the line of stght of a user during descent.

\subsubsection{Climblng Ropes}

Individual vertically suspended climbing ropes are recommended only if they are securely anchored to a footing at the lower end to prevent the rope from being looped back on Itself and forming a noose.

\subsubsection{Belnnce Benms}

To avoid groin injuries to users during falls, balance beams should be no higher than 12 inches.

\subsubsection{Lajout of Climbing Components}

When climbing components are part of a composite structure, their level of challenge and mode of use should be compatible with the trafiftc flow from adjacent components.

The swinging movements generated on upper body devices warrant special precautions to reduce the risk of impact with children on adjacent structures. Upper body devices ( 1.e., overhead hortzontal ladders and overhead rings) should be placed so that swinging children cannot interfere with the movement of children on adjacent structures, particularly with thetr descent on slides.

The design of adjacent play structures should not facilltate climbing to the top support bars of upper body equipment.

\subsection{Mensy-go-rownds}

Merry-go-rounds I also known as whirls l are the most common type of rotating equipment found on public playgrounds. Children usually sit or stand on the platform while other chilldren or adults push the merry-goround to make it rotate. in addition. children often get on and off the merrygo-round while it is in motion.

Merry-go-rourds may present a physical hazard to preschool-age children who have little or no control over such equipment once they are in motion. Merry-go-rourds are not recommended unless the following are observed:

The rotating platform should be continuous and approximately circular. The difference between the mintmum and maximum radil of a non-circular platform should not exceed 2.0 inches (see Figure 13, shown on the next page). No components of the apparatus. including handgrips, should extend beyond the perimeter of the platform. 
Children should be provided with a secure means of holding on. Where handgrips are provided, they should conform to the general requirements for handgripping components in Section 8.2.1.

There should not be any accessible shearing or crushing mechanisms in the undercarriage of the equipment. The rotating platform of a merry-goround should not have any sharp edges. The surface of the platform should be continuous with no openings between the axds and the periphery that permit a rod having a diameter of 5/16 inch to penetrate completely through the surface.

A means should be provided to limit the peripheral speed of rotation to a maximum of $13 \mathrm{ft} / \mathrm{sec}$.

Merry-go-round platforms should not be provided with an oscillatory ( up and down ) motion.

\subsection{Bec-eawe}

The typical see-saw (also known as a teeter-totter / consists of a board or pole supported at the center by a fulcrum and having a seat at each end (see Figure 14, shown on the rightl. Seesaw use is quite complex because it requires two children to cooperate and combine their actions.

Younger chuldren do not generally have the skills required to effectuvely use fulcrum see-saws. Therefore, they are not recommended for preschool-age children unless they are equipped with a spring centering device to prevent abrupt contact with the ground should one child elect to dismount.

There is a trend to replace fulcrum seesaws on public playgrounds with spring-loaded see-saws, which have the advantage of not requiring two children to coordinate their actions in order to

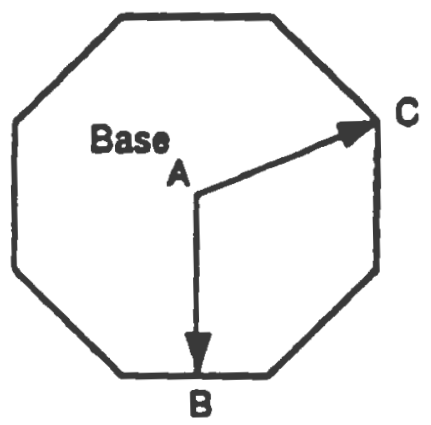

A = Center of the Ads of Rotation AB = Minimum Radius of Platform AC = Madmum Radius of Platform The difference between dimensions $A B$ and $A C$ should not erceed 2.0 inches.

Plgure 13. Mnimum and Merdmum Radil of a Non-Cireular Merry-go-round Platform

play safely (see discusston of Spring Rocking Equipment in Section 9.6).

The fulcrum of fulcrum see-saws should not present a pinch or crush hazard.

Partial car tires. or some other shockabsorbing materlal, should be embedded in the ground underneath the seats of fulcrum see-saws, or secured on the underside of the seats. This will help prevent the limbs of seesaw users from betng crushed between the seat and the ground, as well as cushion the tmpact when the see-saw hits the underlyting surface. Fulcrum see-saws may also be equipped with a spring centering mechanism to mintmize the risk of injury due to tmpact with the underlying surface.

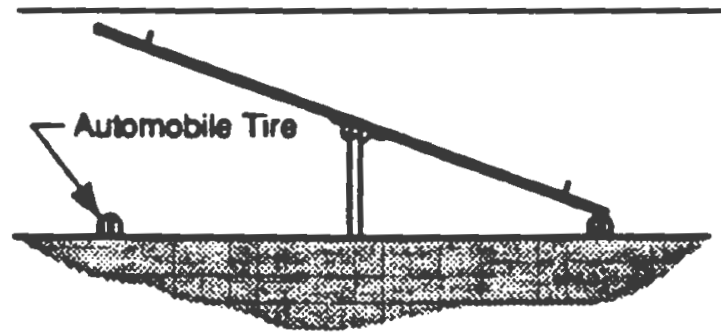

Fgure 14. Typicul Fularum See-ant 
Handholds should be provided at each seating position for gripping with both hands and should not tum when grasped. Handholds should not protrude beyond the sides of the seat. Footrests should not be provided on fulcrum see-saws unless they are equipped with a spring centering mechanism to minimize the likelihood of impact with the underlying surface.

\subsection{Spring Rocking Equipment}

Younger children enjoy the bouncing and rocking activities presented by spring rocking equipment, but older children typically do not find them challenging enough.

Examples of spring rockers are lllustrated in Figures 15a-b. shown on the right. Preschool-age children are the primary users of such rocking equipment. Therefore, the recommendations in this section address only preschool-age children.

Seat deaign should minimize the likellhood of the rocker being used by more than the intended number of users.

Each seating position should be equipped with handgrips and footrests. The diameter of handgrips should follow the general recommendations for handgripping components in Section 8.5.2.

The springs of rocking equipment should minimize the possibllity of their feet between colls or between the spring and a part of the rocker.

\subsection{Trampolines}

Trampolines are not recommended for use on public playgrounds.

\section{BURFACING}

The surface under and around playground equipment can be a major

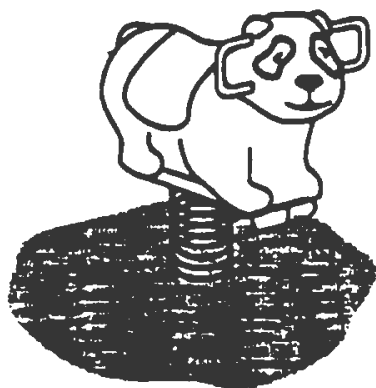

Flgure 15e. Typical 8ingle-User Bpring Rocker

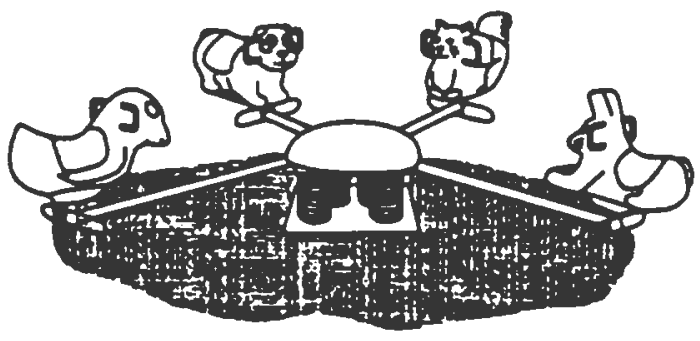

Figure 15b. Typleal Multiple-Ucer Spring Rocker

factor in determining the injurycausing potential of a fall. It is selfevident that a fall onto a shock absorbing surface is less likely to cause a serious injury than a fall onto a hard surface. Because head impact injuries from a fall have the potentlal for being life threatening. the more shock absorbing a surface can be made. the more is the likelihood that the severity of the injury will be reduced. However. It should be recognized that all injuries due to falls cannot be prevented no matter what playground surfacting material is used.

\subsection{Determining 8hock Abeorbency of a Burfacing Mnterinl}

No data are avaulable to predict precisely the threshold tolerance of the human head to an impact injury. However biomedical researchers have established two methods that may be used to determine when such an injury may be life threatening. 
Peal Deceleration - One method holds that if the peak deceleration of the head during impact does not exceed 200 times the acceleration due to gravity - 1.e., $200 \mathrm{G's}$ - a life threatening head injury is not likely to occur.

Bead Injury Criteria - The second method holds that both the deceleration of the head during impact and the time duration over which the head decelerates to a halt are significant in assessing head impact injury. This latter method uses a mathematical formula to dertve a value known as Head Injury Criteria ( HIC ) [6]. Head impact injuries are not believed to be life threatening if the HIC does not exceed a value of 1,000 .

The most widely used test method for evaluating the shock absorbing properties of a playground surfacing matertal is to drop an instrumented metal headform onto a sample of the material and record the acceleration/time pulse during the tmpact. Such a method is described in ASTM Standard specification for Impact Attenuation of Surface Systems Under and Around Playground Equipment. ASTM F1292 [7].

\subsection{Critical Beirht}

This a term originating from Europe and is used to describe the shock absorbing performance of a surfacing material. As it is used in this publication, the critical height for a surfacing material is defined as the maximum height from which the instrumented metal headform. upon impact, yields both a peak deceleration of no more than 200 G's and a HIC of no more than 1,000 when tested in accordance with the procedure described in ASTM F292. Critical Height, therefore, can he considered as an approximation of the maxtmum fall height from which a life-threatening head injury would not expected to occur.
The surfacing materlal used under and around a plece of playground equipment should have a critical height value of at least the height of the highest accessible part of the equipment.

\subsection{Highest Accessible Part of Equipment}

Recommendations for the highest accesstble part for various pleces of playground equipment are as follows.

Swings - Since chlldren may fall from a swing seat at its maxdmum attainable angle (assumed to be $90^{\circ}$ from the vertical "at rest" position). the highest accessible part of a swing structure is the height of the pivot point where the swing's suspending elements connect to the supporting structure.

\section{Blevated Platforms Including Bllde Fiatforms - The highest accessible part of elevated platforms is determined by whether the platform is surrounded by a guardrall or by a protective barrier.}

Stnce children may climb onto or over guardralls, the highest accessible part of a platform surrounded by guardrails is the height above the playing surface of the top of the guardrall.

Since protecttve barriers are designed to minimize the likellhood of climbing. the highest accessible part of a platform surrounded by protective barriers is the height of the platform surface above the ground.

Climbers and Eorisontal Laddere For structures that are intended to be climbed upon, the highest accesstble part is the maximum height of the structure.

Merry-go-rounds - The highest accesstble part is the height above the ground of any part at the perimeter on which a child may sit or stand. 
Bee-ane - The highest accesslble part Is the maxtmum height attainable by any part of the see-saw.

Spring Rockers - The highest accessible part is the maxtmum height above the ground of the seat or designated play surface.

\subsection{Acceptablity of Vartou Surfacing Mnterials}

Hard surfacing materials, such as asphalt or concrete, are unsuitable for use under and around playground equipment of any height unless they are required as a base for a shock absorbing unitary matertal such as a rubber mat.

Earth surfaces such as solls and hard packed dirt are also not recommended because their shock absorbing properties can vary considerably depending on climatic conditions such as molsture and temperature.

Stronllarty. grass and turf are not recommended because their effectiveness in absorbing shock durting a fall can be reduced considerably due to wear and environmental conditions.

Acceptable playground surfacing materials are avallable in two basic types, unitary or locce-an.

Unitars Mnterials - These are generally rubber mats or a combination of rubber-like materials held in place by a binder that may be poured in place at the playground site and cures to form a unitary shock absorbing surface. Unitary materials are avallable from a number of different manufacturers many of whom have a range of materials with differing shock absorbing properties. Persons wishing to install a unitary material as a playground surface should request test data from the manufacturer that should identify the critical height of the desired material. In addition, site requirements should be obtained from the manufacturer because some unltary materials require installation over a hard surface while for others this is not required.

Loose-FUL Mnterisls - These can also have acceptable shock absorbing properties when installed at a sufficient depth. These materials include, but are not confined to. sand, gravel, and shredded wood products. Loose-fill matertals should not be Installed over hard surfaces such as asphalt or concrete.

Because loose-fill materials are generally sold for purposes other than playground surfacing. many vendors are unitkely to be able to provide information on their shock absorbing performance. For that reason. CPSC staff has conducted tests to determine the relattve shock absorbing properties of some loose-fill materials commonly used as surfaces under and around playground equipment. Appendix D contalns a description of the tested materials. The tests were conducted in accordance with the procedure In the voluntary standard for playground surfacing systems. ASTM F1292.

Table 2, on the next page. lists the critical height (expressed in feet) for each of seven materials when tested in an uncompressed state at depths of six. nine and twelve inches. The table also reports the critical height when a nine inch depth of each material was tested in a compressed state.

The table should be read as follows: If, for example, uncompressed wood mulch is used at a mintmum depth of 6 inches, the critical height is 7 feet. If 9 inches of uncompressed wood mulch is used. the critical helght is 10 feet. It should be noted that, for some materials, the critical height decreases when the material is compressed. 
TABLE 2

Critical Heights (in feet) of Tested Loose-Fill Materials

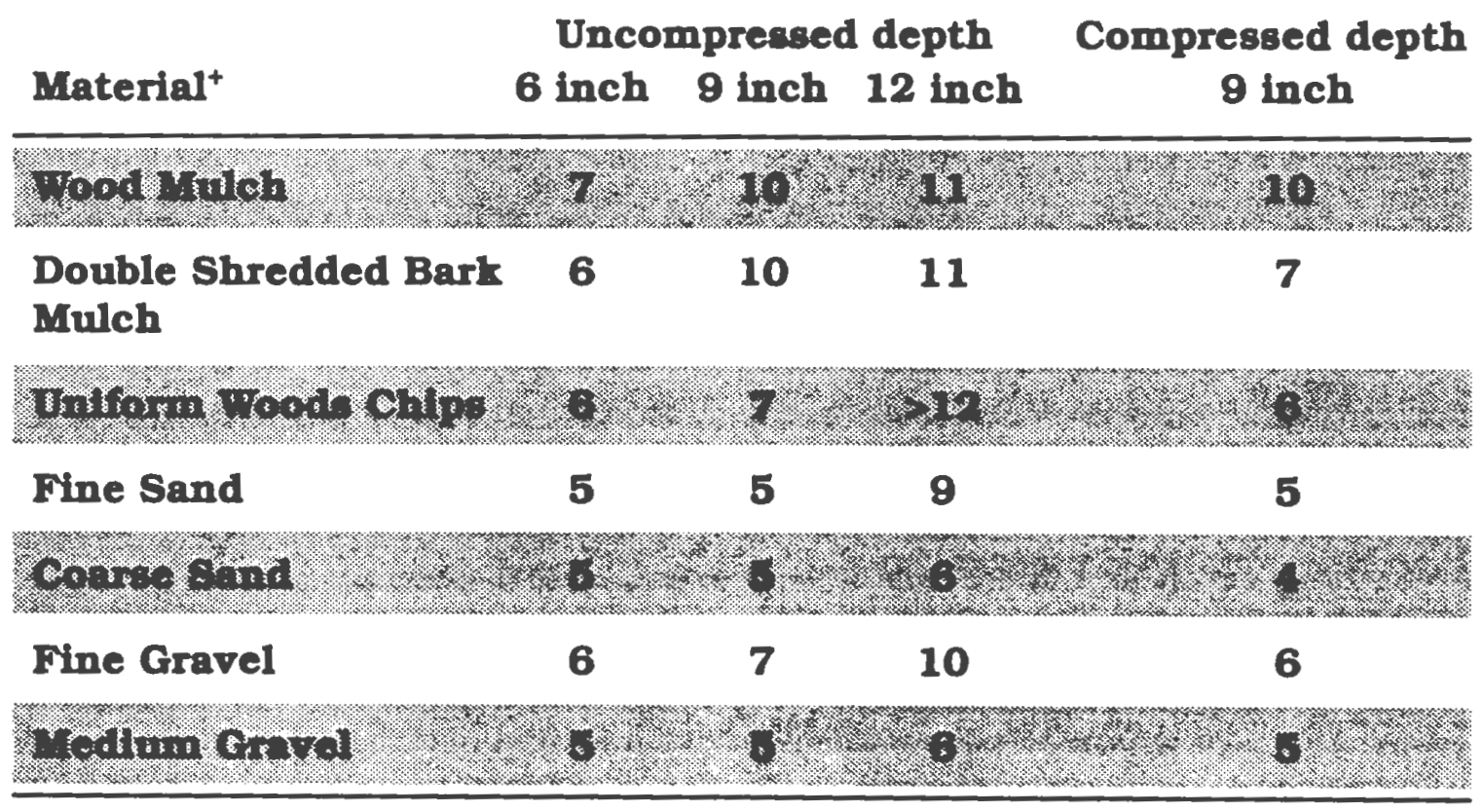

+ Bee Appendix D for descriptioni of the loose-6ll materials

The critical heights shown in the above table may be used as a guide in selecting the type and depth of loose-ril materials that will provide the necessary safety for equipment of various heights. There may be other loose-fill matertals such as bark nuggets or shredded tires that have shock absorbing properties equivalent to those in the above table. However. no tests have been conducted on these materials by CPSC staff.

The depth of any loose fill material could be reduced during use resulting in different shock-absorbing properties. For this reason, a margin of safety should be considered in selecting a type and depth of material for a specific use.

\subsection{Accesalbillts to Individuris With Dianblitiles}

The Americans with Disablities Act of 19900 prohtbits discrimination on the basis of disability in employment. public services, transportation. public accommodations - tncluding many services operated by prtvate entities and telecommunications. Title III of the legislation includes within the definition of public accommodation; "a park, 200, amusement park, or other place of recreation": "a school. Including nursery schools": "a day care center"; and "a gymnasjum. health spa. or other places of exercise or recreation."

Specific Federal requirements for accessiblity to playgrounds by individuals with disabilities are expected to be published.

The Department of Parks and Recreation for the State of Callfornta has advised that after January 1, 1991. regulations requiring that all types of play acturity in new and redone play areas must be accesslble to individuals with disabillities. Other states may stmilarly issue accessibillty requirements. Playground designers, installers and operators should determine what 
Federal and State requitrements for accessibility are in effect. These requirements could necessitate changes to exdsting playgrounds as well as when new playgrounds are planned or exdsting playgrounds refurbished.

\subsection{Other Chnracteristics of Burfacing Materials}

Selection of a surfacing material for a specific location may be governed by the environmental conditions at that location. Appendix C lists some characteristics of surfacing materials that may influence the choice for a particular playground.

\section{USE ZONES FOR EQULPMENT}

The use zone for each plece of equipment is made up of two parts:

(1) the Fall Zone - an area under and around the equipment where protective surfacing is required, and.

(2) the Noencroachment Zone - an additional area beyond the fall zone where children using the equipment can be expected to move about and should have no encroaching obstacles.

With the exception of spring rocking equipment, equipment under 24 inches in height, and the zone between adjacent swings (see Section 11.1.3). the fall zones of adjacent pieces of equipment should not overlap.

However, adjacent pleces of equipment may share a single no-encroachment zone.

Regardless of the type of equipment, the use zone should be free of obstacles that chlldren could run into or fall on top of and thus be injured. For example. there should not be any vertical posts or other objects protruding from the ground onto which a child may fall.

11.1 Recommendations for Fall Zone 11.1.1 8tationng Equipment
The fall zone should extend a minimum of 6 feet in all directions from the perimeter of stationary playground equipment.

\subsection{2 sudee}

The fall zone in front of the access and to the sides of a slide should extend a minimum distance of 6 feet from the perimeter of the equipment. Note: This does not apply to embankment slides.

The fall zone in front of the exit of a slide should extend a mintmum distance of 6 feet from the end of the slide chute or for a distance of $\mathrm{H}+4$ feet whichever is the greater. ( $H$ is the height of the slide platform. ) The $\mathrm{H}+4$ foot measurement is made from a potnt on the chute where the gradient has been reduced to $5^{\circ}$ from the hortzontal (see Figures 16a-b, below).

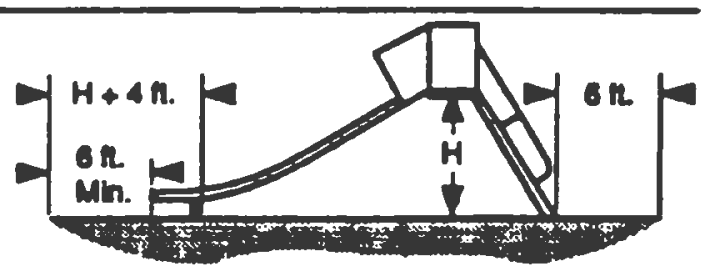

Figure 162. Blevation: Free-tanding Blide wth Fall zones

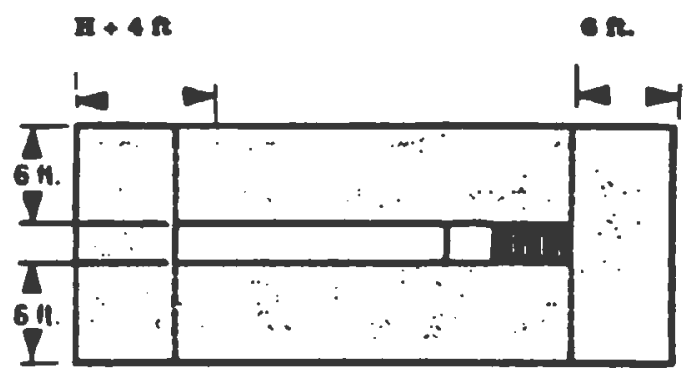

Mgure 16b. Plan: Free-standing slide with Fall zones

\subsubsection{Bingle Ards 8wing}

Because children may deliberately attempt to exdt from a single axds swing while it is in motion, the fall zone in front of and behind the single axis swing should be greater than to the 
sides of such a swing. It is recommended that the fall zone extend to the front and rear of a single axds swing a minimum distance of $2 H$. ( $H$ is the height of the pivot point above the surfacing materal measured from a point directly beneath the pivot on the supporting structure - see Figures $17 a-b$, shown on the right.)

The fall zone to the sides of a single axis swing should extend a mintmum of 6 feet from the perimeter of the swing structure in accordance with the general recommendation for fall zones for stationary equipment. This 6 foot zone may overlap that of an adjacent swing structure.

\subsubsection{Multiple Ads Bwing}

The fall zone for multuple axds swings should extend in all directions from a point directly beneath the pivot point for a minimum distance of $L+6$ feet. ( $L$ is the length of the suspending members - see Figures 18a-b, shown on the right). In addition, the fall zone should extend a mintmum of 6 feet from the perimeter of the supporting structure. This 6 foot pertmeter fall zone may overlap that of an adjacent swing structure.

\subsubsection{Merry-go-rounds}

The fall zone for merry-go-rounds should extend 6 feet beyond the pertmeter of the platform.

\subsubsection{8pring Rocking Equipment}

The fall zone for spring rocking equipment should extend a minimum of 6 feet from the "at rest" pertmeter of the equipment. Adjacent spring rockers with a maxdmum seat height of 24 tnches may share the same fall zone.

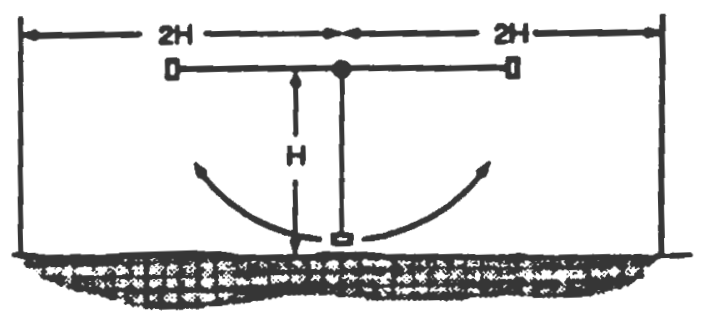

Figure 17a. Elevation: Singe Ads 8wing with Fall zone

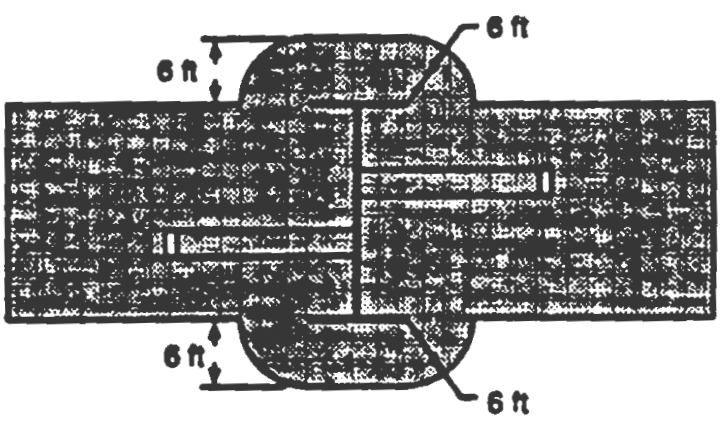

Figure 17b. Plan: Single Ads Swing With Fall Zone

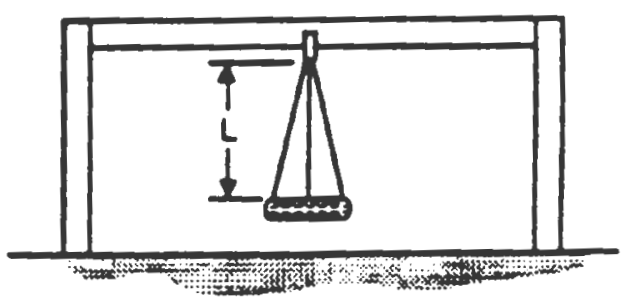

Figure 182. Elevation: Multiple Ads Swing

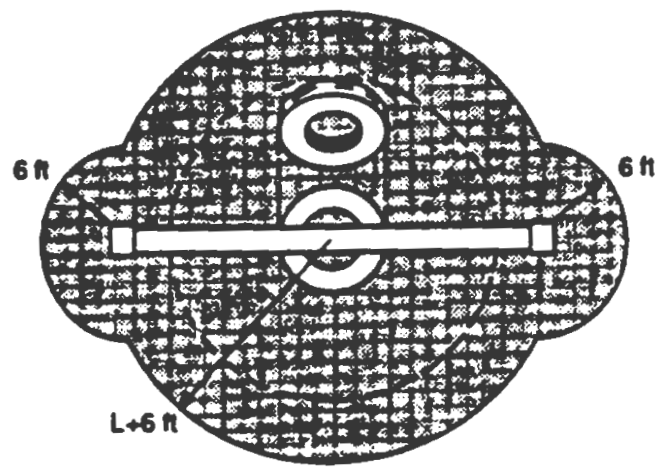

Figure 18b. Plan: Multiple Ads Swing With Fall Zone 


\subsubsection{Composite Equipment}

The above recommendations for individual pieces of equipment should be used as a guide in establishing the fall zones around pieces of composite playground equipment.

It is recommended that single axds swings not be a part of a composite structure.

\subsection{Recommendations for the No-encroachment Zone}

No specific dimensions can be recommended for the no-encroachment zone around individual pleces of playground equipment. These dimensions will vary according to the types of adjacent pleces of equipment and their orientation with respect to one another.

For example, the recommended fall zone at the side of both a slide and a swing is 6 feet. since fall zones should not overlap (with the exception of certain adjacent spring rockers). a slide could be placed with its side no closer than 12 feet to the side of a swing. Therefore, there may be no need to add an additional no-encroachment zone. Conversely. It would not be desirable to have a slide ext facing the front or rear of single axds swing.

No-encroachment zones extending beyond the fall zones are recommended for moving equipment or equipment from which the child is in motton as he or she exdts. This allows more space for children to regain their balance upon exding the equipment and also provides added protection against other chtldren running thto a moving part.

For a single axis swing. It is recommended that there be a barrier beyond the fall zone in front of the swing if it is located in a playground facing other pleces of equipment.

\section{REFERENCES}

1. Ratte, Donna J., Morrison, Melante L., Lerner, Nell D., Development of Human Factors Criteria for Playground Equipment Safety: COMSIS

Corporation. March 1990.

2.Tlnsworth. Deborah Kale. Kramer, John T., Playground Equipment-Related Injuries and Deaths: U. S. Consumer Product Safety Commtssion. Washington D.C. 20207. Aprll 1990.

3. Title 16. Code of Federal Regulations. Part 1303; Ban of Lead-Containing Paint and Certain Consumer Products Bearing Lead-Containing Paint: Superintendent of Documents, U.S. Government Printing Office. Washington, D.C. 20402.

4. Lee, Brian C.. Estimate of Risk of Skin Cancer from Dislodgeable Arsenic on Pressure Treated Wood Playground Equipment: U.S. Consumer Product Safety Commission. Washington, D.C. 20207. January 1990.

5. Consumer Information Sheet Inorganic Arsenical Pressure-Treated Wood; American Wood Preservers Instutute, 1945 Gallows Road, Suite 550. Vienna, Virginia 22182.

6. Collantes, Margarta, Evaluation of the Importance of Usting Head Inyury Criterion (HIC) to Estimate the Liketthood of Head Impact Injury as a Result of a Fall Onto Playground Surface Materlals; U.S. Consumer Product Safety

Commission. Washington, D.C. 20207. October 1990.

7. Standard Specification for Impact Attenuation of Surface Systems Under and Around Playground Equipment, ASTM F1292: ASTM, 1916 Race Street. Phtladelphta, PA 19103. 


\section{APPENDIX B}

Blank NRPA's Playground Safety Audit Form 


\section{Background Information}

Name of Playground/Park Date of Inspection

Street or Intersection Start Time Finish Time

Name(s) of person(s) conducting audit (please print):

Supervisor Name Date Signature

\section{General Environment}

1. Category of playground (circle all that apply):
a. Public school
b. Private school
c. Public recreation facility
d. Neighborhood park/tot lot
e. Day care
f. Community park

g. Other (please specify)

2. Type and amount of equipment. Circle each type of equipment that exists at the playground site. Indicate in the box the number of equipment pieces that exists (these numbers not used in hazard totals):

A. Composite play
structure:
1. Firemen's
pole
2. Flexible
climber
3. Rigid
climber
4. Ramps
5. Clatter
bridge
6. Horizontal
ladder
7. Track ride
8. Vertical
rung ladder
9. Stairway
10. Learning
Wall/Play
Panel
11. Slide
12. Other

13. Other

-

14. Other

15. Other

.

B. Free Standing Equipment

1. Swings (tofro)

2. Tire swings (Rotating)

3. Seesaws

4. Multipurpose/ hard surface (basketball, etc.) area

Climbers (Rigid)

6. Spring rocking equipment

7. Chin-up bars/ Turning bars

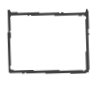

8. Balance beam

9. Slides

10. Merry-goround/Whirl

11. Sandboxes/ Sand areas

12. Benches
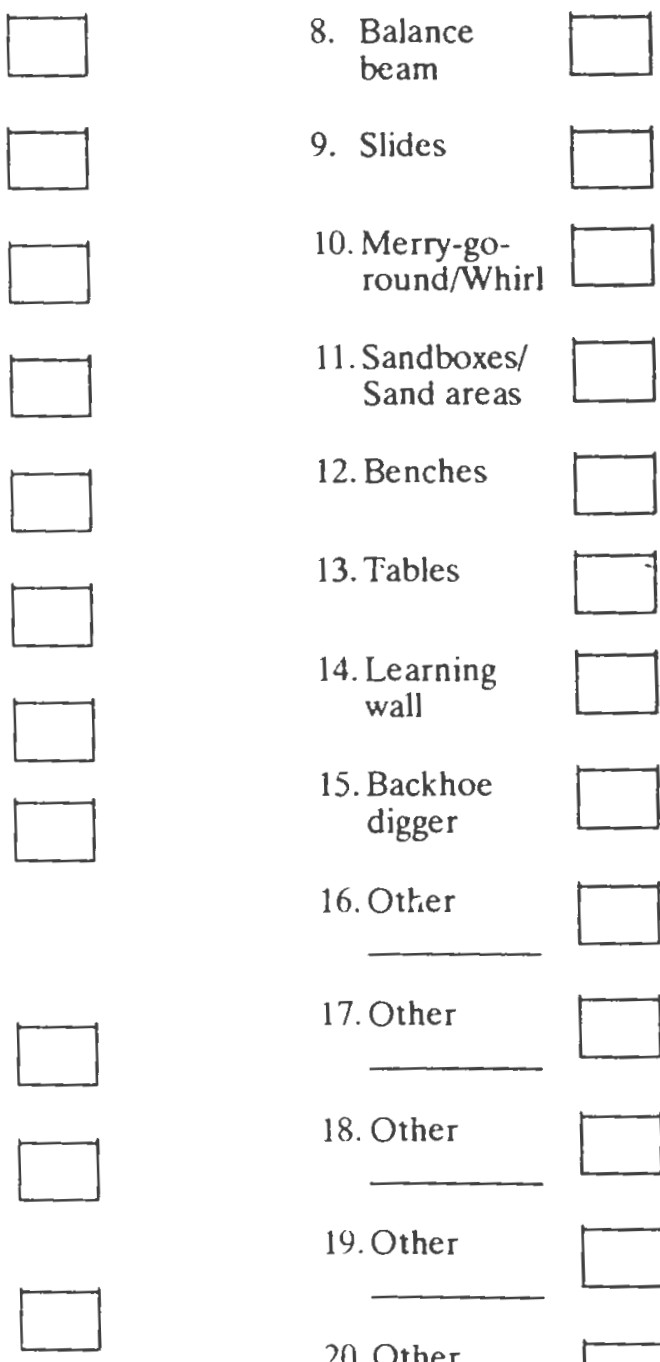

13. Tables

14. Learning wall

15. Backhoe digger

16. Other

17. Other

18. Other

19. Other
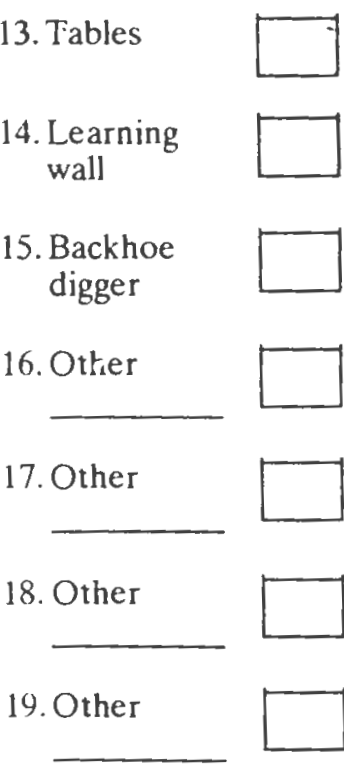

20. Other 
3. Playground border hazards:

Directions: Determine which playground border hazards exist and circle them. In the second column, indicate the actual distance the hazard is from the playground border. In the third column, assign hazard index points based on the distance each potential border hazard is from the nearest playground border (see Key to Border Hazard Points).

\begin{tabular}{|l|}
\hline Key to Border Hazard Points: \\
\hline Within 100 feet ( 5 points) \\
$101-199$ feet ( 2 points) \\
200 feet or more ( 0 points) \\
\hline
\end{tabular}

\begin{tabular}{|l|l|l|}
\hline \multicolumn{1}{|c|}{ Playground Border Hazards } & $\begin{array}{c}\text { Distance } \\
\text { From } \\
\text { Playground } \\
\text { Edge }\end{array}$ & $\begin{array}{c}\text { Hazard } \\
\text { Index } \\
\text { Points }\end{array}$ \\
\hline 1st public street & & \\
\hline 2nd public street & & \\
\hline 3rd public street & & \\
\hline 4th public street & & \\
\hline Streets with heavy traffic & & \\
\hline Water (ponds/stream/drainage ditch) & & \\
\hline Soccer/football field & & \\
\hline Baseball/softball field from home plate & & \\
\hline Basketball court & & \\
\hline Parking lot & & \\
\hline Railroad tracks & & \\
\hline Trees (not pruned up at least 7') & & \\
\hline Golf course & & \\
\hline Other (specify) & & \\
\hline
\end{tabular}




\section{Playground Condition}

\begin{tabular}{l|c|c|}
$\begin{array}{l}\text { Possible } \\
\text { Hazard }\end{array}$ & Hazard & \\
Index & Points & \\
Points & Given & Comments \\
\hline
\end{tabular}

\section{General Environment Hazards}

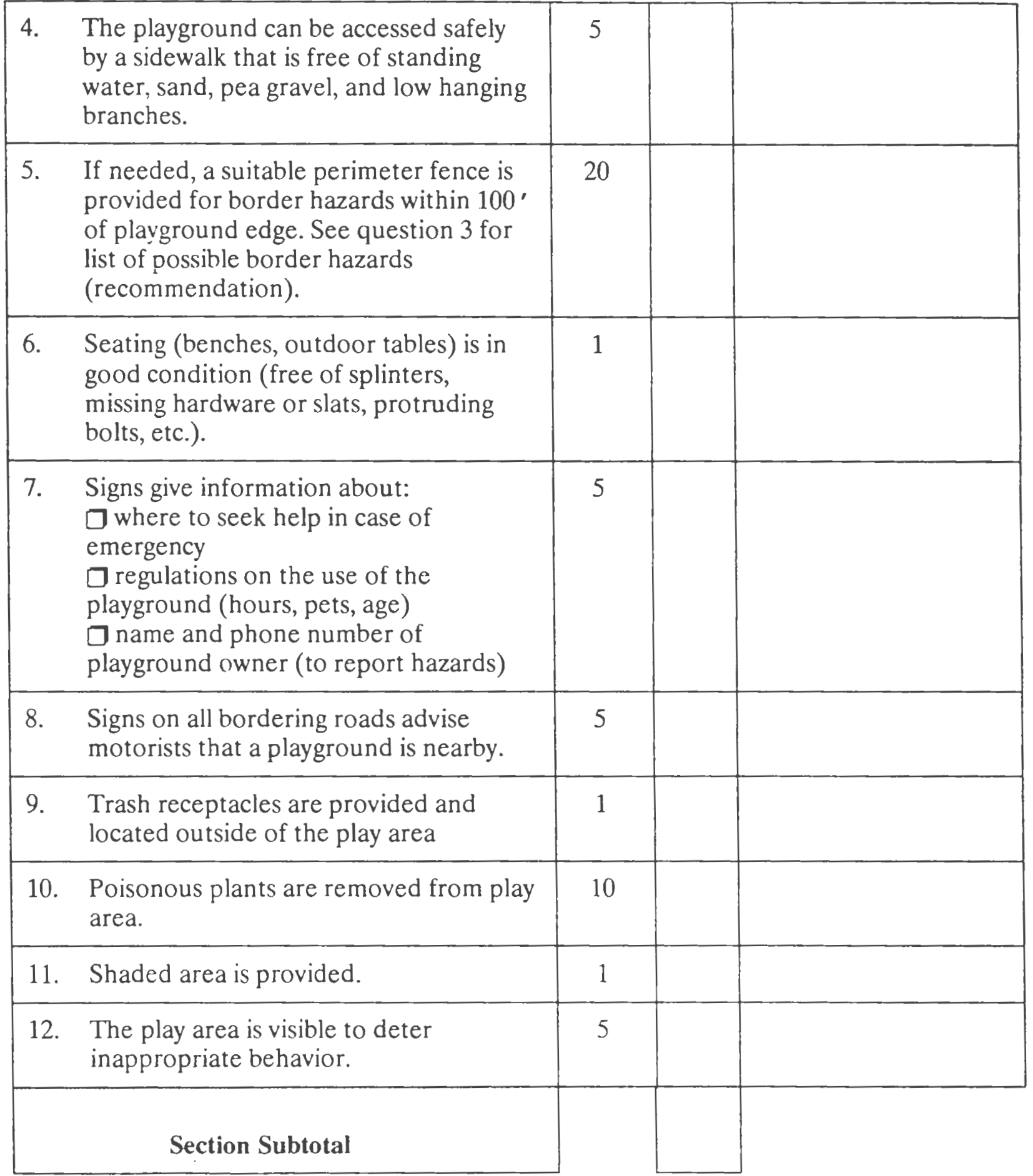


(1) 1992 by NRPA

\section{Age/Size Appropriateness Design}

\begin{tabular}{|l|l|l|l|}
\hline 13. $\begin{array}{l}\text { Are the children who use the equipment } \\
\text { of age/developmental level for which the } \\
\text { equipment was designed (i.e. ages 2-5 } \\
\text { and 6-12)? }\end{array}$ & 10 & 20 & \\
\hline $\begin{array}{l}\text { The playground design separates } \\
\text { younger users (2-5) through } \\
\text { appropriately selected equipment. }\end{array}$ & 20 & & \\
\hline $\begin{array}{l}\text { The play arca has signage that informs } \\
\text { users of the intended user age group. }\end{array}$ & & \\
\hline
\end{tabular}

\section{Accessibility Design}

\begin{tabular}{|c|c|c|}
\hline 16. & $\begin{array}{l}\text { The playground is accessible to people } \\
\text { with disabilities (access to and around } \\
\text { the playground area is at least } 60 \text { "wide) }\end{array}$ & 5 \\
\hline 17. & $\begin{array}{l}\text { The playground use zone has an } \\
\text { accessible safety surface. }\end{array}$ & 10 \\
\hline 18. & $\begin{array}{l}\text { Accessible restroom facilities are located } \\
\text { nearby. }\end{array}$ & 1 \\
\hline 19. & $\begin{array}{l}\text { Accessible seating is located in the play } \\
\text { area. }\end{array}$ & 1 \\
\hline 20. & $\begin{array}{l}\text { Accessible shade is available in the play } \\
\text { area. }\end{array}$ & 1 \\
\hline 21. & $\begin{array}{l}\text { An accessible source of drinking water is } \\
\text { available in or near the play area. }\end{array}$ & 1 \\
\hline & Section Subtotal & \\
\hline
\end{tabular}




\section{Playground Protective Surface}

\begin{tabular}{|c|c|c|}
\hline 22. & $\begin{array}{l}\text { All elevated play equipment (slides, } \\
\text { swings, bridges, seesaws, climbing } \\
\text { apparatus, etc.) has } 12^{\prime \prime} \text { of loose fill or } \\
\text { impact-absorbing material underneath } \\
\text { and extending a minimum of } 6 \text { ' around } \\
\text { the structure. Surfacing materials, such } \\
\text { as sand, pea gravel (round } 1 / 8^{\prime \prime} \text { pellets), } \\
\text { wood chips, or manufactured unitary } \\
\text { surfaces pass the } 200 \text { G test from the } \\
\text { highest accessible part of the equipment. } \\
\text { (ASTM 1292) }\end{array}$ & 20 \\
\hline 23. & $\begin{array}{l}\text { Surfaces are checked at least weekly and } \\
\text { raked to prevent them from becoming } \\
\text { packed down and to remove hidden } \\
\text { hazards (e.g. litter, sharp objects, animal } \\
\text { feces). (Daily }=0 \text { points, weekly }=10 \\
\text { points, monthly }=20 \text { points, } \\
\text { seasonally }=30 \text { points). }\end{array}$ & $\begin{array}{l}30 \\
20 \\
10 \\
0\end{array}$ \\
\hline 24. & $\begin{array}{l}\text { Loose materials are replenished as } \\
\text { needed to maintain adequate depth and } \\
\text { coverage (annually }=10 \text {, seasonally }=5 \text {, } \\
\text { monthly or less }=0 \text { ). }\end{array}$ & $\begin{array}{l}10 \\
5 \\
0\end{array}$ \\
\hline 25. & $\begin{array}{l}\text { Standing water is not found within any } \\
\text { of the use zones. }\end{array}$ & 20 \\
\hline & Section Subtotal & \\
\hline
\end{tabular}

\section{Fall Zone/Use Zone}

26. All swings have adequate use zones (belt, tire, baby, others). Refer to CPSC guidelines pages 22-23 for additional information. This entire area should be covered with impact absorbing surface material.

27. Swings are at least 24 "from each other and $30 "$ away from the frame.

28. Slides have adequate space from other equipment at the bottom (height of slide plus $4^{\prime}$, or $6^{\prime}$, whichever is greater).

\begin{tabular}{|l|l|}
\hline & \\
\hline & \\
\hline & \\
\hline
\end{tabular}




\begin{tabular}{|c|c|c|}
\hline 29. & $\begin{array}{l}\text { There is a minimum of } 6^{\prime} \text { between all } \\
\text { equipment and fixed objects (trees, } \\
\text { buildings, etc.). }\end{array}$ & 20 \\
\hline 30. & $\begin{array}{l}\text { Boundaries or barriers used between } \\
\text { pieces of equipment are installed so as } \\
\text { not to create a trip hazard and are free } \\
\text { of protrusions, splinters, sharp edges, } \\
\text { etc. }\end{array}$ & 10 \\
\hline 31. & $\begin{array}{l}\text { Areas for active play (e.g. playground } \\
\text { equipment, bike riding, running games) } \\
\text { are located away from area for quiet } \\
\text { activities (e.g. sandbox, outdoor tables). }\end{array}$ & 10 \\
\hline & Section Subtotal & \\
\hline
\end{tabular}

IMPORTANT: For the following audit sections, if multiple types of the same equipment exists (such as two swing sets), you can apply the questions to all multiple pieces of equipment as a whole. However, full hazard index points should be applied if a negative response exists on any single piece of equipment. Also, deficiencies on a specific piece of equipment should be noted in the comments section for repair or future consideration.

\section{Slide}

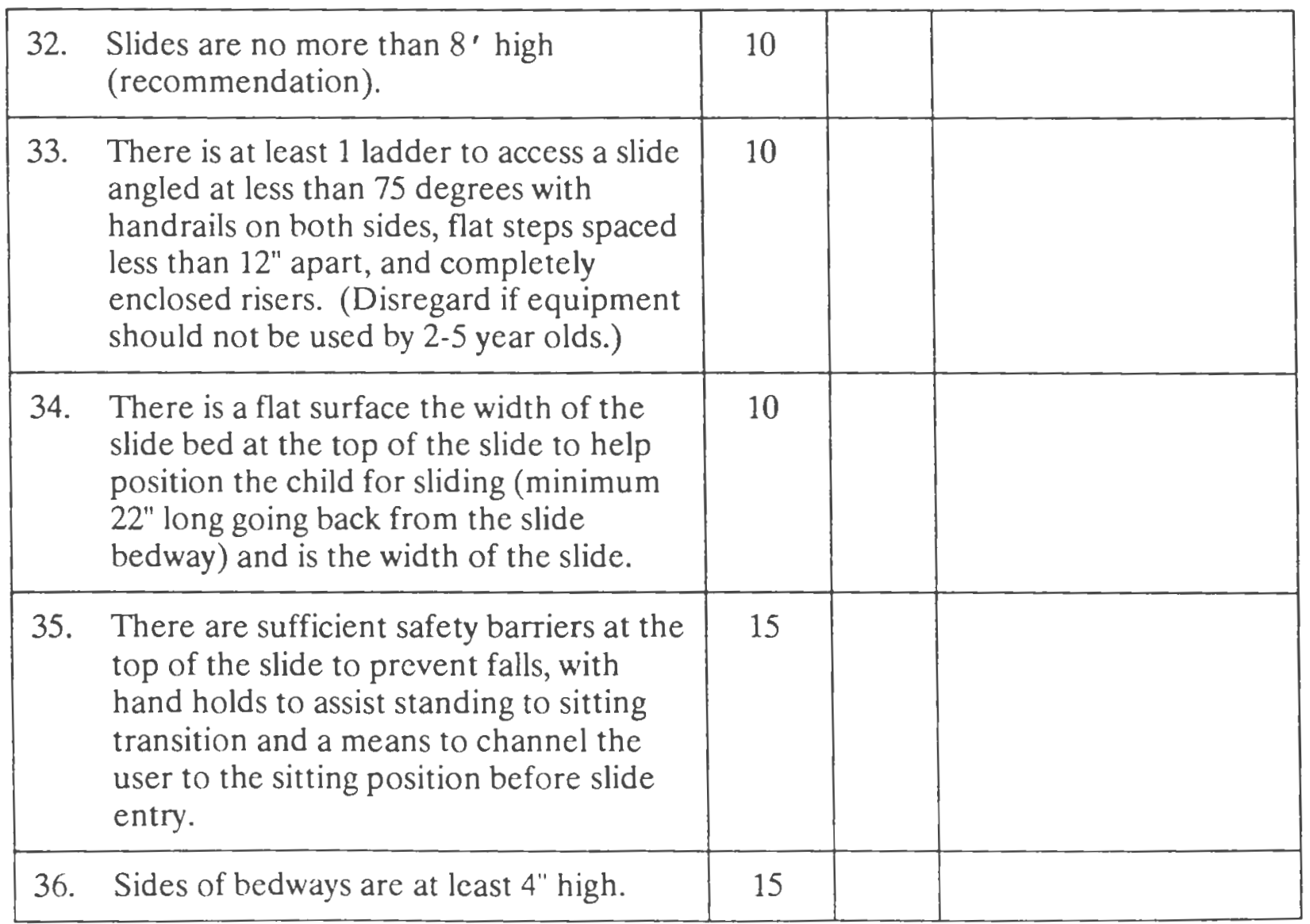




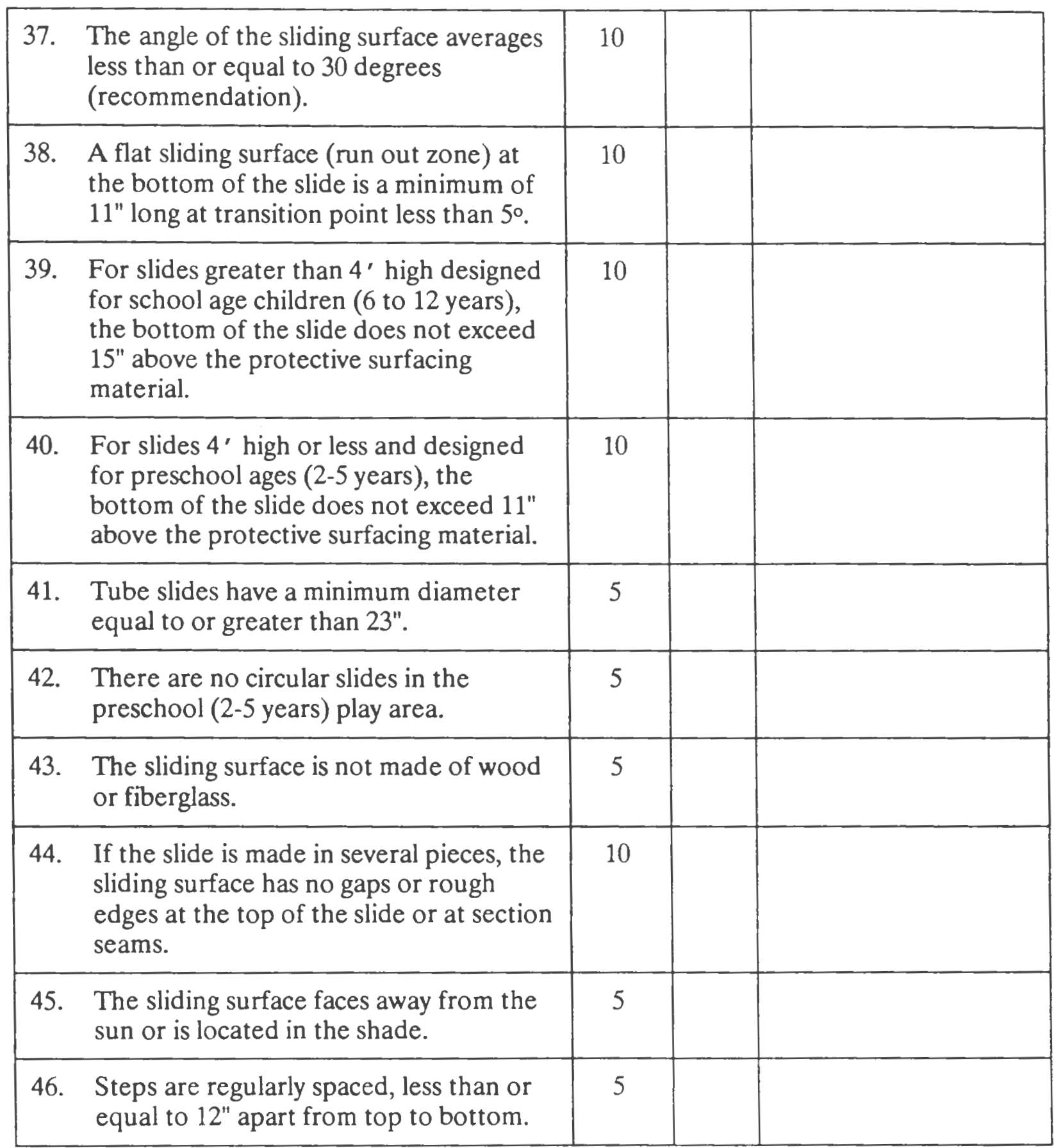


- 1992 by NRPA

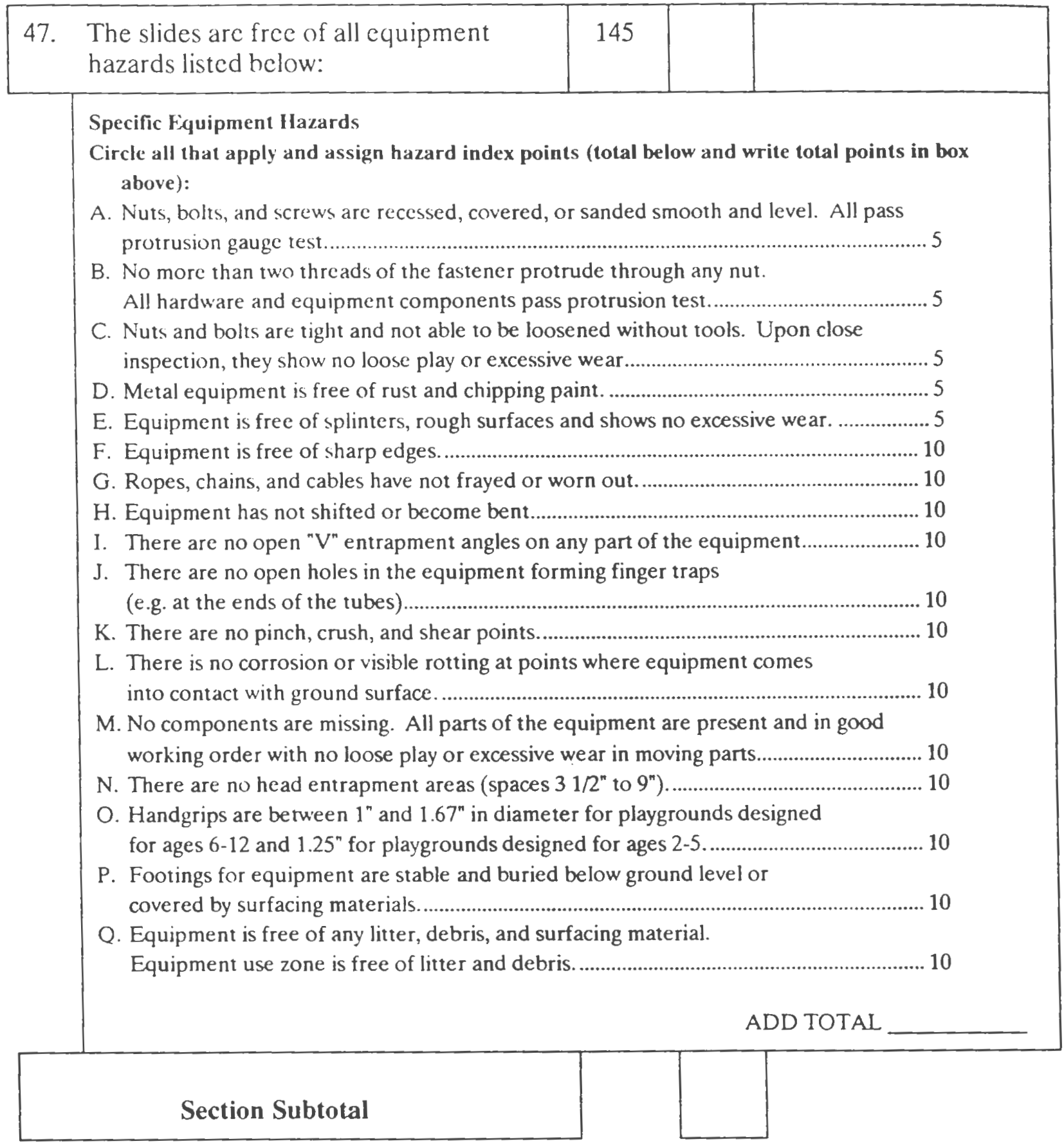




\section{Climbing Equipment}

\begin{tabular}{|c|c|c|c|}
\hline 48. & Handholds stay in place when grasped. & 5 & \\
\hline 49. & $\begin{array}{l}\text { Accessible equipment height (platform, } \\
\text { deck, etc.) does not exceed } 4 \text { ' for } 2 \text { to } 5 \\
\text { year old users. }\end{array}$ & 5 & \\
\hline 50 & $\begin{array}{l}\text { Climbers have regularly spaced } \\
\text { footholds (less than or equal to } 12^{\prime \prime} \\
\text { apart) from top to bottom. }\end{array}$ & 5 & \\
\hline 51. & $\begin{array}{l}\text { Children have an easy, safe way to } \\
\text { descend equipment when they reach the } \\
\text { top. }\end{array}$ & 10 & \\
\hline 52. & $\begin{array}{l}\text { Climbing bars and handrails are between } \\
1 " \text { and } 1.67^{\prime \prime} \text { in diameter. }\end{array}$ & 5 & \\
\hline 53. & $\begin{array}{l}\text { There is a } 29 \text { " high (minimum) } \\
\text { protective perimeter barrier around pre- } \\
\text { school }(2-5) \text { equipment that is more } \\
\text { than } 30^{\prime \prime} \text { above the underlying surface. }\end{array}$ & 10 & \\
\hline 54. & $\begin{array}{l}\text { There is a } 38 \text { " high (minimum) } \\
\text { protective perimeter barrier on all } \\
\text { elevated surfaces } 48 \text { "above the } \\
\text { underlying surface for school age } \\
\text { children's (6-12) equipment. }\end{array}$ & 10 & \\
\hline 55. & $\begin{array}{l}\text { The space between slats of protective } \\
\text { barriers is less than } 31 / 2^{\prime \prime}\end{array}$ & 15 & \\
\hline 56. & $\begin{array}{l}\text { Guardrails or protective barriers are } \\
\text { present for all elevated surfaces } 30^{\prime \prime} \\
\text { above the underlying surface for school } \\
\text { age children's (6-12) equipment ( } 38^{\prime \prime} \text { top } \\
\text { edge, } 24^{\prime \prime} \text { high lower edge). }\end{array}$ & 10 & \\
\hline 57. & $\begin{array}{l}\text { Guardrails or protective barriers are } \\
\text { present on all elevated surfaces greater } \\
\text { than } 20^{\prime \prime} \text { above the underlying surface } \\
\text { for ( } 29 \text { " top edge } 23^{\prime \prime} \text { lower edge) } \\
\text { preschool age children's equipment (2- } \\
5 \text { ). }\end{array}$ & 10 & \\
\hline
\end{tabular}

*Refer to CPSC Guidelines for additional information (pages 10-11) for questions 53-57. 


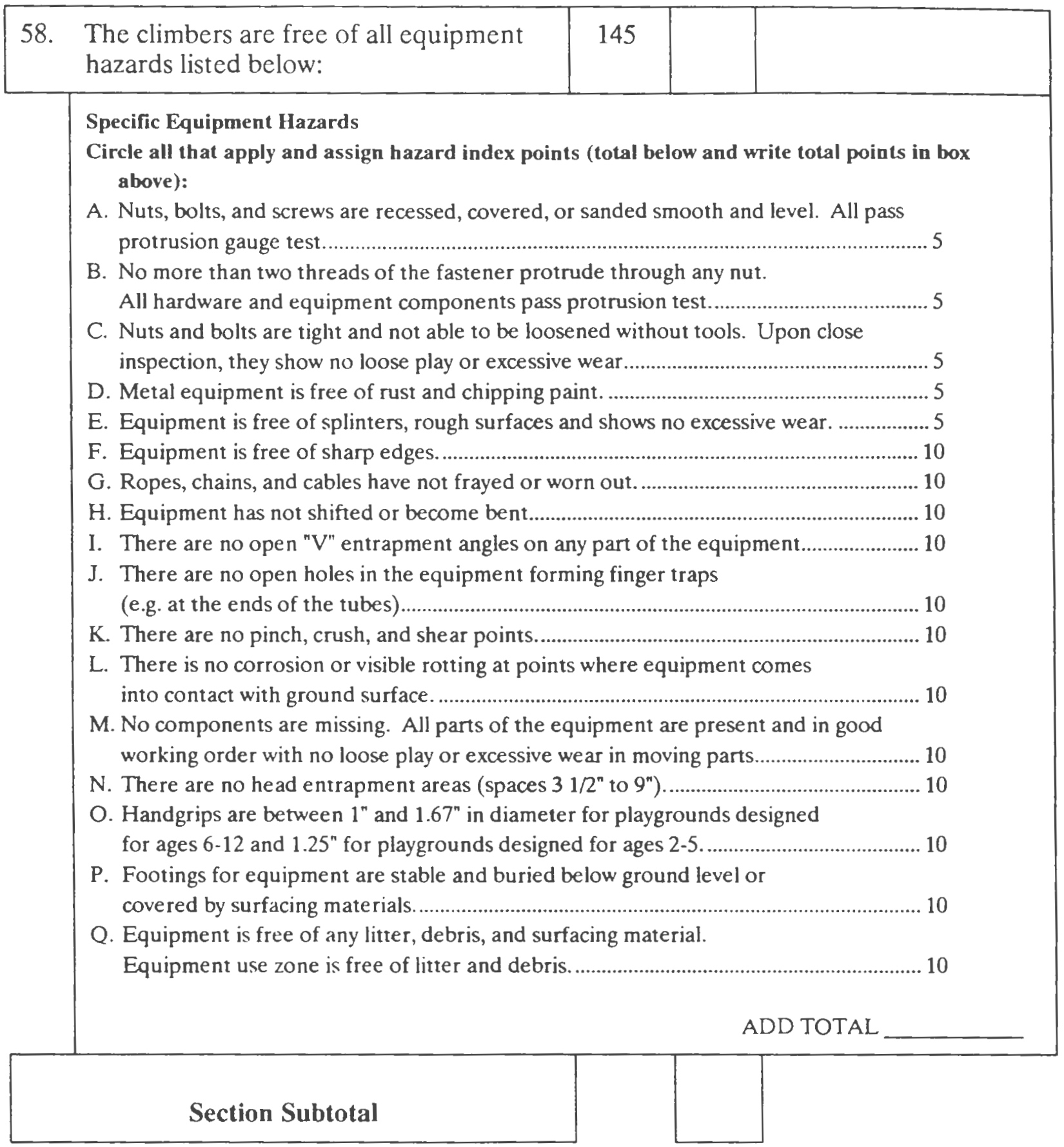

\section{Swing set}

\begin{tabular}{|l|l|l|l|}
\hline 59. $\begin{array}{l}\text { All flying animal figure swings, multiple } \\
\text { occupancy swings (except tire swings), } \\
\text { rope swings, and trapeze bars are } \\
\text { removed from public playgrounds. }\end{array}$ & 20 & & \\
\hline 60. $\begin{array}{l}\text { Lightweight bucket type swing seats are } \\
\text { available for toddlers and children with } \\
\text { disabilities and all openings meet } \\
\text { entrapment criteria. (See Appendix B, } \\
\text { page 25, in CPSC Handbook.) }\end{array}$ & 5 & & \\
\hline
\end{tabular}




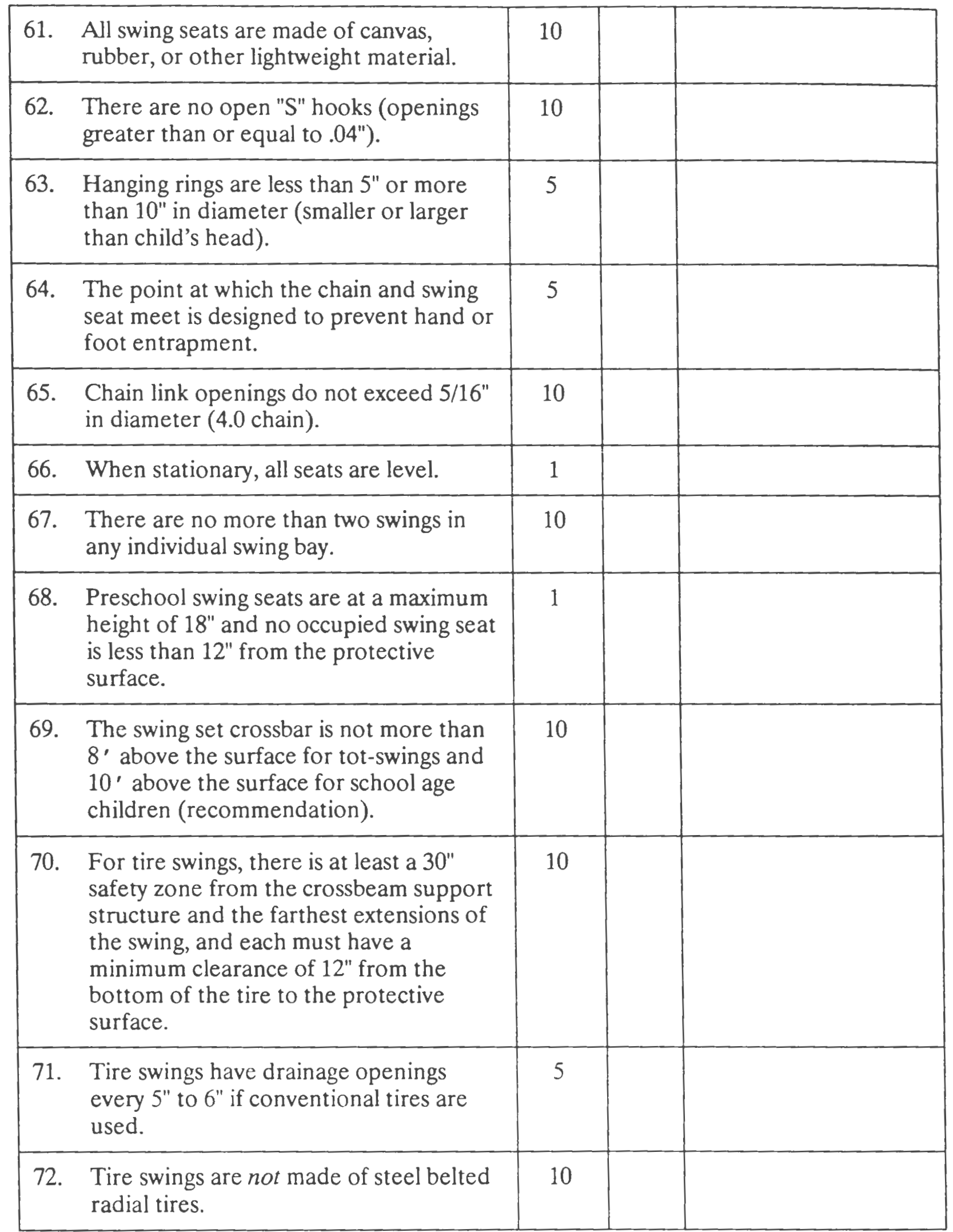




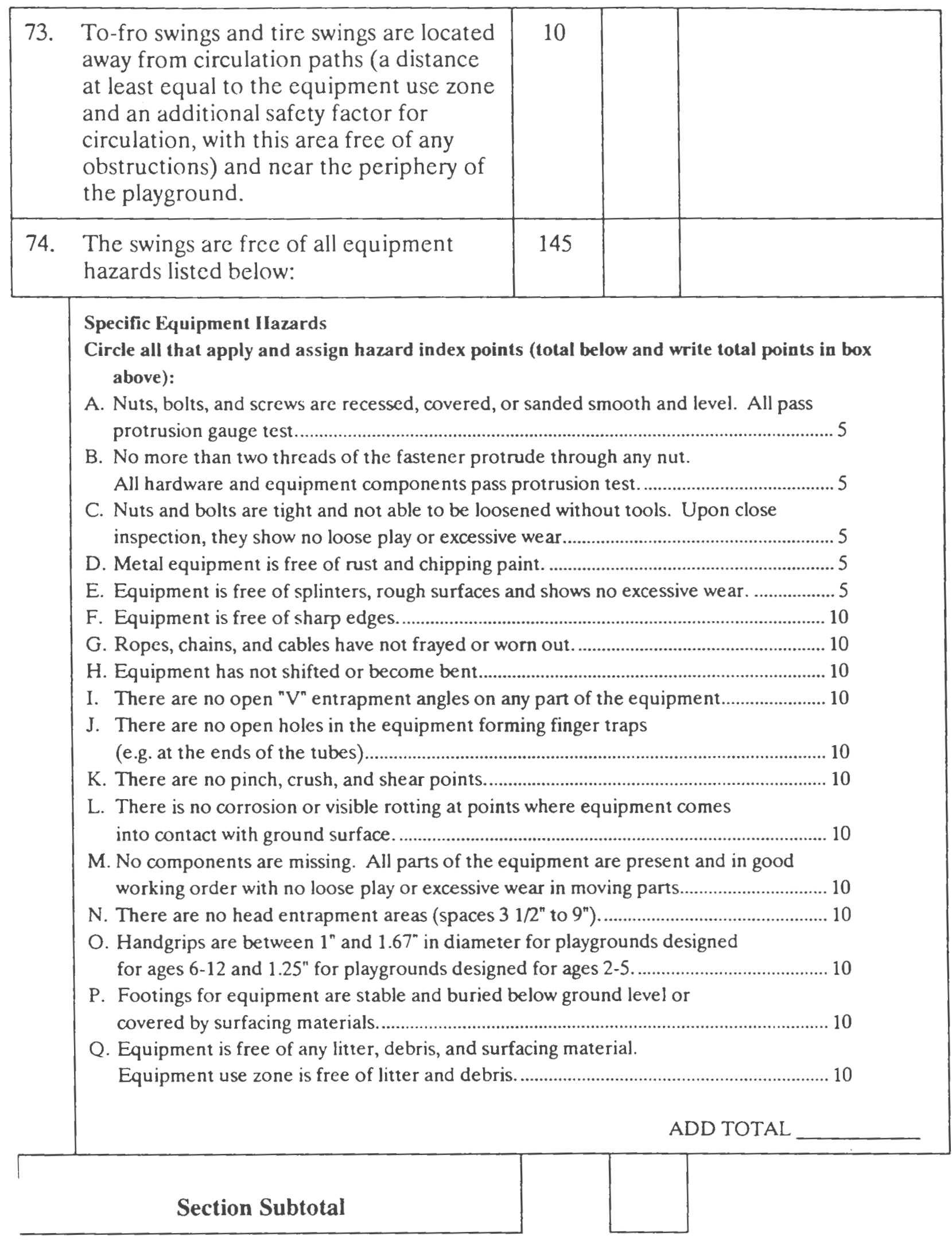




\section{Seesaw}

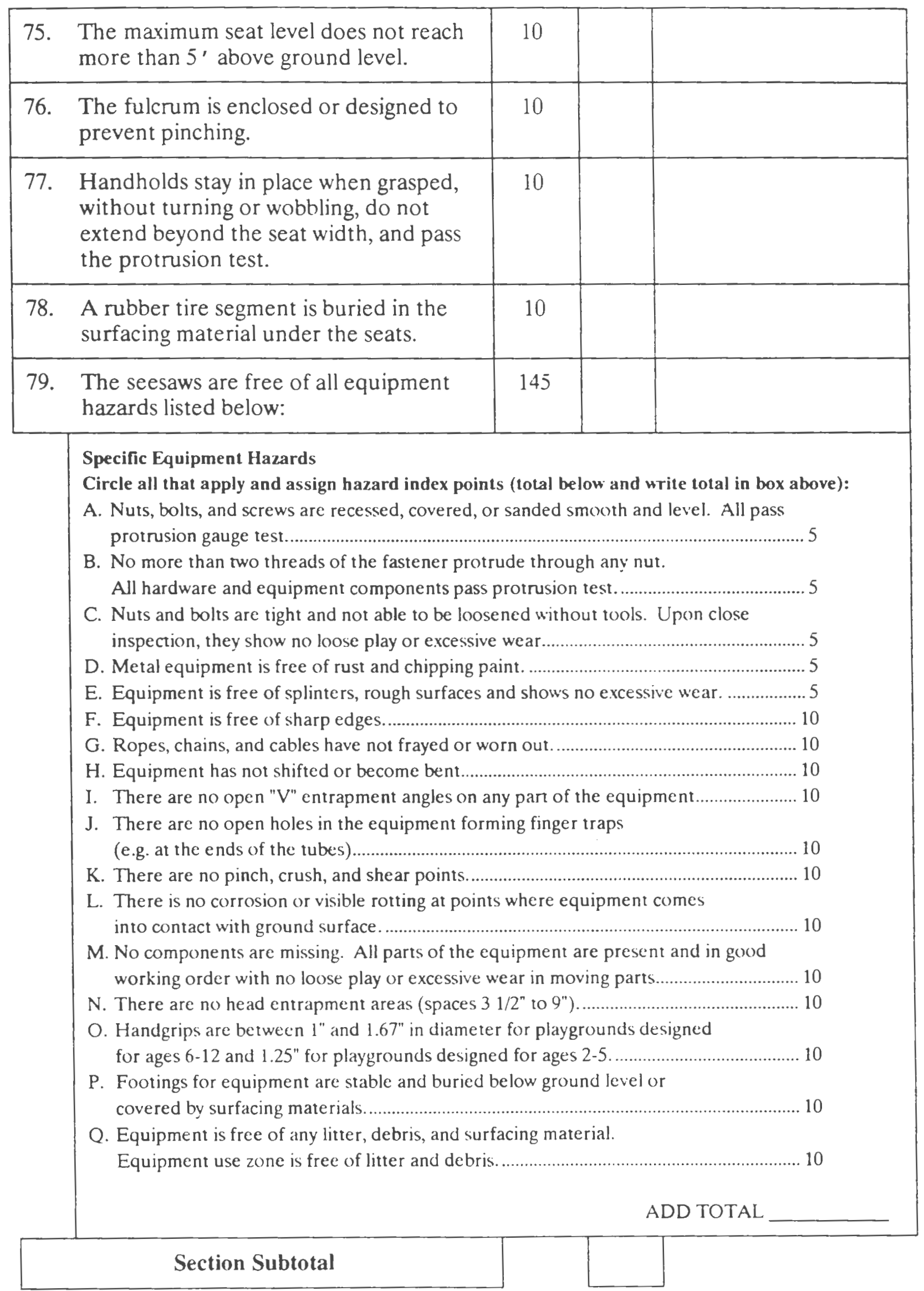




\section{Sand Play Area}

\begin{tabular}{|ll|c|c|c|}
\hline 80. Sand play is located in a shaded area. & 1 & 5 & & \\
\hline 81. $\begin{array}{l}\text { The sand play area is inspected and } \\
\text { raked at least every week for debris and } \\
\text { to provide exposure to air and sun. }\end{array}$ & 5 & 5 & & \\
\hline 82. $\begin{array}{l}\text { If the sand play area is in a box, it is } \\
\text { covered at night to prevent animal } \\
\text { excrement contamination. }\end{array}$ & $\begin{array}{l}\text { The sand play area does not have } \\
\text { standing water. }\end{array}$ & $\begin{array}{l}\text { The sand play area is free of all } \\
\text { equipment hazards listed below: }\end{array}$ & \\
\hline 83. & T4. & & \\
\hline
\end{tabular}

\section{Specific Equipment Hazards}

Circle all that apply and assign hazard index points (total below and write total points in box above):

A. Nuts, bolts, and screws are recessed, covered, or sanded smooth and level. All pass

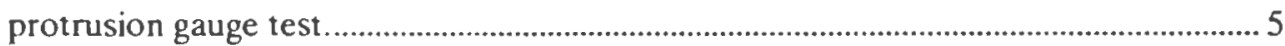

B. No more than two threads of the fastener protrude through any nut. All hardware and equipment components pass protrusion test....................................... 5

C. Nuts and bolts are tight and not able to be loosened without tools. Upon close inspection, they show no loose play or excessive wear......................................................... 5

D. Metal equipment is free of rust and chipping paint. ........................................................... 5

E. Equipment is free of splinters, rough surfaces and shows no excessive wear. ................. 5

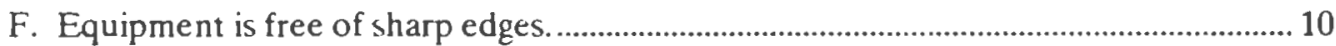

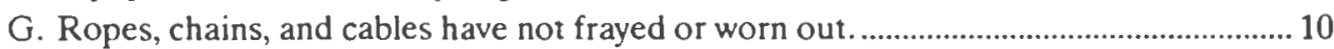

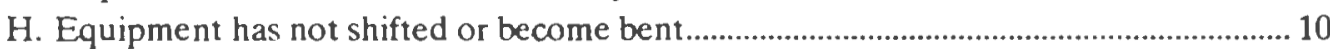

I. There are no open " $\mathrm{V}$ " entrapment angles on any part of the equipment...................... 10

J. There are no open holes in the equipment forming finger traps

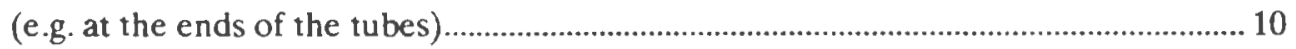

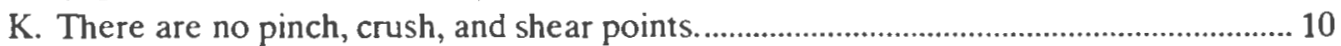

L. There is no corrosion or visible rotting at points where equipment comes

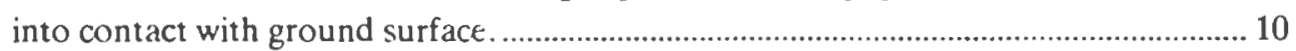

M. No components are missing. All parts of the equipment are present and in good working order with no loose play or excessive wear in moving parts............................... 10

N. There are no head entrapment areas (spaces $31 / 2^{n}$ to $9^{n}$ )............................................ 10

$O$. Handgrips are between $1^{\prime \prime}$ and $1.67^{n}$ in diameter for playgrounds designed for ages 6-12 and $1.25^{\prime \prime}$ for plavgrounds designed for ages 2-5.

P. Footings for equipment are stable and buried below ground level or covered by surfacing materials

Q. Equipment is free of any litter. debris, and surfacing material. Equipment use zone is free of litter and debris. 


\section{Rocking Equipment}

\begin{tabular}{|c|c|c|c|}
\hline 85. & $\begin{array}{l}\text { Seating surfaces are less than } 30^{\prime \prime} \text { above } \\
\text { the protective surfacing. }\end{array}$ & 10 & \\
\hline 86. & $\begin{array}{l}\text { There are no equipment parts that could } \\
\text { cause a pinching or crushing injury. }\end{array}$ & 10 & \\
\hline 87. & $\begin{array}{l}\text { Handholds stay in place when grasped } \\
\text { and pass the protrusion test. }\end{array}$ & 5 & \\
\hline 88. & $\begin{array}{l}\text { Footrests stay in place and pass the } \\
\text { protrusion test. }\end{array}$ & 5 & \\
\hline 89. & $\begin{array}{l}\text { The rocking equipment is free of all } \\
\text { equipment hazards listed below: }\end{array}$ & 145 & \\
\hline & \multicolumn{3}{|c|}{ 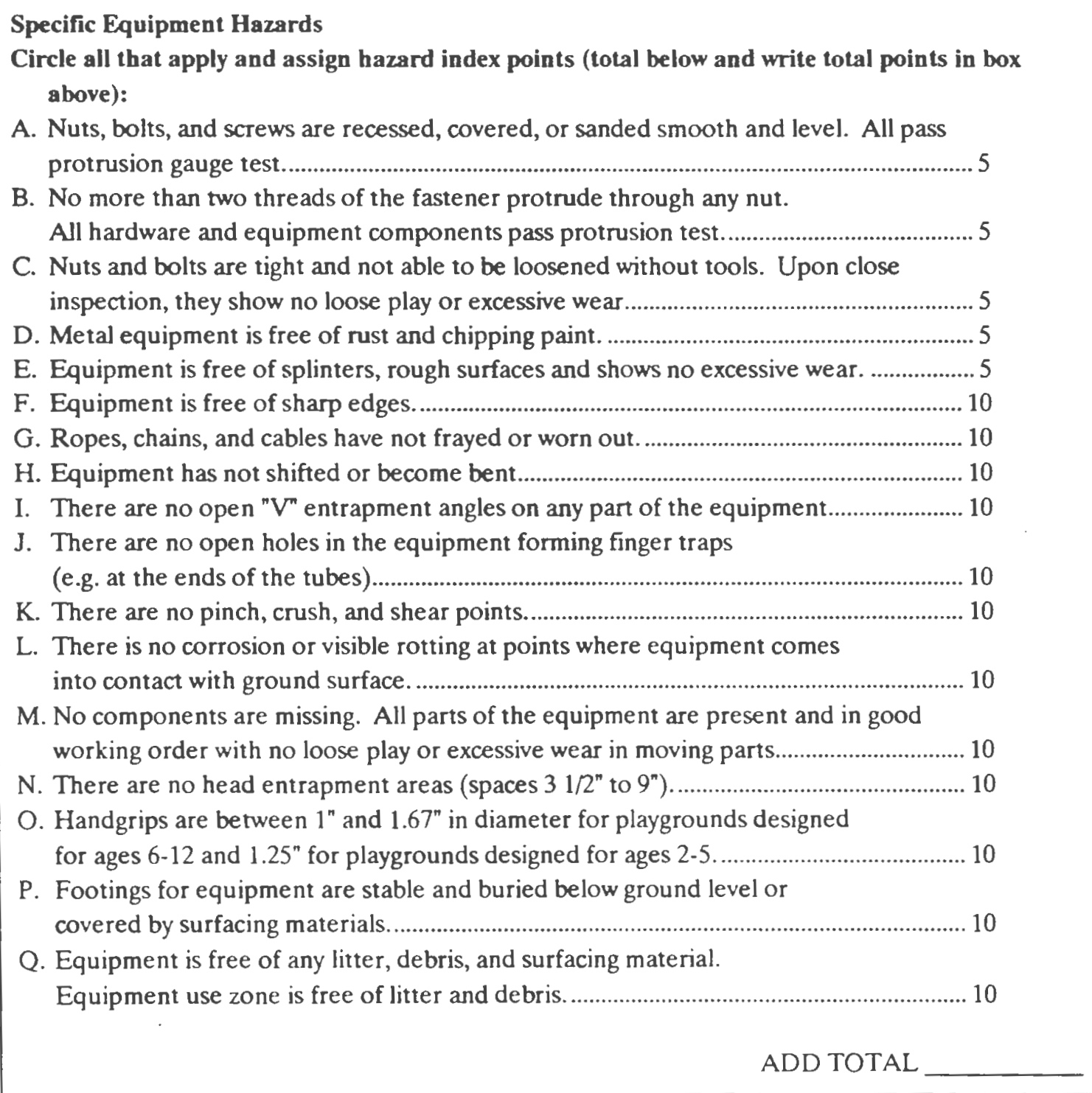 } \\
\hline
\end{tabular}




\section{Crawl Through Tunnel}

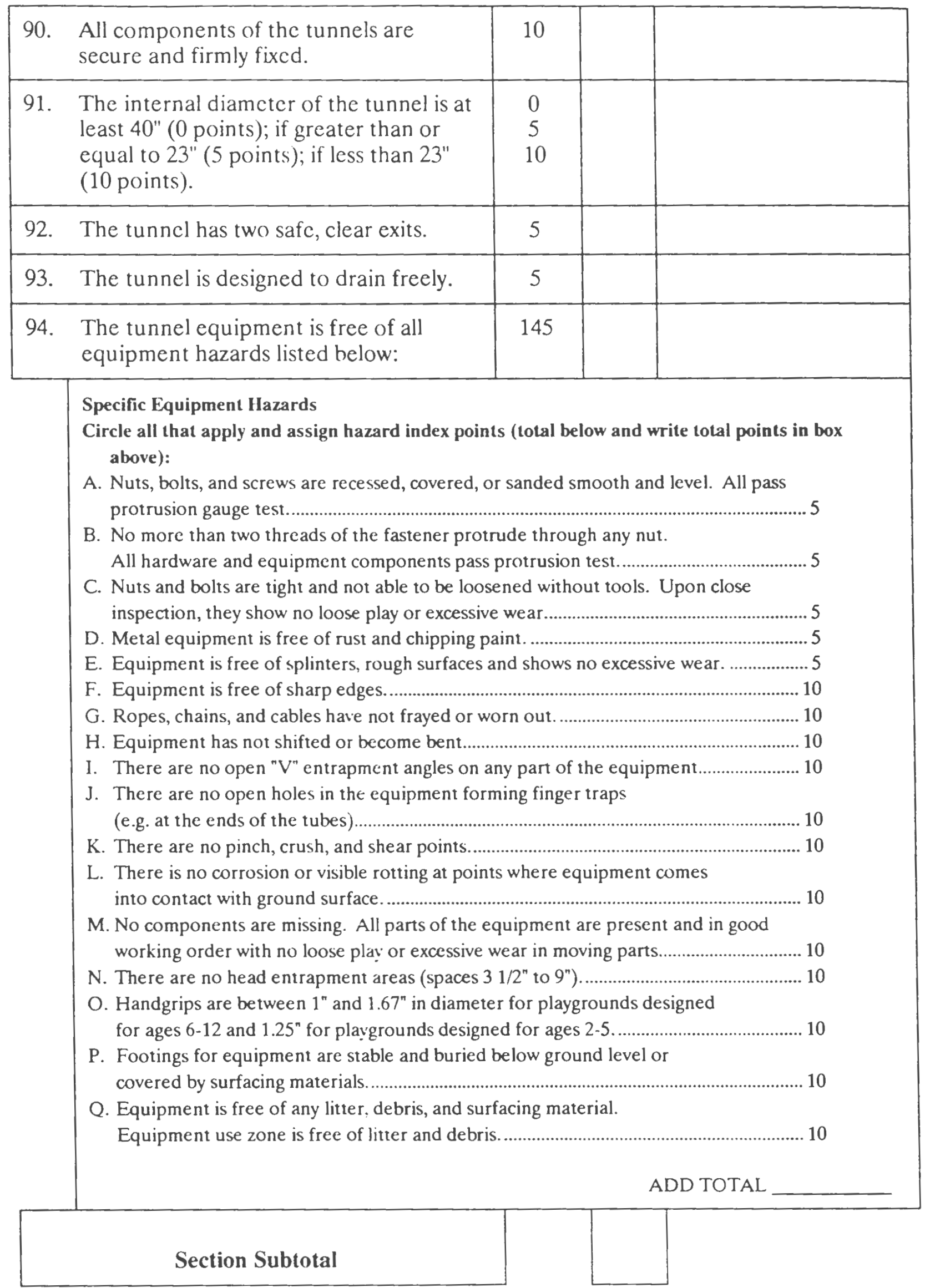




\section{Merry-Go-Round}

\begin{tabular}{|l|l|l|l|}
\hline 95. $\begin{array}{l}\text { Merry-go-round is approximately } \\
\text { circular, and the distance between the } \\
\text { minimum and maximum radil of a non- } \\
\text { circular platform does not exceed 2". } \\
\text { (See CPSC Guidelines, page 18, figure } \\
\text { 13.) }\end{array}$ & 10 & & \\
\hline 96. $\begin{array}{l}\text { Components of the merry-go-round do } \\
\text { not extend beyond the platform } \\
\text { perimeter. }\end{array}$ & 10 & & \\
\hline 97. $\begin{array}{l}\text { There are no openings in the surface of } \\
\text { the platform that permit the penetration } \\
\text { of 5/16" rod through the surface. }\end{array}$ & 10 & & \\
\hline 98. $\begin{array}{l}\text { There are no accessible shearing or } \\
\text { crushing mechanisms in the } \\
\text { undercarriage of the equipment, and the } \\
\text { platform does not provide an oscillatory } \\
\text { (up and down) motion. }\end{array}$ & 10 & & \\
\hline 99. $\begin{array}{l}\text { The peripheral speed of the platform } \\
\text { does not exceed 13 feet per second. }\end{array}$ & 10 & & \\
\hline
\end{tabular}




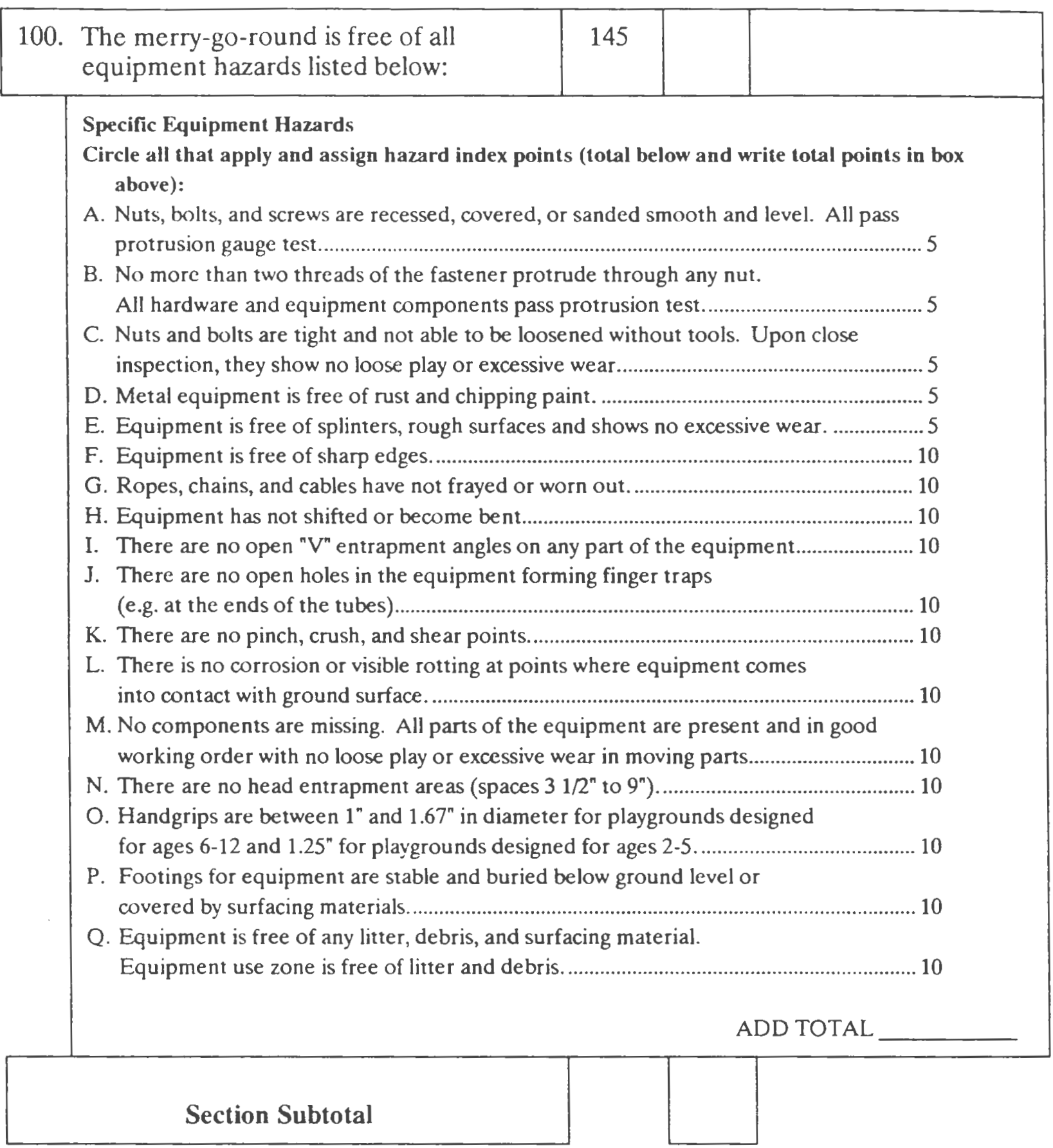


Audit Summary

\begin{tabular}{|c|c|c|c|}
\hline Audit Section Headings & Questions & $\begin{array}{l}\text { Possible Hazard } \\
\text { Index Points }\end{array}$ & $\begin{array}{l}\text { Hazard } \\
\text { Score }\end{array}$ \\
\hline Border Hazards & 3 & 70 & \\
\hline General Environment & $4-12$ & 53 & \\
\hline $\begin{array}{c}\text { Age/Size } \\
\text { Appropriateness Design }\end{array}$ & $13-15$ & 50 & \\
\hline Accessibility Design & $16-21$ & 19 & \\
\hline Playground Protective Surfacing & $22-25$ & 80 & \\
\hline Fall Zone/Use Zone & $26-31$ & 100 & \\
\hline SUBTOTAL & & 372 & \\
\hline Slides & * $32-47$ & 280 & \\
\hline Climbing Equipment & $48-58$ & 230 & \\
\hline Swings & $59-74$ & 267 & \\
\hline Seesaws & $75-79$ & 185 & \\
\hline Sand Play Areas & $80-84$ & 161 & \\
\hline Rocking Equipment & $85-89$ & 175 & \\
\hline Crawl Through Tunnels & $90-94$ & 175 & \\
\hline Merry-Go-Round & $95-100$ & 195 & \\
\hline Other & & $(145)^{* *}$ & \\
\hline Other & & $(145)^{* *}$ & \\
\hline Other & & $(145)^{* *}$ & \\
\hline Other & & $(145)^{* *}$ & \\
\hline Other & & $(145)^{* *}$ & \\
\hline Other & & $(145)^{* *}$ & \\
\hline & Site Total & & \\
\hline
\end{tabular}

*The major heading sections beginning with question 32 include a series of specific equipment hazard questions at the conclusion of each section and are included in section point totals.

${ }^{* *} 145$ is the possible points for the Specific Equipment Hazard Form (page 46).

\section{IMPORTANT}

This information is for internal use only and is not to be released or otherwise disseminated to anyone other than an agency official, or designated representative. 
Equipment/Component Name

\section{Specific Equipment Hazards Form}

Use this form for equipment not covered on the playground audit form. For each piece of equipment, add 145 points to the total possible hazard index points in the Audit Summary section. Add the number of points that the equipment received to your hazard score column. A negative response to the below questions receives the hazard index points.

\begin{tabular}{|c|c|c|c|c|}
\hline A. & $\begin{array}{l}\text { Nuts, bolts, and screu's are recessed, covered, or } \\
\text { sanded smooth and level. All pass protrusion gauge } \\
\text { test. }\end{array}$ & 5 & & \\
\hline B. & $\begin{array}{l}\text { No more than two threads of the fastener protrude } \\
\text { through any nut. All hardware and equipment } \\
\text { components pass protrusion test. }\end{array}$ & 5 & & \\
\hline C. & $\begin{array}{l}\text { Nuts and bolts are tight and not able to be loosened } \\
\text { without tools. Upon close inspection, they show no } \\
\text { loose play or excessive wear. }\end{array}$ & 5 & & \\
\hline D. & Metal equipment is free of rust and chipping paint. & 5 & & \\
\hline E. & $\begin{array}{l}\text { Equipment is free of splinters and rough surfaces and } \\
\text { show no excessive wear. }\end{array}$ & 5 & & \\
\hline F. & Equipment is free of sharp edges. & 10 & & \\
\hline G. & Ropes, chains, and cables are not frayed or worn out. & 10 & & \\
\hline H. & Equipment has not shifted or become bent. & 10 & & \\
\hline I. & $\begin{array}{l}\text { There are no open "V" entrapment angles on any part } \\
\text { of the equipment. }\end{array}$ & 10 & & \\
\hline $\mathrm{J}$. & $\begin{array}{l}\text { There are no open holes in the equipment forming } \\
\text { finger traps (e.g. at the ends of the tubes). }\end{array}$ & 10 & & \\
\hline $\mathbf{K}$. & There are no pinch, crush, and shear points. & 10 & & \\
\hline L. & $\begin{array}{l}\text { There is no corrosion or visible rotting at points where } \\
\text { equipment comes into contact with ground surface. }\end{array}$ & 10 & & \\
\hline M. & $\begin{array}{l}\text { No components are missing. All parts of the } \\
\text { equipment are present and in good working condition } \\
\text { with no loose play or excessive wear in moving parts } \\
\text { or hardware. }\end{array}$ & 10 & & \\
\hline $\mathbf{N}$ & No head entrapment areas exist (spacts $31 / 2 "$ to 9"). & 10 & & \\
\hline $\mathrm{O}$ & $\begin{array}{l}\text { Handgrips are between } 1 " \text { and } 1.67^{\prime \prime} \text { in diameter for } \\
\text { playgrounds designed for ages } 6-12 \text { and } 1.25^{\prime \prime} \text { for } \\
\text { playgrounds designed for ages } 2-5 \text {. }\end{array}$ & 10 & & \\
\hline P. & $\begin{array}{l}\text { Footings for equipment are stable and buried below } \\
\text { ground level or covered by surfacing meterials. }\end{array}$ & 10 & & \\
\hline $\mathrm{Q}$ & $\begin{array}{l}\text { Equipment is free of litter, debris, and surfacing } \\
\text { material. Equipment use zone is fret of litter and } \\
\text { debris. }\end{array}$ & 10 & & \\
\hline & Section Subtotal & & & \\
\hline
\end{tabular}


Playground Audit Hazard Score Summary Form For All Agency Sites

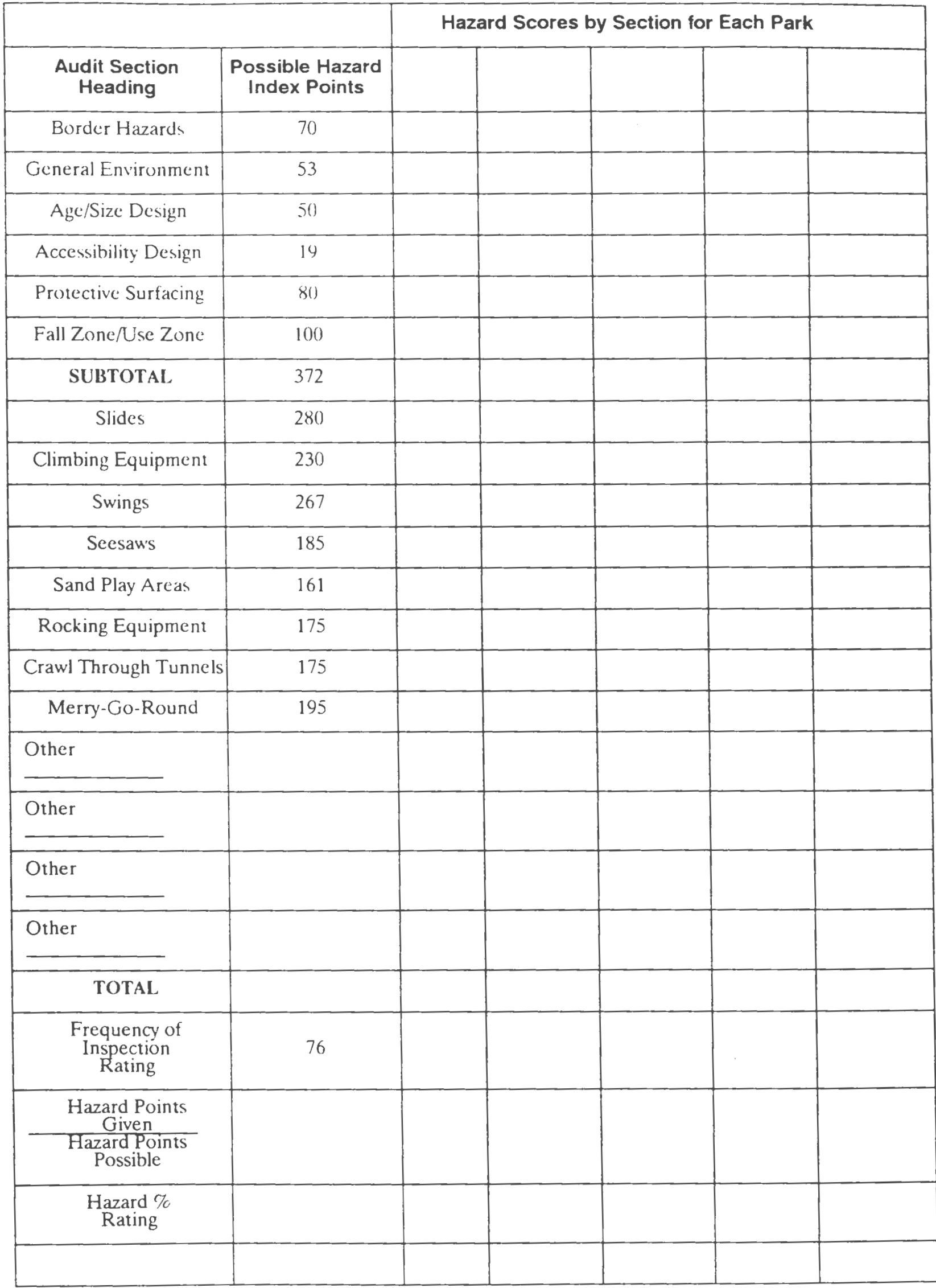

IMPORTANT: This information is for intermal use only and is not to be released or otherwise disseminated to anyone other than an agency official, or designated representative. 


\section{APPENDIX C}

Blank NRPA's Playground Safety Inspection Form 
e Name/ID Number:

ipector Name: Date Start/Finish Times

pairer Name: Date Start/Finish Times

Use the following codes: $1=$ Okay 2 = Needs Maintenance $3=$ Request for Repair

$\mathrm{O}=$ Supervisor notified and work order written $\mathrm{X}=$ Corrective Action Complete

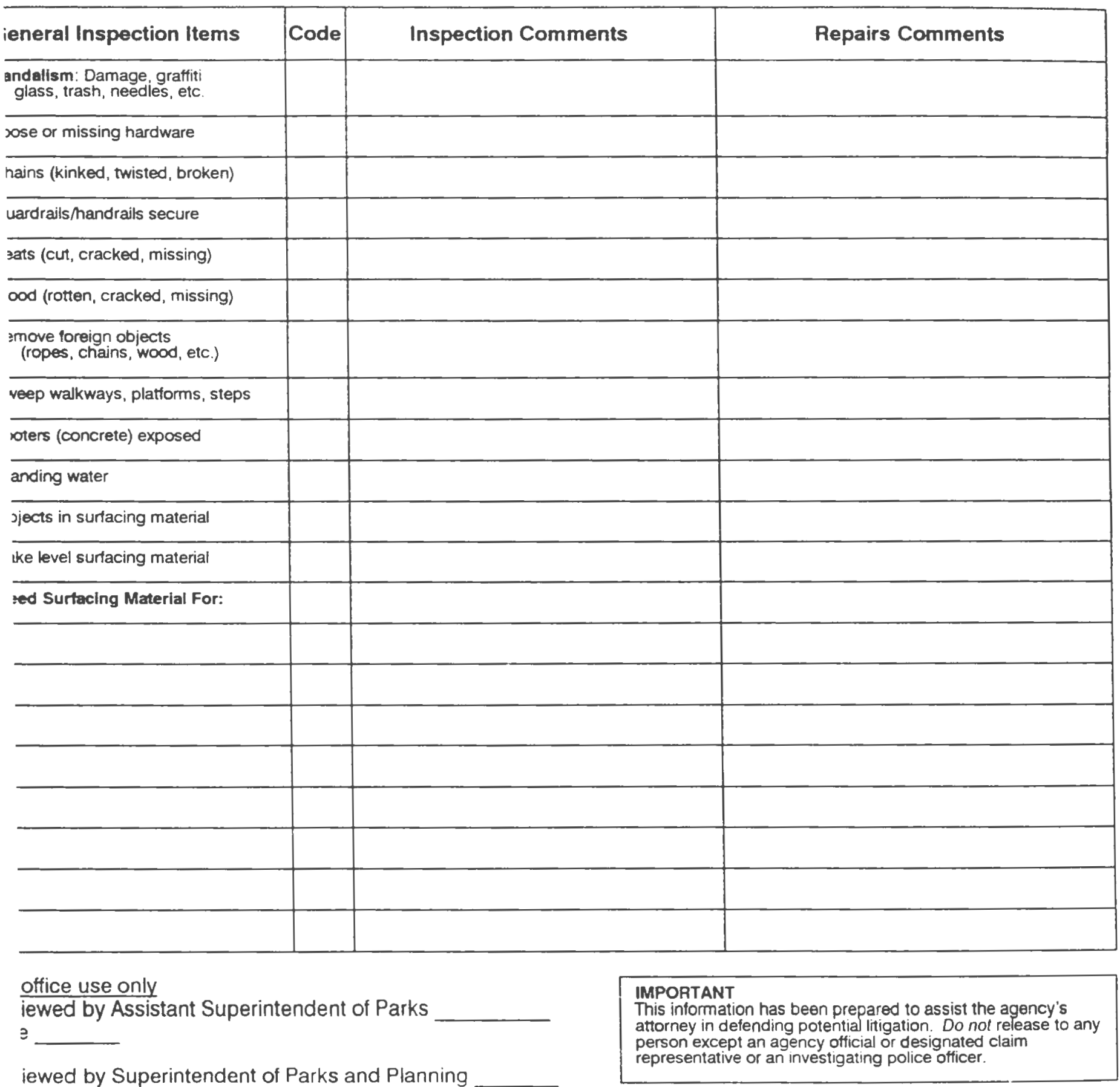




\section{Itemized List of Playground Equipment}

Site Name/ID Number:

Inspector Name:

Date

\begin{tabular}{|c|c|c|c|}
\hline $\begin{array}{l}\text { Play } \\
\text { Area }\end{array}$ & $\begin{array}{l}\text { Component } \\
\text { Number }\end{array}$ & $\begin{array}{l}\text { Description of Play Area } \\
\text { or Component }\end{array}$ & Comments \\
\hline & & & \\
\hline & & & \\
\hline & & & \\
\hline & & & \\
\hline & & & \\
\hline & & & \\
\hline & & & \\
\hline & & & \\
\hline & & & \\
\hline & & & \\
\hline & & & \\
\hline & & & \\
\hline & & & \\
\hline & & & \\
\hline & & & \\
\hline & & & \\
\hline & & & \\
\hline & & & \\
\hline & & & \\
\hline & & & \\
\hline & & & \\
\hline & & & \\
\hline & & & \\
\hline & & & \\
\hline & & & \\
\hline
\end{tabular}


992 by NRPA

Low Frequency Site Plan Playground Inspection Form

: Name/ID Number:

Jector Name:

zairer Name:
Date

Date
Start/Finish Times

Start/Finish Times

Use the following codes: $1=$ Okay $2=$ Needs Maintenance $3=$ Request for Repair $\mathrm{O}=$ Supervisor notified and work order written $\mathrm{X}=$ Corrective Action Complete

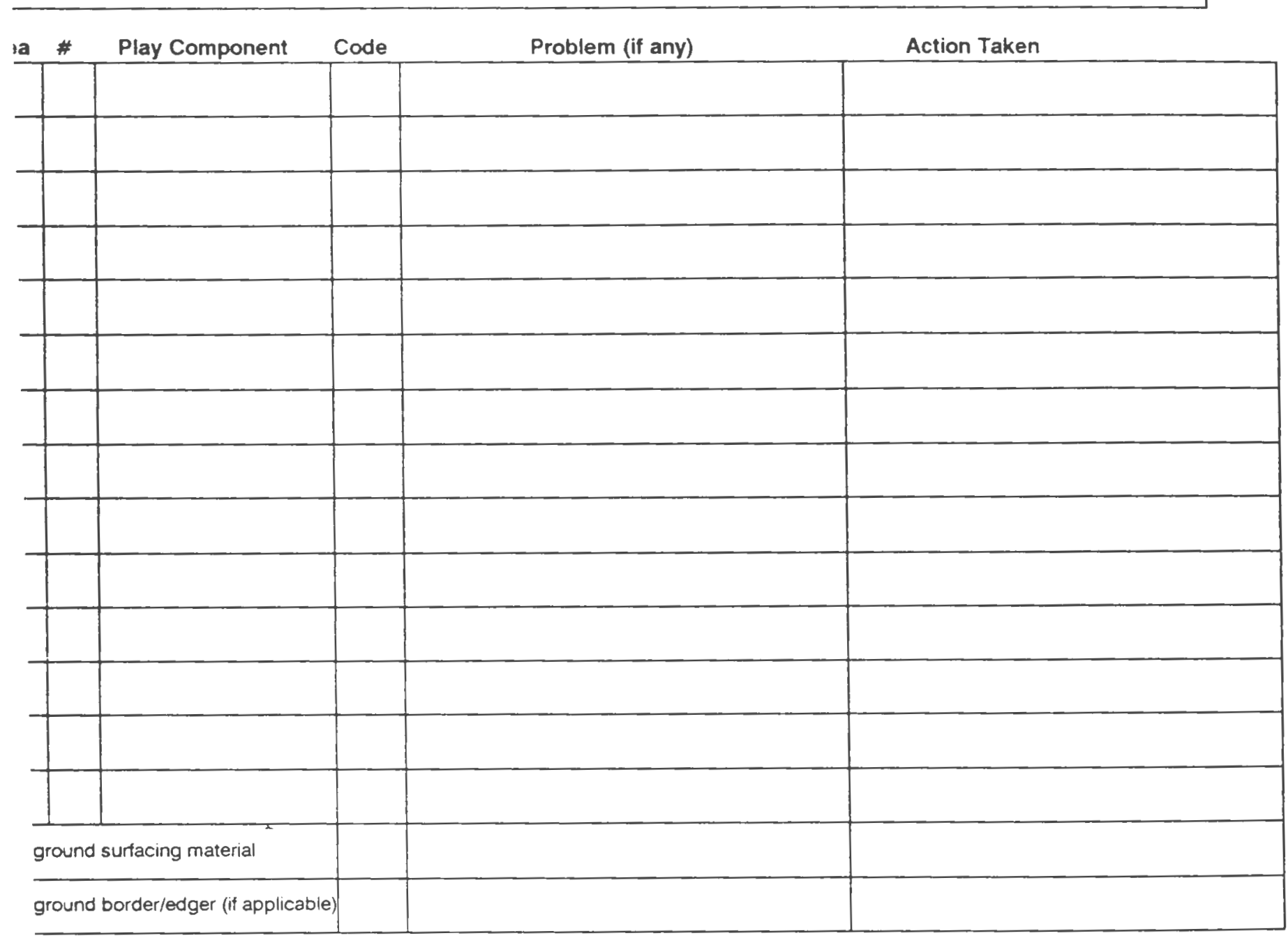

io

Lust each piece of playground equipment in the "Play Components" column.

As each component is inspected, indicate the appropriait codes in the Code column

Describe the nature of any maintenance or follow-up repars

File each inspection report with your permanent records

Order Numbers (list all that apply):

rvisor

Signature

Date

form has been prepared to assist the District Attorney in d $\epsilon^{t} \in$ nding potential litigation. DO NOT release to any person except an agency Il, designated claim representative, or an investigating office: 


\section{BIBLIOGRAPHY}

Allen, Sandra and Johnson, Robert. "A Study of Hazards Associated with Playgrounds", Journal of Environmental Health, June 1995

American City and County, "Safety Guidelines Help Reduce Accidents". American City and County, July 1995

Biehler, Robert F. and Snowman, Jack. Psychology Applied to Teaching. Seventh Edition, Houghton Mifflin Company, Boston MA, 1993

Burton, Scott. "Playground Safety Solutions", Safety Play, St.

Petersburg, FL. 1997

Butler, George D. Introduction To Community Recreation: Prepared for the National Recreation Association, 1950

Christiansen, Monty. ed., Points About Playgrounds. The National Recreation and Park Association, Arlington, Virginia: 1995

Clement, Annie. Where Our Children Play - Litigation and Playgrounds (chapter 8), American Alliance for Health, Physical Education, Recreation and Dance, Reston, VA. 1989

ERIC Clearinghouse on Teacher and Teaching Education. "How Can We Provide Safe Playgrounds", ACCESS ERIC. 1996

Eriksen, Aase. "The Play's the Thing", Landscape Architecture, Nov./Dec. 1984

Eriksen, Aase. Playground Design. Van Nostrand Reinhold Company, New York: 1985

Frost, Joe and Klein, Barry. Children's Play and Playgrounds. Allyn and Bacon, Inc. 1979

Hennher, Michael. "Enriching The Outdoor Play Experience", Childhood Education, Winter 1993

Hughes, Fergus. Children, Play and Development. Allyn and Bacon, Needham Heights, Massachusetts: 1991 
King, Steve. "Prevent Playground Injuries With Professional Inspection", Parks and Recreation, April 1996

Kutska, Kenneth and Hoffman, Kevin. Playground Safety is No Accident. National Recreation and Park Association, Arlington, Virginia : 1992

La Farge, Phyllis. "Why Kids Need Playgrounds". Parents' Magazine, October 1988 V63 N10 P124

Miller, Peggy. Creative Outddor Play Areas . Prentice-Hall, Inc., Englewood Cliffs, New Jersey: 1972

National Playground Safety Institute. "The Dirty Dozen: Are They Hiding in Your Child's Playground?", National Recreation and Park Association, Arlington, VA, 1996

Patton, Pettis L. "Urban Playgrounds Of Learning", Parks and Recreation, April 1996

Roberts, Paul. "Goofing Off", Psychology Today, 1995

Salkind, Neil. Child Development Sixth Edition. Holt, Rinehart and Winston, Inc. Fort Worth, TX: 1990

Schell, Robert and Hall,Elizabeth Developmental Psychology Today . Random House, New York, New York: 1983

Teague, Travis. "Playgrounds: Managing Your Risk", Parks and Recreation, April 1996

U.S. Consumer Product Saftey Commission. Handbook For Public Playground Saftey. U.S. Cnsumer Product Saftey Commission, Washington, DC: 1993

U.S. Consumer Product Safety Commission. "Tips For Public Playground Safety: Publication \# 327". U.S. Consumer Product Safety Commission, Washington, DC, 1992

Wallach, Frances. "An Update On The Playground Safety Movement", Parks and Recreation, April 1996 
Wallach, Frances. "Playground Safety Article". The World Playground, Park \& Recreation Products and Services Web Directory. 1996b

Woodbridge, Sally. "In Search Of A Place To Play", Landscape Architecture, May 1990 